\title{
Peripheral ganglia and the eye : a connection tracing study
}

Citation for published version (APA):

ten Tusscher, M. P. M. (1989). Peripheral ganglia and the eye : a connection tracing study. [Doctoral Thesis, Maastricht University]. Rijksuniversiteit Limburg. https://doi.org/10.26481/dis.19890922mt

Document status and date:

Published: 01/01/1989

DOI:

10.26481/dis.19890922mt

Document Version:

Publisher's PDF, also known as Version of record

\section{Please check the document version of this publication:}

- A submitted manuscript is the version of the article upon submission and before peer-review. There can be important differences between the submitted version and the official published version of record.

People interested in the research are advised to contact the author for the final version of the publication, or visit the DOI to the publisher's website.

- The final author version and the galley proof are versions of the publication after peer review.

- The final published version features the final layout of the paper including the volume, issue and page numbers.

Link to publication

\footnotetext{
General rights rights.

- You may freely distribute the URL identifying the publication in the public portal. please follow below link for the End User Agreement:

www.umlib.nl/taverne-license

Take down policy

If you believe that this document breaches copyright please contact us at:

repository@maastrichtuniversity.nl

providing details and we will investigate your claim.
}

Copyright and moral rights for the publications made accessible in the public portal are retained by the authors and/or other copyright owners and it is a condition of accessing publications that users recognise and abide by the legal requirements associated with these

- Users may download and print one copy of any publication from the public portal for the purpose of private study or research.

- You may not further distribute the material or use it for any profit-making activity or commercial gain

If the publication is distributed under the terms of Article $25 \mathrm{fa}$ of the Dutch Copyright Act, indicated by the "Taverne" license above, 



\section{PERIPHERAL GANGLIA AND THE EYE}

-a connection tracing study- 



\section{PERIPHERAL GANGLIA AND THE EYE}

-a connection tracing study-

\section{PROEFSCHRIFT}

ter verkrijging van de graad van doctor aan de Rijksuniversiteit Limburg te Maastricht, op gezag van de Rector Magnificus Prof.Dr. F.I.M. Bonke, volgens het besluit van het College van Dekanen, in het openbaar te verdedigen op vrijdag, 22 september 1989 om 14.00 uur door

Marcellinus Paulus Maria ten Tusscher geboren te Tubbergen 
Promotores:

Prof. dr. W.P.M.A. Lamers

Prof. dr. G.F.J.M. Vrensen

Beoordelingscommissie: Prof. dr. J. Drukker

Prof. dr. E.L. Greve

Prof. dr. E.H.M.A. Marres

Prof. dr. G.L. Ruskell

Prof. dr. H.A.J. Struyker Boudier 
Aan mijn ouders 



\section{CONTENTS}

I SURVEY OF LITERATURE

II BLOOD-GANGLION CELL BARRIER

Satellite cells as blood-ganglion cell barrier in autonomic ganglia. ( M.P.M. ten Tusscher, J. Klooster and

G.F.J.M. Vrensen; Brain Research, in press)

III RETROGRADE TRACING STUDIES

III.2: The innervation of the rabbit's anterior eye segment: a retrograde tracing study. ( M.P.M. ten Tusscher, J. Klooster and G.F.J.M. Vrensen; Experimental Eye Research,

$46,717-730(1988))$

IV THE SENSORY INNERVATION

The allocation of nerve fibres to the anterior eye segment and peripheral ganglia of rats. Part I: the sensory innervation.

( M.P.M. ten Tusscher, J. Kllooster, J.J.L. van der Want,

W.P.M.A. Lamers and G.F.J.M. Vrensen; Brain Research, in press)

\section{$\checkmark$ THE SYMPATHETIC INNERVATION}

The allocation of nerve fibres to the anterior eye segment and peripheral ganglia of rats. Part II: the sympathetic innervation. ( M.P.M. ten Tusscher, J. Klooster, J.J.L. van der Want, W.P.M.A. Lamers and G.F.J.M. Vrensen; Brain Research, in press)

VI THE FACIAL PARASYMPATHETIC INNERVATION

Pre- and post-ganglionic nerve fibres of the pterygopalatine ganglion and their allocation to the eyeball of rats. ( M.P.M. ten Tusscher, J. Klooster, B. Baljet, F. Wan der Werf and G.F.J.M. Vrensen; Submitted to Brain Research) 



\section{CHAPTER $\mathbb{1}$}

\section{SURVEY OF LITERATURE}

1.1. INTRODUCTION

1.2. GROSS ANATOMY OF THE SENSORY (NON-VISUAL) AND THE AUTONOMIC INNERVATION OF THE EYEBALL

1.3. THE SENSORY INNERVATION OF THE ANTERIOR EYE SEGMENT

1.4. THE AUTONOMIC INNERVATION OF THE ANTERIOR EYE SEGMENT

I.4.1.Introduction

1.4.2.Sympathetic nerve fibres to the eye

1.4.3.Parasympathetic nerve fibres to the eye

1.5. SUMMARY AND EVALUATION

I.6. SCOPE AND OUTLINE OF THE PRESENT THESIS

1.7. REFERENCES 
Glatucomat has a chronic, relentless course and, as a rule, it needs unending medical therapies which, in fact, do not reverse the process, are difficult to administer, and may have significant morbidity......

Open angle glaucoma: Why not a cure?

The truth is that our fundamental knowledge of the normal and abnormal processes of the trabecular meshwork is too primitive to allow the development of specific trabecular medical or surgical therapies.

(Epstein, 1987)

Autonomic effects on aqueous dynamics are of central importance in the determination of intraocular pressure. The medication most often prescribed in the treatment of glaucoma- pillocarpine, timolol, guanethidine, and adrenalineacts primarily through manipulation of the autonomic nervous system in the anterior segment. The demonstration of parasympathetic neuropathy in $42 \%$ of patients with ocular hypertension suggests that elevation of intraocular pressure is not an exclusively ocular phenomenon but may be a manifestation of systemic disease.

(Clark and Mapstone, 1985) 


\section{I INTRODUCTION}

The confuent anterior and posterior eye chambers are delineated by the cornea, the trabecular meshwork, the iris, the lens, the cillary body and the vitreous (Fig. 1). Both chambers are filled with a fluid, known as intraocular fluid or aqueous humour, which main function is the metabolic support of the avascular lens and cornea. The aqueous humour, with a total volume of about $300 \mu$, represents about $5 \%$ of the total volume of the eye in primates. It is constantly produced and constantly drained with a renewal-time of about 10 hours (Hollwich, 1982). The non-pigmented cells of the ciliary epithelium, which cover the ciliary processes, are the site of formation of the aqueous humour. The main ontflow-route of the aqueous is the passage through the pores of the trabecular meshwork and subsequent drainage into the canall of Schlemm and finally the blood-vessels (Fig.1). In addition loss of aqueous humour occurs by uveoscleral drainage, by vitreous exchange and by the exchange across iris vessels and corneal endothelium. Because the exchange by these structures, except the uweoscleral drainage, is bidirectional, the outflow of aqueous through the irideal, corneal and vitreous routes is counterbalanced by the inflow of fluid through these pathways (Tripathi, 1982). Approximately $80 \%$ of the drainage of aqueous humour takes place through the trabecular meshwork route, whereas the remaining $20 \%$ leaves the eye chambers through the uveoscleral pathway (Grierson, 1986; Kanski, 1984). In order to maintain the eyeball in a shape optimal for optical functioning, a constant intraocular pressure on the distensible global lining and vitreous is required. This pressure is exerted by the aqueous humour. Intraacular pressure (IOP), therefore, is defined as the pressure exerted by the aqueous on the distensible global lining and can be numerically expressed as the pressure required to prevent the outlow of aqueous humour on insertion of a canulla into the anterior chamber of the eye (Davson, 1984). The intraocular pressure is the result of the homeostatic balance of production and outhow of aqueous humour superposed on the venous pressure and the mechanical tension of the global lining and the vitreous. In men the normal intraocular pressure varies between 15 and $22 \mathrm{~mm}$ $\mathrm{Hg}$ and is the same for both eyes. The intraocular pressure varies rhythmically with the cardiac and respiratory cycles. These variations are determined by the size of the diastolic-systolic difference, the distensibility of the eyeball and the volume of the vascular bed. Normally the pressure has a diurnal rhythm; it 


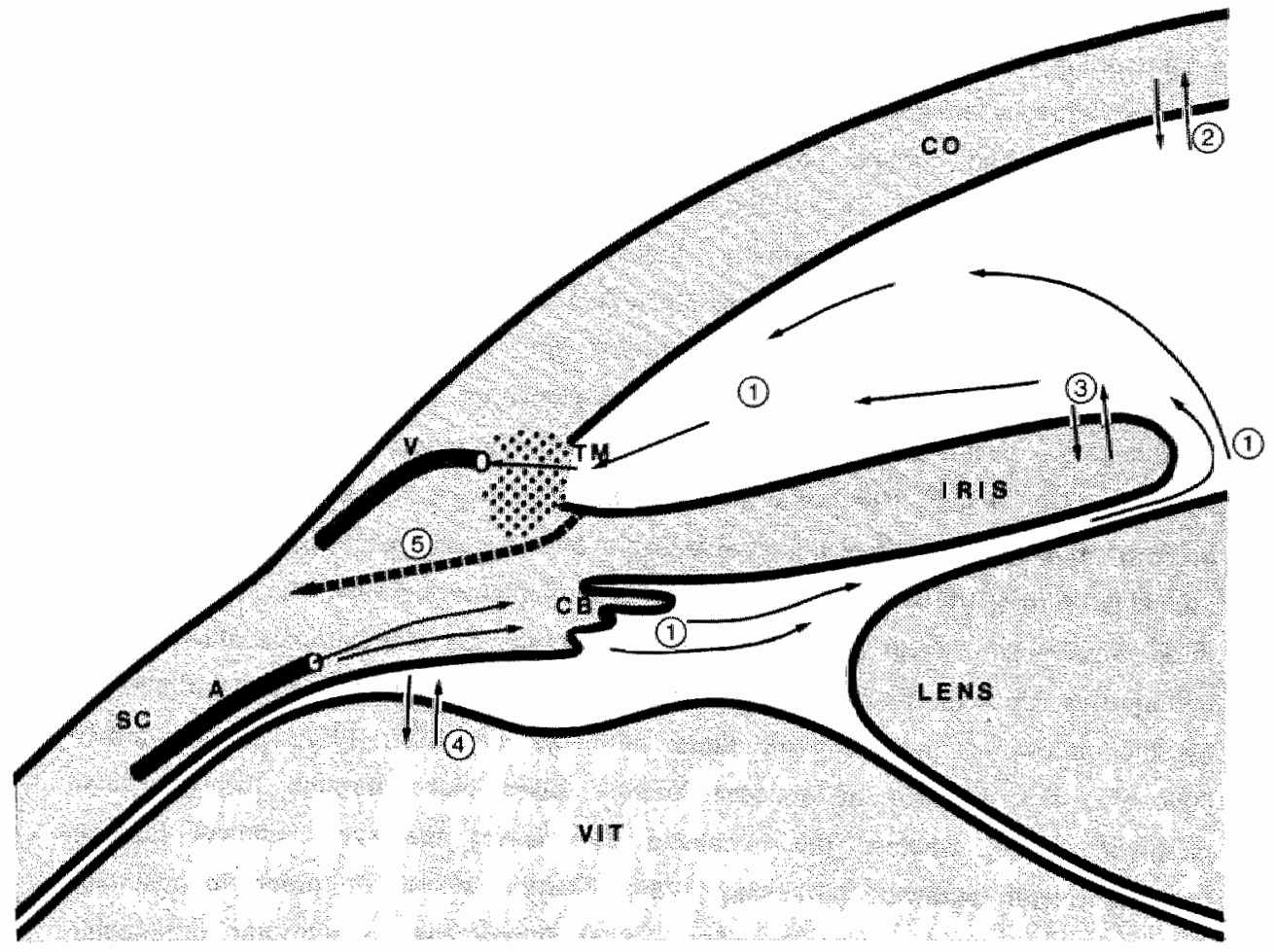

Figure 1: Schematic drawing of a transverse section of the anterior eye segment. The anterior eye chamber is delineated by the cornea (CO), the trabocular meshwork (TM) and the iris. Through the pupillary opening the anterior eye chamber conflues with the posterior eye chamber which is delimeated by the postertor aspect of the iris " the cillary body (CB), the vitreous body (VTT) and the lens. Both chambers are fuled with aqueous humour which originates in the cillary arteries (A) and is secreted and filtrated by the cillary body. The main outflow route of the aqueous (1) is through the pupllary opening to the pores of the trabecular meshwork and subsequently the aqueous veins (V). Additional outflow routes are the cornea (2), the iris (3), the vitreous (4) and the uveoscleral pathway (5). 
is highest in the early morning and decreases during day time. These vartations seidom exceed $4 \mathrm{~mm} \mathrm{Hg}$.

The IOP is kept within clase limits and gross alterations appear to be compensated. The diumal variation in IOP has been demonstrated to result from changes in the amount of aqueous produced by the ciliary body. In addition, changes in IOP lead to distension or compaction of the trabecular meshwork (Grierson, 1986). Alterations in the venous pressure were shown to cause marked changes in IOP. After tying the yortex veins, ligation of the anterior ciliary veins or a ligature around the neck, the IOP can dramatically rise up to $90 \mathrm{~mm} \mathrm{Hg}$ (Duke Elder et al, 1961). Therefore, the loP can be regulated either by changing the rate of production of aqueous, or by resisting the outflow of aqueous through the trabecular meshwork or through the blood vessels into which it is drained. Disturbance of the regulatory mechanism and the heighth of the IOP are related to the functional status of the optic nerve fibres in the scleral lamina cribrosa. A derangement of this mechanism, as in glaucoma, is a threat to the visual functioning of the eye, It has been hypothesized that optic nerve fibre damage is due to a distortion of the shape of the scleral lamina cribrosa through which perforated sheets the nerve bundles pass to the optic nerve. An IOP raise tends to compress the laminar sheets and induce inside-out and lateral traction on the sheets. Nerve fibres with the least amount of structural support are the most vulnerable to this traction and compression (Quigley, 1980). It has also been postulated that an elewated IOP causes optic nerve fibre damage by interfering with the microcirculation of the optic nerve head. However, recent studies of blood flow, capillary integrity and axygen delivery at the optic nerve head do not support this hypothesis. Moreover, glaucomatous visual field defects are not necessarily accompanied by an elevated IOP, although experimentally raised IOP in primates causes glaucomatous visual defects (Quigley, 1980). The nature of the modulation of the homeastatic mechanism has not defenitely been established. Hormones, humoral factors, mechanical factors and the central and peripheral nervous system have all been mentioned as possible candidates.

Duke-Elder et al. (1961) have emphasized that the nervous system must be considered as the most important regulator of IOP. Changes in IOP were vecorded after stimulation of sensory, sympathetic and parasympathetic (both aculomotor and facial) nerve fibres. Data concerning these experiments are summarized in Table I. Variations in intraocular pressure can cause discharges 
of impulses in the ocular branches of the trigeminal nerve in cats, rabbits and monkeys (Tower, 1940; Von Sallmann et al., 1966; Review: Trzeciakowski, 1987). Nether lowering the lop below resting levels, nor resting levels itself, however, appeared to evoke afferent activity in cats (Lele et al, 1960). In addition, cardiovascular autonomic function tests revealed systemic parasympathetic neuropathy in $58 \%$ of closed-angle glaucoma and in $42 \%$ of ocular hypertension patients whereas only $2.6 \%$ of the controls showed parasympathetic neuropathy (Clark et al., 1985).

\section{TABLE I}

\begin{tabular}{|c|c|c|c|}
\hline & $\begin{array}{l}\text { Experimental } \\
\text { procedure }\end{array}$ & $\begin{array}{l}\text { Effect on } \\
\text { IOP }\end{array}$ & $\begin{array}{l}\text { Site of } \\
\text { action }\end{array}$ \\
\hline Sympathetic & $\begin{array}{l}\text { ganglionectomy: } \\
\text { p.g.neuratomy: } \\
\text { p.g.stimulation: }\end{array}$ & $\begin{array}{l}10 P \downarrow \\
10 P= \\
10 P \downarrow\end{array}$ & $\begin{array}{l}\text { outflow } \uparrow(\alpha) \\
\text { production } \downarrow(\beta)\end{array}$ \\
\hline $\begin{array}{l}\text { Parasympathetic } \\
\text { (octolomotor) }\end{array}$ & $\begin{array}{l}\text { ganglionectomy: } \\
\text { p.g.stimulation: }\end{array}$ & $\begin{array}{l}\text { IOP } \\
\text { IOP } t \\
\text { IOP }\end{array}$ & $\begin{array}{l}\text { extraocular m. } \\
\text { outflow } \uparrow \\
\text { production }\end{array}$ \\
\hline $\begin{array}{l}\text { Parasympathetic } \\
\text { (facial) }\end{array}$ & $\begin{array}{l}\text { ganglionectomy: } \\
\text { p.g. stimulation: }\end{array}$ & $\begin{array}{l}\text { IOP } \\
\text { IOP }\end{array}$ & \\
\hline Sensory & $\begin{array}{l}\text { central stimulation: } \\
\text { central neurotomy: } \\
\text { central neurotomy } \\
\text { stimulation peripheral } \\
\text { stump: }\end{array}$ & $\begin{array}{l}\operatorname{IOP} 4 \\
\operatorname{IOP} \downarrow \\
\operatorname{IOP} 4\end{array}$ & \\
\hline Central & $\begin{array}{l}\text { stimulation area in } \\
\text { medial hypothalamus: }\end{array}$ & IOP & \\
\hline
\end{tabular}

A summary of the experiments that revealed IOP changes. IOP: intraocular pressure; RR: blood pressure; p.g.: preganglionic; $\alpha$ : $\alpha$-receptors; $\beta$; $\beta$-receptors; $\mathrm{m}$ : muscles; $=$ no change; increase; :decrease

From 24 hours till 3 to 4 days after sympathetic superior cervical ganglionectomy the IOP is reduced due to a rellease of catecholamines by degenerating sympathetic fibres and an increase in the number and sensitivity of a-receptors in the outflow mechanism (Barany, 1962; Canon et al., 1949; Eakins et al., 1964 and b; Greaves et al., 1952; Langham et al., 1959, 1960a; Lieb et al., 1958; Sears et al., 1964). Preganglionic sympathotomy does not change the IOP whereas sustained stimulation of the preganglionic nerve fibres causes a significant fall in IOP due to a decrease in the rate of secretion (mediated by $\beta$-receptors) (Langham et 
al., 1960b, 1966, 1978). Sympathetic nerve fibres infuence the circadian rhythm of IOP; endogenous catecholaminergic activity stimulates aqueous formation during the day and this stimulus subsides during the night (Brubaker et al., 1984; Reiss et al., 1984 ; Gregory et al., 1985). Parasympathetic ciliary ganglionectomy revealed a decrease of IOP up to 6 months, when complete reinnervation occurs (Erickson-Lamy ot al., 1988). Preganglionic aculomotor stimulation resulted in a small rise or fall in IOP (Armaly, 1959; Greaves et al., 1953; Lele at al, 1960; Von Hippel et al., 1868). When the influence of extraocular muscles was excluded a rise in IOP, an increased outflow and an increased formation were found (Macri et al., 1975). Pterygopalatine ganglionectomy results in a decrease in IOP till $\mathbb{1}$ year after the operation (Ruskell, 1970a). Stimulation of the facial nerve revealed an increased IOP (Gloster, 1961; Greaves et al., 1956). Neurotomy, irritation and stimulation of the trigeminal nerve and ganglion or the peripheral stump of the distally cut trigeminal nerve all result in a rise or fall in IOP accompanied by miosis or mydriasis and hyperemia of the skin (Bernard, 1858; Hartman, 1924, Henderson et al. 1904; Magendie, 1824; Maurice, 1954; Perkins, 1957; Stjernschantz et al., 1979). These responses are more sensitive in sympathectomized eyes (Unger et al., 1981). Centrally, stimulation of a discrete area in the medial hypothalamus lead to a fall in IOP, accompanied by a rise in blood pressure (Gloster et al,, 1957; Schmerl et al., 1950).

A neural center regulating IOP has been postulated to explain these findings. Its existence, however, has not been unequivocally demonstrated. Proof is required of afferent and efferent pathways by which the IOP homeostasis is maintained. After a description of the gross anatomy of the innervation of the eyeball (1.2) and an overview of the sensory (non-visual) (1.3) and autonomic (I.4) innervation of the anterior eye segment, the scope and outline of the present study is dealt with (I.6.).

\subsection{GROSS ANATOMY OF THE SENSORY (NON-VISUAL) AND AUTONOMIC INNERVATION OF THE EYEBALL}

The gross anatomy of the innervation of the eyeball of vertebrates is outlined in Figures 2A, B and C (compiled from Carpenter, 1978; Maldowsky, 1980 and Brodal, 1981). This paragraph is meant as an introduction to the detailed discussion on the different aspects of the innervation of the anterior eye segment. The essentials of this innervation are described and the many variations on the precise course of the different nerves among species is left out. The non-visual innerwation of the eye is of tripartite origin: i) sensory, ii) sympathetic and iii) parasympathetic. Despite their different origin in the brain, their different course and different ganglia, the nerve fibres of these 
three entites enter or leave the eyeball by a common set of mixed nerves: the short and long cllary nerves.

The sensory nerve supply of the eyeball is of trigeminal origin (Fig. 2A). The trigeminal nerve arises at the lateral margin of the pons and the cell bodies of Its sensory root are located in the trigeminal ganglion (ganglion semilunare, ganglion Gasseri). Closely distal to the ganglion three branches are formed: the ophthalmic, the maxillary and the mandibulary nerve. The ophthalmic nerve branches into the lacrimal, the frontal and the nasociliary nerve. The nasociliary nerve gives off two branches which supply the eyeball. A main branch enters the long ciliary nerves and a small branch the short ciliary nerves including the cillary ganglion. In addition the nasociliary nerve gives rise to the posterior ethmoid and infratrochlear nerve.

The sympathetic innervation of the eye (Fug. 2B) originates from thoracic ventral root fibres. The branches conflue and run to the superior cervical ganglion which is located in the bifurcation of the carotid artery. After leaving the ganglion, sympathetic nerve fibres form a plexus around the internal carotid artery. Sympathetic nerve fibres branching from this plexus run along the ophthalmic artery or join the nasociliary oculomotor and trochlear nerve. Finally these fibres reach the eye through the short and long ciliary nerves.

The parasympathetic innervation of the eye (Fig. 2C) consists of nerve fibres that run along with both the oculomotor and facial nerve. The oculomotor

Figure 2: Outline of the main branches of the nerves that supply the anterior eye. A: The sensory trigeminal nerve (trig.n.) courses to the trigeminal ganglion (trig.g.) and gives rise to: the ophthalmic nerve (VI), the maxillary nerve (V2), the mandibulary nerve (V3), the lacrimal nerve (lan.), the frontal nerve (fr.n.), the nasocilary nerve (na.m.), the posterior ethmoid nerve (et.n.), the infratrochlear nerve $\left(t^{\prime} n_{n}\right)$, the short ciliary nerves (s.c.n.) and the long clliary nerve (l.c.n.). cil.g.: ciliary ganglion

B: The sympathetic merve branches run to the superior cerpical ganglion (s.c.g.), and form a plexus around the internal carotid artery (i.c.a.). The sympathetic nerve fibres reach the eye along with arteries and nerves through the short cillary nerves (s.c.n.) and the long ciliary nerwe (l.c.n.). cil.g.: clliary ganglion $C_{i}$ The parasympathetic nerwe fibres run to the eye along with motor fibres in the oculomotor nerve (oculn.) and the facial nerve (fac.n.). The motor fibres in the oculomotor nerve branch into the superior (s.o.n.) and inferior aculomotor nerve (i.o.n.). The parasympathetic nerve fibres run to the cillary ganglion (cilg.) and reach the eye through the short clliary nerves (s.c.n.). The facial nerve gives rise to the chorda tympani (c.t.), the gentculate ganglion (gen.g.), the minor petrosal nerve (mi.p.n.), the major petrosal nerve (ma,p.n.). the pterygopalatine ganglion (pter.gu) and the rami oculares (r.o.). 


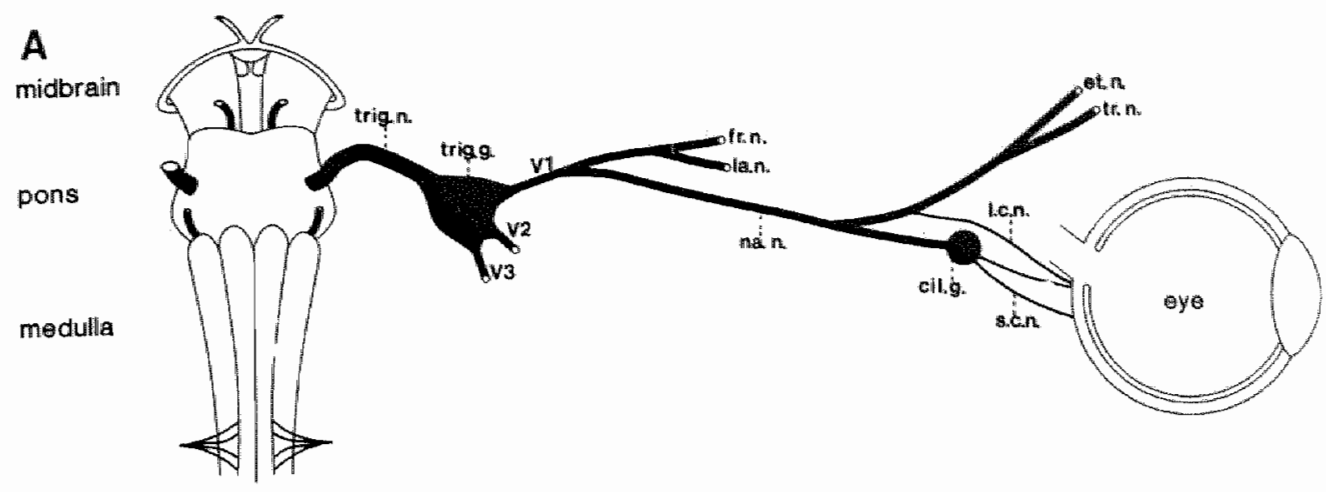

\section{B}

midbrain

pons

medulla

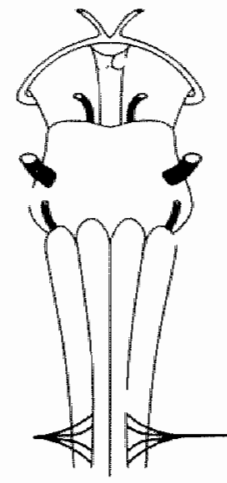

C.

mıdbrain

pons

medulla

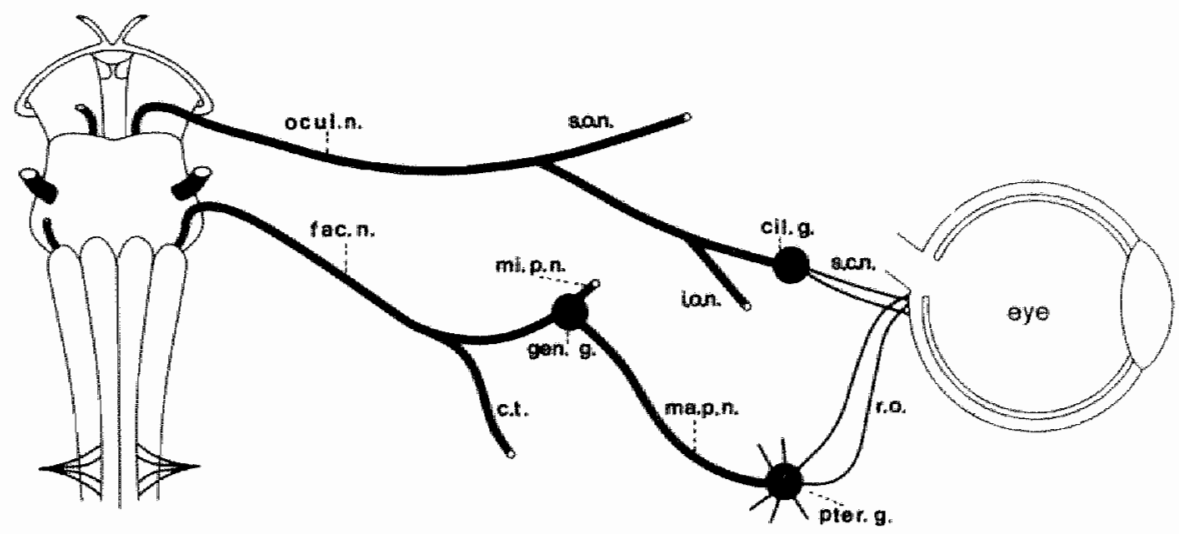


nerve originates at the medial aspect of the crus cerebri. It gives rise to the motor superiot and inferior oculomotor branches. The parasympathetic nerve fores run to the chliary ganglion and reach the eye by way of the short cilliary nerves. The facial nerve emerges from the caudolateral aspect of the ventral pons. It gives off the chorda tympani, which contains the parasympathetic nerve fubres that supply the mandibular ganglion, and subsequently passes through the geniculate ganglion. Rostrally to the geniculate ganglion it gives rise to the major and minor petrosal nerves. The minor petrosal nerve courses to the otic ganglion and the major petrosal nerve runs through the fossa pterygopalatina to the pterygopalatine ganglion (sphenopalatine gangliond. At the foramen lacerum the deep petrosal nerve, a sympathetic branch coming from the plexus around the internal carotid artery, joins the major petrosall nerve which is called vidian nerve then. Sensory taste fibres arising from the palate also course through the major petrosal nerve to their cell bodies in the geniculate ganglion. The facial parasympathetic nerve fibres synapse in the pterygopalatine ganglion and reach the eye by way of the nerwi oculares through the inferior orbital fissure.

Since this thesis deals with the anterior eye segment innervation of rabbits and rats the differences of the gross anatomy in rabbits and rats from that in primates are indicated in Figs. $3 A$ and $B$. The main differences are that in rabbits and rats the trigeminal ganglion has only two branches: the ophthalmomaxillary nerve and the mandibulary nerve. The ophthalmic branches join the maxillary branches at the foramen orbitorotundum. The maxillary branches course through the base of the orbit and lie dorsal to the pterygopalatine ganglion in rats and lateral to this ganglion in rabbits.

\section{Flgure 3 :}

Oulline of the gross anatomy of the innervation of the rat eye.

A: The anterior cranial fossa of a rat skull. The optic nerve (II) enters the orbit through the optic foramen; the mandibulary" nerve (V3) through the foramen ovale; the oculomotor nerve (III), the trochlear nerve (IV), the ophthatmomaxillary nerve (VIV2) and the abducens nerve (VI) all enter through the foramen orbitorotundum (Courtesy of v. Horssen and Baljet).

B: The course of sensory trigeminal and parasympathetic pterygopalatime nerve fibres within the orbit is shown on the left whereas the motor branches are shown on the right. mos: superior oblique muscle; mrm: medial rectus muscle; nul: lateral rectus muscle; mirs: superior rectus muscle; milp: palpebral levator muscle; $n$ opht: ophhalmic nerve; nio: infraorbital nerve; nnc: nasociliary nerve; ch: external nasal nerves; nf: frontal nerve; nzf: zygomaticofacial nerve; Ml: lacrimal nerve; gll: intraorbital lacrimal gland: gglpp: pterygopalatine ganglion (Courtesy of Kretger and Baljet). 


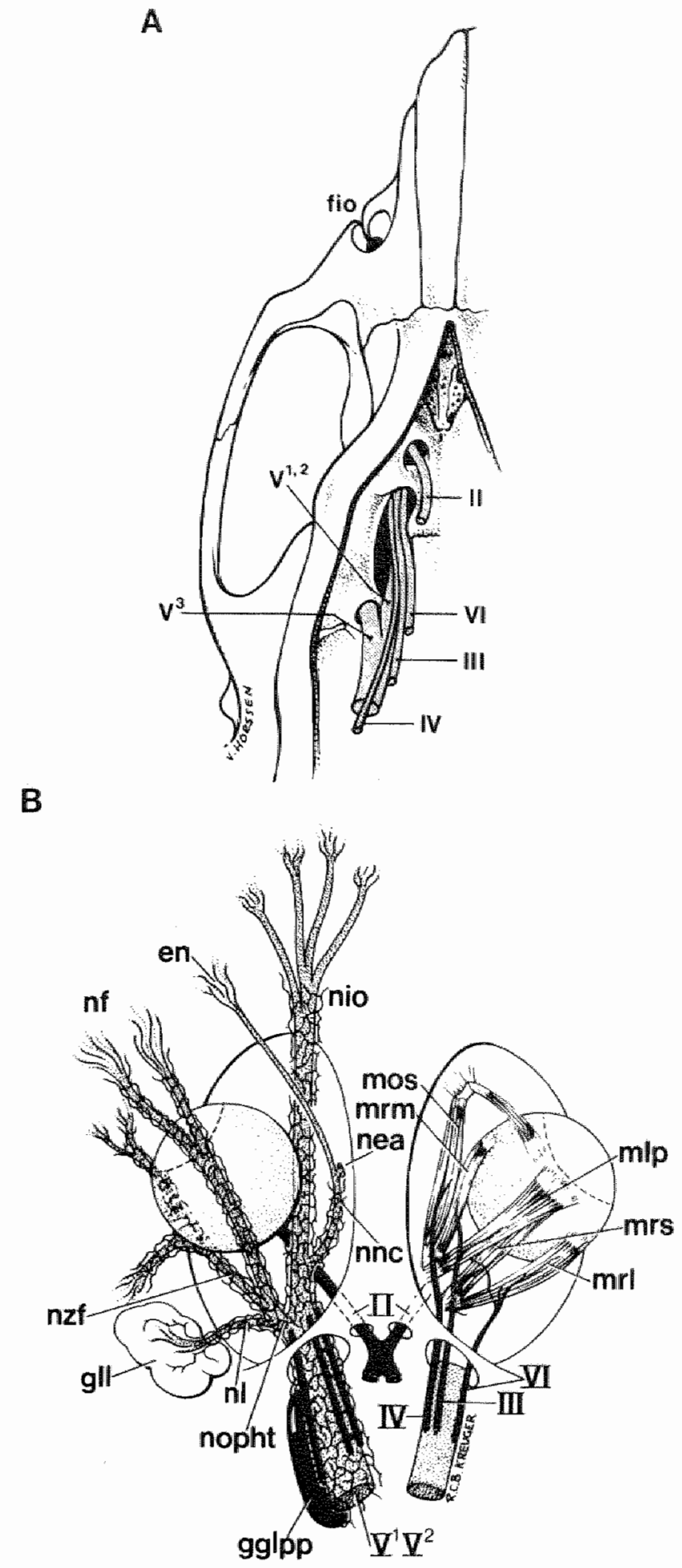




\subsection{THE SENSORY INNERVATION OF THE ANTERIOR EYE SEGMENT}

Most structures lining the anterior eye chambers: the comea, the trabecular meshwork, the cillary body and the iris were found to have a sensory Inmervation (Fig, 4). As outlined in the previous paragraph most sensory nerve fibres run along the ophthalmic nerve: the first branch of the trigeminal nerwe, and in primates a small number along the maxillary nerve (Ruskell, 19746). The ganglion cell somata are located in the trigeminal ganglion. The cornea has one of the richest sensory nerve supplies of any eye tissue (Hogan et al., 19711). The inmervation pattern within the cornea has been investigated after methylene blue staining and silver impregnation (Zander et al, 1951) and after gold chloride staining (Rozsa et al., 1982; Scmimmelpfennig, 1982). The ganglionic origin of the corneal nerve fibres and their terminals has been investigated by degeneration experiments and by tracing studies. In monkeys and rabbits degenerating nerve fibre terminals in the cornea were found only after trigeminal ganglionectomy and were absent after superior cervical ganglionectomy (Zander et al., 1951). Corneal nerve fibres were labelled after injection of horseradish peroxidase (HRP) into the trigeminal ganglion of rats (Marfurt et al., 1983). Therefore, the innervation of the cornea is chiefly, if not exclusively, sensory (for a discussion on the autonomic innervation see paragraph 1.4). The nerve fibres in the trabecular meshwork were originally believed to be in transit to the cornea (Kolmer, 1914). However, Chapman et al. (1963), Feeney (1962), Holland et al. (1956, 1957), Valu (1966), and Ruskell (1976) demonstrated the presence of nerve terminals in addition to nerve fibres. in the trabecular meshwork of men, monkeys and rabbits. Degeneration experiments were performed to unravel the origin of these fibres and terminals but these experiments were inconclusive. In primates, Ruskell (1976) found degenerating fibres and terminals after ophthalmic neurotomy which Lamers (1962) did not find (for a review on the inmervation of the chamber angle see Stone et al. 1987). Sensory nerve fibres were labelled in the stroma of the ciliary body and in the uris of guinea-pigs after anterograde HRP labelling from the trigeminal ganglion. Labelled nerve fibres and terminals were found only at the electron-microscopic level (Lehtosalo et al, 1983,1984). After ophthalmic nourotomy degenerating terminals appeared in the anterior stroma of the ciliary body and the iris-root of monkeys (Bergmanson, 1977). The iris of some monkeys was found to be devoid of sensory nerve fibres. Injection of HRP into 


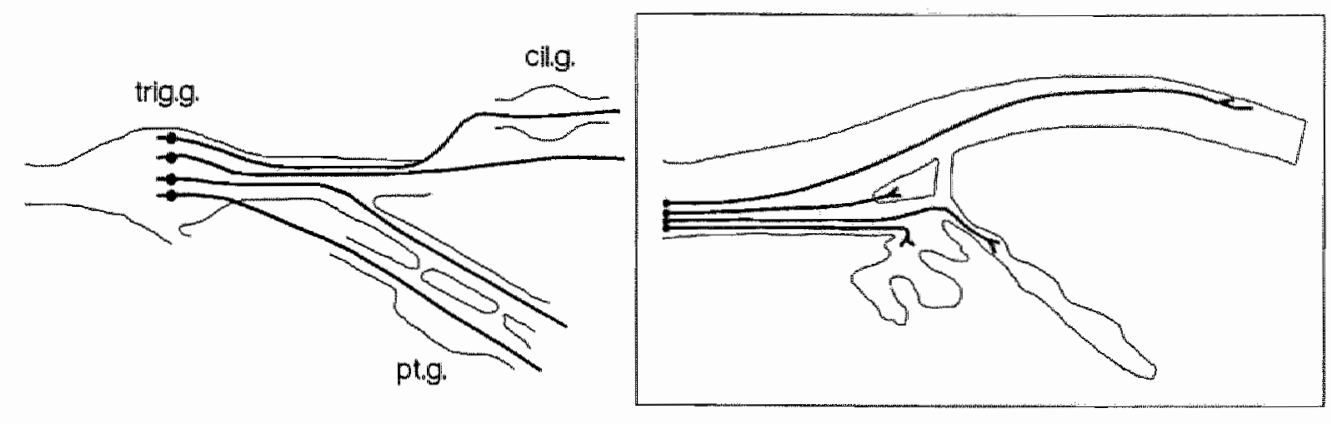

Figure 4:

The course of sensory nerve fibres originating in the trigeminal ganglion (trig.g.) in relation to the eye related ganglia and their allocation to anterior cye segment structures (boxed area) of primates. The sensory nerve fibres course through the ciliary ganglion (cil.g.) and the pterygopalatine ganglian (pt.g.). As to the anterior eye segnent, sensory nerve fibres supply the cornea, the peripheral iris, the anterior stroma of the ciliary body and the trabecular meshwork. s.c.g.: superior cervical ganglion

the anterior chamber of the eye of mice, rats (Arvidson, 1979; Jaeger et al., 1980) and cats (Marfurt, $1981 \mathrm{a}+\mathrm{b}$ ) revealed the presence of labelled trigeminal ganglion cells. The trigeminal. ganglion has a somatotopic representation of the structures that it supplies, i.e. particular areas of ganglion-cells receiving nerve fibres from particular peripheral sites. Ganglion-cells with dendrites originating in the anterior eye segment are located in the anteromedian part of the trigeminal ganglion (Arvidson, 1979). The trigeminal ganglion, like the dorsal root ganglia, contains morphologically different types of ganglion cells (Lieberman, 1976; Rambourg et al., 1983). The significance of these differences has not been elucidated yet.

Degeneration studies in primates (Ruskell, 1974a) and histochemical experiments in dogs (Hara et al. 1982 ) revealed the presence of sensory nerve fibres in the ciliary ganglion. In contrast, the ciliary ganglion of rabbits and cats exclusively receives parasympathetic nerve fibres (Grimes and von 
Salliman, 1960). Sensory nerves are supposed to pass the pterygopalatine ganglion as well (Duke-Elder et all, 1961) (Fig.4).

The axons of the trigeminal ganglion cels nu ipsilaterally in the trigeminal nerve to the central nervous system and project to the trigeminal brainstem nuiclear complex (TBNC). The TBNC is subdivided into the principal sensory nucleus and the spinal trigeminal nucleus. About half of the axons dichotomize to send one collateral to the principal sensory nucleus and one to the spinal trigeminal nucleus. The other half of the axons project to these nuclei without forming collaterals (Windle, 1926). A small number of dendrites pass the trigeminal ganglion and run to the mesencephalic trigeminal nucleus; these nerve fibres form the sensory branch of the chewing-reflex. The cell somata of these passing nerve fores are located in the mesencephalic nucleus. The spinal trigeminal nucleus is subdivided into three nuclei: the nucleus oralis, the nucleus interpolaris and the nucleus caudalis (Olszewski, 1950). The central. projections of primary trigeminal afferents, however, appeared not to be restricted to these trigeminal sensory nuclei but trigeminal nerve fibres also terminate in the dorsal horn of the upper cervical spinal cord as far caudally as the $C 7$ segment and in the solitary tract nucleus. Contralateral trigeminal projections were found in the nucleus caudalis and in the dorsal horn at $\mathrm{Cl}-3$ levels (Arvidsson et al., 1979; Pfaller et al., 1988). Trigeminosolitary projections have been shown to arise from lingual, inferior alveolar, mylohyoid and auriculotemporal afferents (Jaquin et al., 1983). The caudal cervical projections are supposed to be of maxillary or ophthalmic origin (Pfaller et al., 1988),

\section{Figure $5:$}

This figure shows the central projections from the trigeminal brainstent nuclear complex (TBNC) which is subdivided into the principal nucleus $(P)$, the nucleus oralis (O), the nucleus interpolaris (I) and the caudal mucleus (C). IS: trigeminal nerve tract: $S^{*}$ superior colliculus; $E W$ : nucleus of EdingerWestphat: VPM: ventero-pasterontedial thalamic nuclens.

A: All TBNC subnuclei project to the contralateral superior colliculus. Most projections originate in the mucleus interpolaris, less in the rucleus oralis and least in the principal and caudal nucleus. Few ipsilateral projections originate in the viucleus oralis and interpolaris.

B: Contralateral thatamic projections originate in all TBNC subnucle; most from the principal muclews, less from the mucleus interpolaris and least from the oral and caudal mucleus. A small ipsilateral projection originates in the principal nucleus.

C: All spinal subnuclei give rise to contralateral inferior olive projections whereas the interpolaris and oralls also project directly to the cerebellum. 

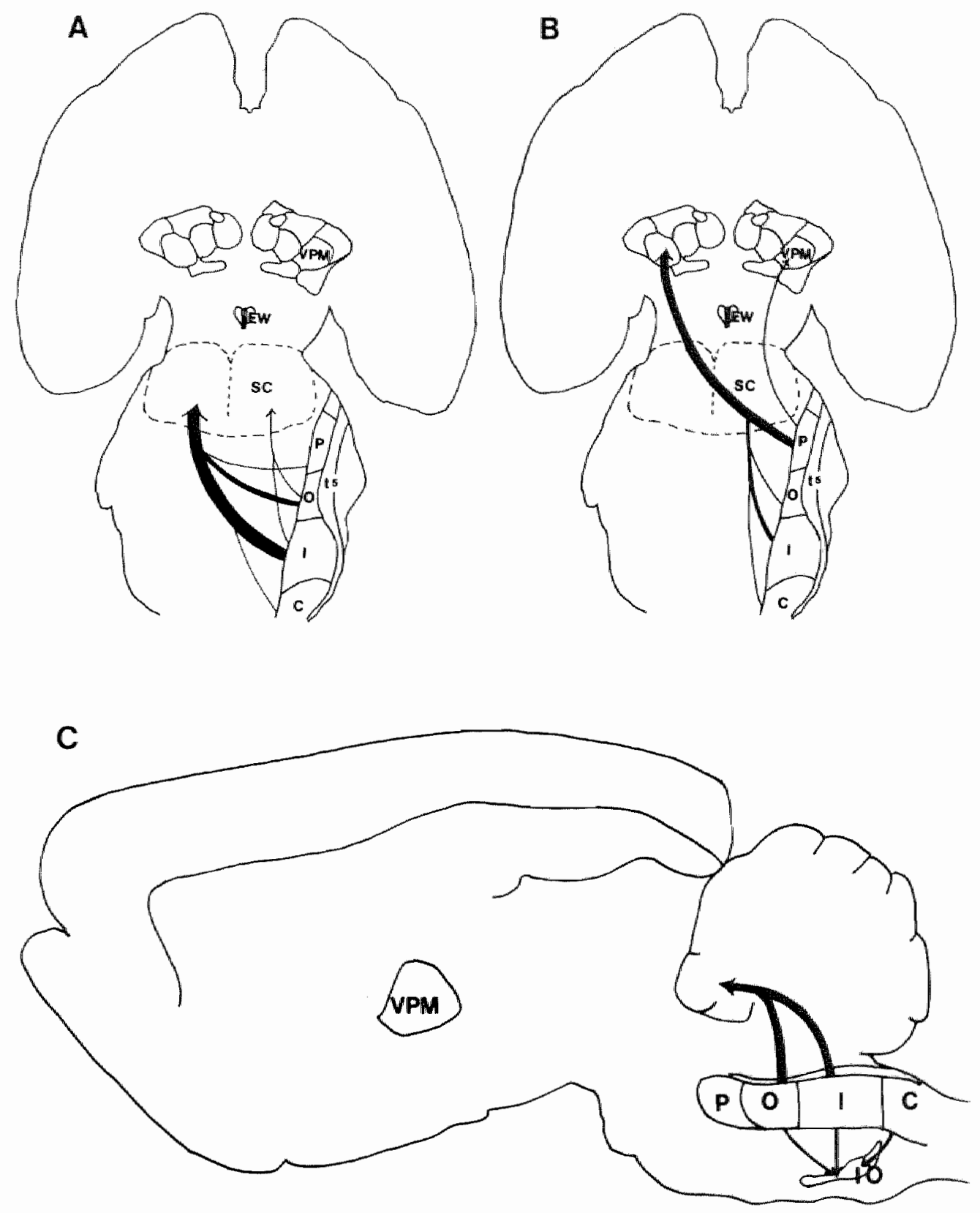
The central trigeminal nuelei are also somatotopically organized but concerning the projection area of the eye inconclusive evidence has been obtainted. Marfurt et al. (1987) described corneal projections to the nucleus interpolaris and caudalis but not to the nucleus oralis and principalis in rats. Nagano et al. (1975) found projections to the whole TBNC of rats. As in rats, dissimular results were obtained in monkeys, rabbits and cats (Ken et al., 1968; Wall et al., 1962; Nord, 1967; Panneton et al., 1981; Shigenaga et al., 1986). In the dorsal-ventral axis, most ophthalmic terminals occur ventrally (Torvik, 1956).

Within the TBNC there are many projections between the sub-nuclei. Ascending projections from the caudal nucleus project to all rostral nuclei except for the caudal part of the nucleus interpolaris and the dorsal part of the principal nucleus. Somata from the caudal interpolaris project to dorsomedial and rostrodorsomedial divisions of the spinal complex and the ventral part of the principal nucleus. Somata which give rise to descending internuclear pathways are distributed in all trigeminal nuclei (Nasution et al., 1987).

The TBNC projects to the wentero-posteromedial nucleus of the thalamus, the superior colliculus, the cerebellar cortex, the medullary dorsal horn and different parts of the dorsal accessory and principal olives (Fig. 5) (Bruce et al., 1987; Patrick et al., 1987; Falls, 1984; Huerta et al., 1985).

\subsection{THE AUTONOMIC INNERVATION OF THE ANTERIOR EYE SEGMENT}

\subsubsection{Introduction}

Irrespective of their central origin nerwes beyond the bony shelter of the skull and spine, form by defenition the peripheral nervous system which is divided into somatic and autonomic nerves. The somatic nerves are the nonvisceral sensory and motor nerves. The somatic sensory innervation of the anterior aye segment has been described in paragraph I.3. The autonomic nervous system is subdivided into three major divisions: the sympathetic (orthosympathetic), the parasympathetic and the enteric division.

Morphologically autonomic nerves are characterized by a sequence of preganglionic neuronal perikarya in the central nervous system and postganglionic neurons outside the central nervous system in specific ganglia. Centrally the preganglionic neurons are thought to be controlled mainly by the hypo- 
thalamus. The localization of the perikarya of the pre and postganglionic neurons differs for the sympathetic and parasympathetic neurons (Fig. 6). The preganglionic neurons of the sympathetic nervous system in primates have their perikarya in the thoracic and lumbar segments of the spinal cord. These perikarya are located in several areas: i) The sympathetic intermediolateral cell column which can be subdivided into two nuclei: the nucleus intermediolateralis thoracolumbalis pars principalis (a compact column in the lateral horn) and the adjacent nucleus intermediolateralis thoracolumbalis pars funicularis (extending into the lateral funiculus), ii) Medial to the pars principalis lies the nucleus intercalatus spinalis, iii) In monkeys an additional nucleus intercalatus pars paraependymalis has been described but this has not been found to exist in quite the same lacation in other animalls. Therefore this nucleus is commonlly described more generally as central autonomic neurons (Petras et al "1972; Chung et al., 1975). The sympathetic postganglionic perikarya are located in the vertebral and prewertebral ganglia. The perikarya of the parasympathetic preganglionic neurons are located in the brainstem and in the sacral segments of the spinal cord. Parasympathetic postganglionic perikarya are situated in or near the organ they supply.

The role of the hypothalamus in the regulation of homeostatic mechanisms and its function in metabolic intergration has been fairly well established. Of the many groups of nerve cells or nuclei in the hypothalamus, the ventromedial hypothalamic nucleus and the lateral hypothalamic nucleus are the most important in neuronal control of the peripheral metabollism via autonomic nerves (Shimazu, 1979, 1981, 1983, 1987). Lesions of the ventromedial hypothalamic nucleus appeared to affect the autonomic nervous system by increasing the parasympathetic tone and decreasing the sympathetic tone, whereas lesions of the lateral hypothalamic nucleus increase the sympathetic tone (Opsahl, 1977; Van der Tuig et al. 1982; Yoshimatsu et al., 1984).

\subsubsection{Sympathetic nerve fibres to the eye}

The central sympathetic centers involved in pupillomotor control bave been studied in detail mainly by means of electrical stimulation (discussed by Loewy et al., 1973). Sympathetic fibres from the intermediolateral cell column of the spinal segments $C_{8}-T_{3}$, the ciliospinal center of Budge and Waller (1851) produce pupillary dilatation. Other areas i.e. the amygdala, the cerebral cortex, 
the hypothalamus, Forels field $\mathbb{H}_{*}$ the septal and preoptic areas and the periaqueductal gray, in rabbits, cats and primates can produce pupillary dilatation after stimulation as well (Hodes et al., 1942a and $b_{4}^{*}$ Jampel, 1960; Loww et al., 1973). However, the trajectory of the pupillomotor pathways unvolved; is not fully known. The trajectory of hypothalamo-autonomic connections has been studied, using tracers (Saper et al., 1976; Horst ter, 1986). It was found that the intermediolateral cell column receives projections from the periaqueductal gray, the caudal periaqueductal gray, the ventromedial area of the lower brainstem, the rostroventrolateral and the caudowentrolateral area of the lower brainstem. Whereas the hypotlialamus projects to these latter areas (Horst ter, 1986).

Preganglionic sympathetic neurons from the spinal segments C8-T5 project to the superior cervical ganglion of rats. Ninety percent of these neurons are located in the segments TI-T3 and neurons are distributed in the four earlier mentioned regions: $75 \%$ was located in the pars principalis, $23 \%$ in the pars funicularis, $1 \%$ in the central autonomic ares and $1 \%$ in the intercalated region (Rando et al., 1981). Preganglionic sympathetic merves leave the central nervous system through the ventral roots of the thoracic nerves $I$ to III in cats, dogs and monkeys (Langley, 1900, 1921). The sympathetic postganglionic perikarya projecting to the eye are located in the superior cervical ganglion. This ganglion is a diverging relay center with a ratio of preganglionic to postganglionic nerve fibres 1 to 4 in rats (Brooks-Fournier et al,, 1981). If it is a relay center which only transfers information from the central

\footnotetext{
Plgure $a$ :

Outline of the localization of the autonomic pre and postganglionic neurons.

A. Sympathetic pregangliontic neurons originate in the thoracic and upper limbar spinal segments (uninterrupted lines). Postganglionic sympathetic neurons ariginate in the vertebral ganglia (v.g.). Sympathetic fibres from the spinal segments C8-T3 project to the stuperior cervical ganglion (s.c.g.) which projects to the eye. Parasympathetic preganglionic somata are located in the brainstem and the sacral segments of the spinal cord. The ganglionic somata are located in or near the organ they supply. The parasympathetic oculomotor preganglionic neurons (interrupted lines) originate in the midbrain (m.b.). project to the postgangliontic netrons which somata are located in the ciliary ganglion (cil.g.). m: meduilla, b: bladder.

B: Shows a transverse section through spinal cord segment TI2 indicated in A. The preganglionic sympathetic cell bodies occupy the apical region of the lateral hom in the thoracic and lumbar segments. This nuclear column is the intermediolateral cell columin (IML).
} 
A

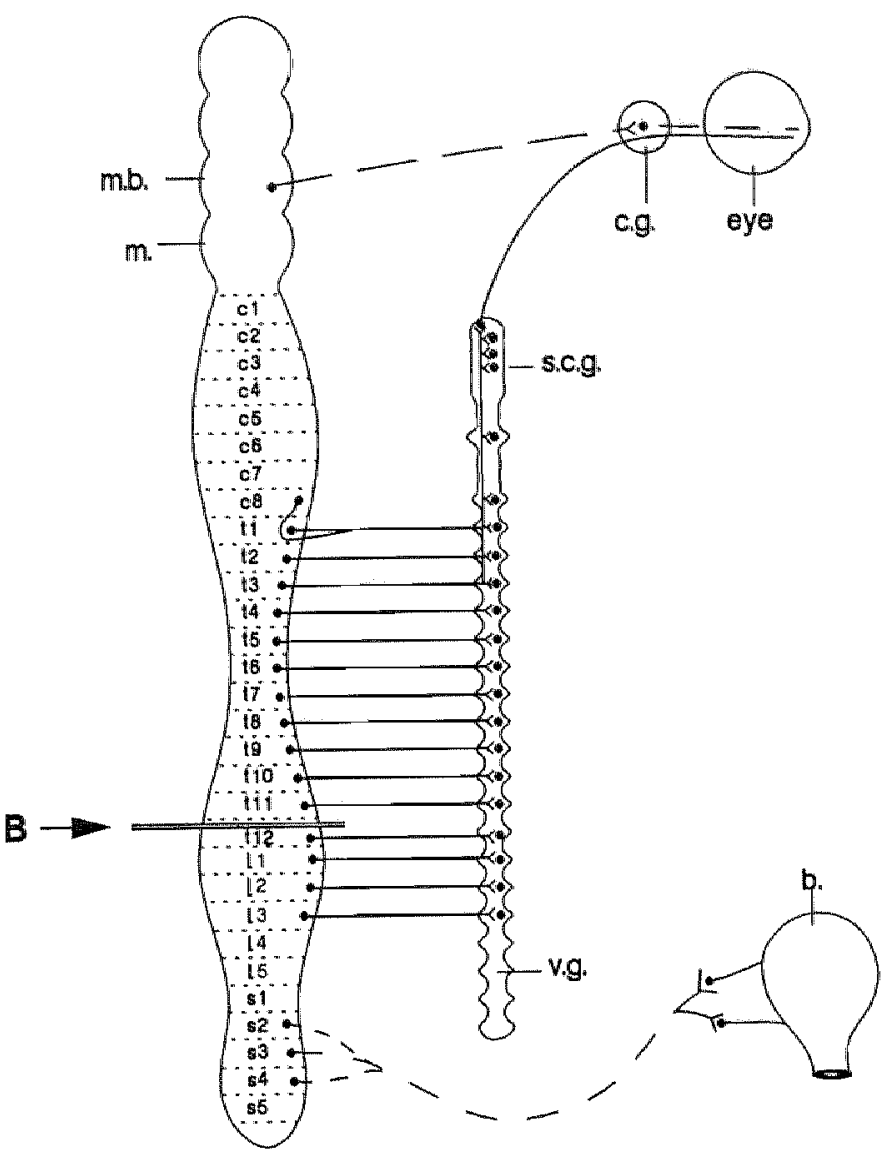

B

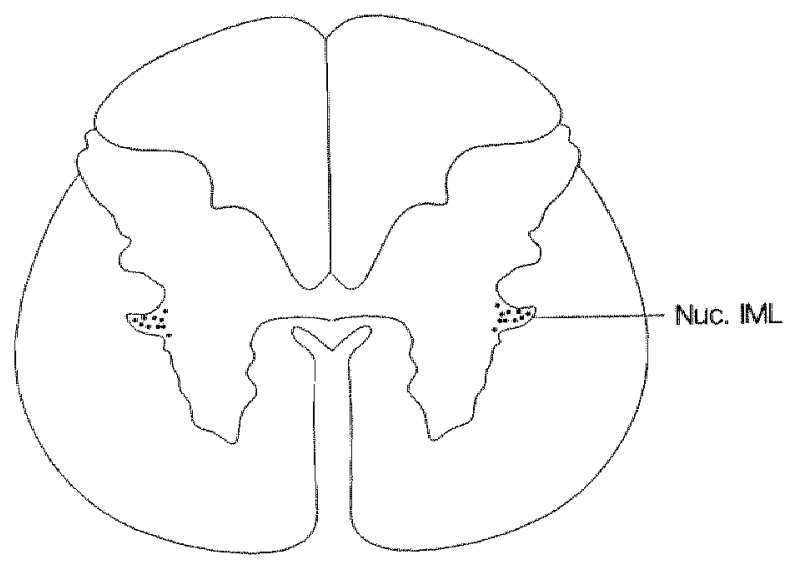


nervous system to the periphery has become particularly unlkely for the superior cervical ganglion. Eccles (1935) showed that preganglionic stimulation not only gives a simple fast excitatory potential of the postganglionic neuron but allso fascilitation, convergence and inhibition. In the superior cervical ganglion a small group of cells mostly called SIF cells (small intensely fuorescent, also called chromafin cells or small granule containing cells, depending on the method of detection) hawe been identified. Electronmicroscopic and physiological studies indicate that some SIF cells are interneurons, interposed between pre and postganglionic neurons (Dail et al., 1983). In rats SIF cells of the superior cervical ganglion had efferent contacts predominantly to axons rather than to dendrites. About $5 \%$ involved postsynaptic structures which resembled the sensory nerve endings in the carotid body. Neurotomy of the glossopharyngeal nerve (the source of sensory fibres to the carotid body) showed degenerated afferents on SIF cells of rats (Grillo, 1978).

As was mentioned in the gross anatomy sympathetic nerwe fibres reach the eye along with arteries and nerves. Sympathetic nerve fibres were found in the oculomotor nerve, the cilliary ganglion and the ophthalmic nerve (Marfurt et al., 1986; Tamamaki et al., 1987; Maldowsky, 1980).

In the classical concept catecholaminergic nerve fibres are thought to be of sympathetic origin only. Catecholaminergic nerve fibres are located in the cornea (Ehinger, 1966; Laties et al., 1964, 1966), the trabecular meshwork (Nomura et al., 1974; Sugita et al, 1984; Akagi et al., 1976 1981; Ruskell, 1976), the ciliary body (Akagi et al., 1976, 1981; Malmfors, 1965a; Ehinger, 1966; Laties et al., 1964, 1966) and the irus (Malmfors, 1965b, Laties et al., 1964, 1966; Ehinger, 1966) (Fig. 7). The catecholaminergic nerve fibres are detected by means of the formaldehyde induced fluorescence of Falck and Hillarp and the glyoxylic acid method. Both methods do not discriminate between distinct catecholamines and also have a low sensitiwity to serotonin (Nieuwenhuys, 1985). Sensory neurons in the nodose, petrosial and dorsal root ganglia of rats express catecholaminergic fluorescence (Katz et al., 1983, 1987; Price et al, 1983). Nine percent of all trigeminal neuronal somata of rats contain serotonin (Kai-Kai et al., 1985). Subpopulations of sensory small dark cells appeared to contain these substances. Most trigeminal sensory somata that supply the anterior eye segment were found to be small dark cells (Palkama, 1987). So, nerve fibres detected by these methods are not necessarily 


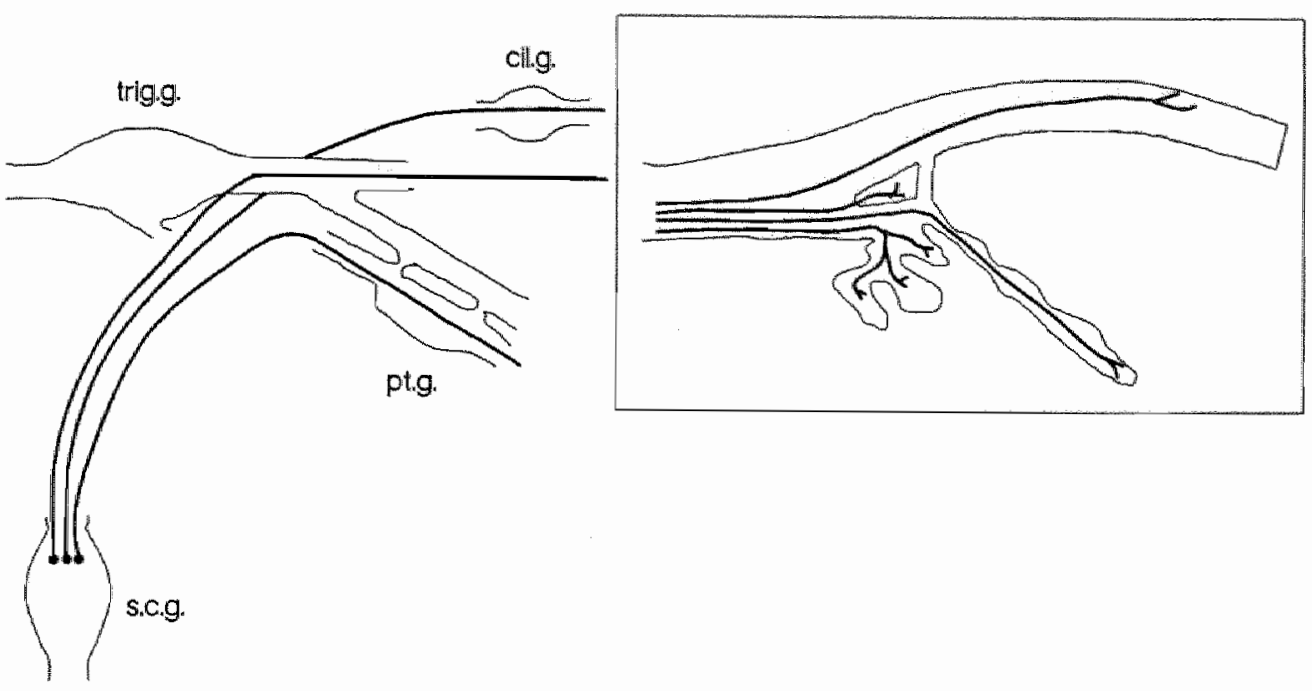

Figure 7: The course of sympathetic nerve fibres originating in the superior cervical ganglion (s.c.g.) in relation to the eye related ganglia and their allocation to the anterior eye segment structures (boxed area) of primates is outlined. The sympathetic nerve fibres course through the cillary ganglion (cil.g.) and the pterygopalatine ganglion (pt.g.). As to the anterior eye segment, sympathetic nerve fibres supply the cornea, the tris, the clliary body and the trabecular meshwork. trig.g.: trigeminal ganglion.

sympathetic. Moreover, it has been established that not all sympathetic neurons contain catecholamines either (Dail et al., 1983; Landis, 1983). This means that neither all catecholaminergic nerve fibres are of sympathetic origin, nor are all sympathetic nerve fibres catecholaminergic. Therefore, data on the catecholaminergic nerve fibre supply need to be supported by degeneration and tracing experiments in order to obtain more definite proof. A few tracer experiments and degeneration studies were performed. By the injection of HRP and WGA-HRP into the anterior chamber of the eye the rostral part of the superior cervical ganglion was found to project to the anterior eye segment in mice (Arvidson, 1979). By injection of these tracers into the superior cervical ganglion of cats and rats labelled axons appeared in the iris and cornea (Marfurt, 1988; Morgan et al, 1987). Ruskell (1971) investigated the fine structure of degenerated nerve terminals in the ciliary muscle using superior cervical ganglionectomy. 


\subsubsection{Parasympathetic nerye fores to the eye}

Till recently it was generally accepted that the preganglionic neurons of the parasyrnpathetlc nuclews of Edinger-Westphal (NEW), located in the midbrain, send their axons directly and exclusively through the oculomotor nerve to the postgamglionic cillary ganglion where they make synaptic connections and are thought to regulate pupillary constriction and lens accomodation (Warwick, 1954; Duke Elder et al., 1961). However, two additional descending pathways from the NEW were found: i) a mediat descending pathway terminating in the dorsal accessory olive and ii) a lateral descending pathway. Some of the latter nerve fibres terminate in the medial parabrachial nucleus while others are located ventral to the spinal trigeminal complex with axons terminating in the subtrigeminal nuclei and other fibres which continue their course ventral to the caudal part of the spinal trigeminal nucleus and even project as far caudally as the lumbar spinal cord. Moreover, the NEW appeared to project directly to the cerebellum in cats (Sugimoto et al. 1978). In order to determine to what extent neuroms in the NEW send their axons or axon collaterals into the oculomotor nerve, the oculomotor nerve was intracranially transected and incubated with HRP. Only a small percentage of the neurons in the NEW was labelled despite the fact that most neurons of the oculomotor nucleus were extremely heavily labelled. Besides these NEW and somatic oculomotor meurons, a small number of neurons was labelled in the ventral tegmental areas, in the region lateral to the medial longitudinal fasciculus and in the periaqueductal gray. Incubation of the preganglionic nerve to the ciliary ganglion revealed labelling in the NEW, the periaqueductal gray and the ventral tegmental area (Sugimoto et al., 1977; Loewy et al., $1978 \mathrm{a}+\mathrm{b}$ ). Therefore, it may be concluded that both a fraction of the neurons of the NEW and neurons in the periaqueductal gray and the ventral tegmental area. project to the cilliny ganglion.

In addition to the parasympathetic nerve supply of the anterior segment by nerve fibres running along with the oculomotor nerve, a parasympathetic nerve supply by nerve fibres running along with the facial nerve has become more and more likely. These parasympathetic nerve fibres have their origin in the superior salivatory nucleus, located in the pons, and have synaptic contacts on ganglion cells in the pterygopalatine ganglion. In monkeys, rabbits, rats and cats nerves that are called rami oculares, enter the eyeball (Kuwayama et al., 1987; Lin et al., 1988; Ruskell, 1965, 1970a and b). By means 
of degeneration studies, these rami oculares were found to originate in the pterygopalatine ganglion (Ruskell, 1970a,b).

As compared to the sympathetic and sensory imnervation pattern, the parasympathetic innervation of the anterior seye segment has been studied less intensively. Because the parasympathetic ganglia i.c. the pterygopalatine and ciliary ganglion are small and contain passing sensory and sympathetic nerve fibres in dogs and primates (Ruskell, 1974a; Hara et al., 1982; Duke Elder et al., 1961) tracer studies and degeneration experiments are technically difficult and their selectivity in determining parasympathetic nerve fibres is often questionable. The parasympathetic innervation has been studied almost exclusively with the histochemical method for acetylcholinesterase activity (Koelle et al., 1952). Acetylcholinesterase actiwity, however, can be detected in sensory and sympathetic nerve fibres as well (Tewari et al., 1963; Baljet et al., 1987). Acetylcholinesterase activity was demonstrated in the cornea of monkeys, cats and rabbits, in the filtration angle of cats, rabbits and very infrequently in monkeys, in the ciliary processes and in the iris (both the sphincter and dilatator) of all three species (Laties et al., 1964, 1966). Ehinger (1966) showed the presence of acetylcholinesterase activity in the cornea, the chamber angle, the ciliary body and the iris of rabbits, rats and guinea pigs. Degeneration experiments were performed by Ruskell (1971, 1976) Geltser (1969) and Roth et al. (1969). Superior cervical ganglionectomy alone and a combined ganglionectomy of the ciliary and superior cervical ganglion to exclude the sympathetic fibres passing the ciliary ganglion, revealed the parasympathetic innervation of the iris. Parasympathetic nerve fibres originating in the pterygopalatine ganglion appeared to terminate in the choroid of primates and the trabecular meshwork and scleral spur of three out of six monkey eyes (Ruskell, 1971, 1976). Vasoactive intestinal peptide (VIP)immunoreactive nerve fibres, present in the choroid, the posterior third of the cillary muscle and the ciliary processes of cats, likely originate in the pterygopalatine ganglion since pterygopalatine ganglionectomy resulted in the disappearance of all VIP fibres (Uddman et all, 1980). However, VIP-like immunoreactive nerve fibres also originate in the ciliary ganglion of rats (Kuwayama et al, 1987) and in the choroid of guinea pigs (Terenghi et al., 1982). 


\subsection{SUMMARY AND EVALUATION}

Discharges of sensory nerve fibres were observed when the intraocular pressure was artificially raised. In addition it appeared possible to bring about changes in the intraocular pressure by stimulation of sensory, sympathetic and parasympathetic (both ocillomotor and faciai) nerve fibres. Howewer, it may hardly be possible to variate the intraocular pressure artificially without the stimulation of nerve terminals other than baroreceptors. The experiments in which IOP changes were recorded after stimulation of nerve fibres may be influenced by extraocular muscles and bload pressure. Nevertheless, the apparent ease with which the untraocular pressure can be changed makes it the more fascinating that the intraocular pressure is kept within close limits. One can hardly doubt the existence of a homeostatic mechanism and it seems very likely that central and peripheral nerve fibres involved in the innervation of the eyeball play an important role in this mechanism. However, morphological data do not allow the selection of specific nerve fibres or the sites of mutual contact between nerve fibres that play a role in this mechanism.

The morphological aspects of the peripheral innervation of the anterior eye segment have mainly been studied by means of the histochemical localization of catecholamines and acetyl-cholinesterase, by the visualisation of degenerating nerve fibres after specific lesions and by connection tracing with HRP and WGA-HRP. In order to study the innervation neuropeptides have recently been detected (Review: Palkama et al., 1987). These techniques revealed that most elements of the anterior eye segment, i.e. the cornea, the trabecular meshwork, the ciliary body and the iris, have a sympathetic and sensory innervation whereas the parasympathetic oculomotor innervation seems to be restricted to the iris and cilliary muscle although there may be some nerve endings in the trabecular meshwork. Whether facial parasympathetic nerve fibres also supply the ciliary body and iris in addition to their choroidal innerwation has not been elucidated yet. As for the sympathetic and sensory innervation the many techniques used revealed comparable results.

The central sensory and autonomic nucle are summarized in Table II. 


\begin{tabular}{|c|c|c|c|}
\hline Sensory trigeminal & Sympathetic & Ootalomotor & Facial \\
\hline $\begin{array}{l}\text { TBNC } \\
\text { dorsal horn } \\
\text { STN }\end{array}$ & IML & $\begin{array}{l}\text { EW } \\
\text { PAG } \\
\text { VTA }\end{array}$ & SSN \\
\hline
\end{tabular}

Centrally sensory trigeminal nerve fibres project to the trigeminal brainstem nuclear complex (TBNC), the dorsal horn of the upper cervical spinal cord and the solitary tract nucleus (STN). The preganglionic sympathetic nerves come from the intermediolateral cell column (IML). From the IML only the segments C8-T5 project to the superior cervical ganglion. Parasympathetic oculomotor preganglionic nerve fibres ariginate in the Edinger-Westphal nucleus (EW), the periagueductal gray (PAG) and the ventral tegmental area (VTA), whereas parasympathetio facial preganglionic nerve fibres come from the superior salivatory nucleus $(\mathrm{SSN})$.

As discussed in the previous paragraphs, the selectivity of the techniques used in the experiments on the innervation of the anterior eye segment is often questionable. Catecholamine and acetyl-cholinesterase are not restricted to sympathetic and parasympathetic nerve fibres respectively. Degeneration experiments and anterograde tracing studies with HRP and WGA-HRP have the inherent draw-back that it is impossible to discriminate between ganglionic somata and fibres of passage. In addition, retrograde tracing experiments from the eyeball often do not allow the selective study on the innervation of particular elements of the eyeball. This means that the innervation of the anterior eye segment may be more complicated than can be concluded on account of the previous studies.

\subsection{SCOPE AND OUTLINE OF THE PRESENT THESIS}

Eccles introduced the epitome "little brains", referring to the peripheral ganglia in general. However, data on the possible circuitry among other than enteric ganglia are very scanty. Sensory and autonomic neurons were thouglat to carry information from the eye to the central nervous system and from the central nervous system to the eye respectively. The ganglia present in this circuitry were thought of as being mainly relay stations passing on impulses with little or no modification. Little attention has been paid to the possibility of interconnections between the sensory and autonomic neurons within these 
peripheral ganglia. Only the parasympathetic ganglia, i.e. the ciliary and pterygopalatime ganglia, were found to contain nerve fibres of mixed origin. Evidence on the possible intermingling of sensory and autonomic nerve fibres in other than parasympathetic ganglia is only circumstantial. Stimulation of the distal sensory branches after a central trigeminal neurotomy revealed peripheral effects. These peripheral effects are thought to be due to an antidromic stimulation of sensory nerve fibres (Stjernschantz et al, 1979). It is possible that antidromic stimulation is only elicited by nerve endings (Holtzer, 1988). If antidromic stimulation can be elicited by sensory somata as well, this raises questions as to the physiological significance and the way in which these somata are activated. Moreover, these responses to sensory stimulation appeared to be more sensitive in sympathectomized eyes (Butler et al., 1979; Unger et all., 1981; Krootila et al., 1987). The anatomical substrate by which sympathetic nerve fibres may modulate the sensory information in the periphery has not been found yet. Although pericellular nerve fibre plexi, which were thought to have an extraganglionic origin, appeared to be present in the trigeminal ganglion (Cajal, 1909; Choukov et all 1988), synaptic contacts were never observed in the trigeminal ganglion (Lieberman, 1976).

In this thesis, the peripheral ganglia inwolwed in the innervation of the eyeball were investigated at the light and electron microscopic level. By means of tracing techniques the connectivity between the eye related ganglia is presently investigated in rats at the light microscopical level. By way of these connection tracing techniques the allocation of distinct nerve fibres to the structures of the anterior eye segment was studied as well.

As indicated in the previous paragraph many experiments on the origin of peripheral nerwe fibres have the disadwantage of being not strictly selectiwe in their identifcation of an anatomical entity of nerve fibres. In the present experiments two methods of connection tracing were employed. Tracing of neuronal connections is based on the property of axoplasmic transport of neurons. This transport is directed either away from the soma to the axons and dendrites (anterograde transport) or from the axons and dendrites to the soma (retrograde transport). Distinct tracers have different properties as to the direction in which they are transported. Some tracers are taken up by the somata and are subsequently transported along the axons and dendrites (anterograde tracing), whereas other tracers are taken up by nerve terminals and are transported to the soma (retrograde tracing). Moreover, injection of 
tracers into axonal bundles traversing the injection site may lead to the uptake and transport of the tracer by these traversing axons (tracing nores of passage). In the present experments horseradish peroxidase (HRP), HRP conjugated to the lectin wheatgerm agglutinin (WGA-HRP) and trituted leucine $\left({ }^{3}\right.$ H-Leucine) were used as tracers. The use of WGA-HRP is based on a modification of the original HRP-method as introduced by LaVaul and LaVail (1972). WGA-HRP is a more potent tracer as compared to native HRP because its uptake is enhanced by the wheatgerm agglutinin molety of the molecule. HRP and WGA-HRP can be used to trace comections both anteragradely and retrogradely. In addition both tracers are taken up by fibres of passage. A more selective means of connection tracing is the technique of autoradiography as introduced by Cowan et al. (1972). A radioactively labelled amino acid e.g. ${ }^{3}$ H-leucine, will only be preserved in the tissue and detected later by photographic procedures when it has been incorporated into proteins. Because axons and dendrites lack the capacity of significant protein synthesis the radioactively labelled amino acid will only be incorporated into proteins after its uptake by the cell soma. Hence connection tracing by means of autoradiography is restricted to anterograde tracing only.

In the course of our studies we were confronted with a striking difference between the superior cervical and trigeminal ganglion as to their uptake and transport of HRP and WGA-HRP. At first, this difference was considered to be of technical origin. Further analysis, however, revealed a fundamental difference between sensory and autonomic ganglia regarding their uptake of tracer molecules. In Chapter 2 the experiments on the distribution of WGAHRP and HRP in sensory and autonomic ganglia after intraganglionic and systemic injection are described.

In Chapter 3 retrograde tracing studies, used to outline the ganglia which are involved in the innervation of the anterior eye segment of rabbits (3.2) and rats (3.3), are discussed after a short description of the differences between the filtration angle of distinct species. The retrograde tracing experiments were performed in both rabbits and rats since pharmacological and physiological studies on the IOP are mostly done in rabbits, whereas tracing studies of the anterior eye segment are most frequentlly performed in rats. As no major differences between the anterior eye segment innerwation of rats and rabbits were found and as most neuroanatomical data result from experiments 
in rats, all anterograde tracing experiments were done in rats only.

Chapter deals with the sensory trigeminal innerwation of the anterior eye segment. In addition the sensory nerve fibre distribution to the peripheral ganglia was sudied.

Chapter 5 deals with the sympathetic innervation of the anterior eye segment atcd the sympathetic nerve fibre distribution to the eye related ganglia.

Chapter 6 deals with the parasympathetic facial innervation of the eveball and the localization of the superior salivatory (lacrimal) nucleus. 


\subsection{REFERENCES}

Akagi, Y., lbata, Y. and Sano, Y. (1976) The sympathetic innerwation of the ciliary body and trabecular meshwork of the cat Cell Tissue Res. 173, $261-269$

Akagi, Y., Sasamoto, K, Kodama, $Y$. and Tamura, K. (1981) Sympathetic innervation of the site of the aqueous secretion and outtow of the Japanese monkey (Macacus fuscatus); Fluorescent histochemistry and electron microscopy. Acta Soc. Ophthal. Jpn. 85, \339-1349

Armaly, M.F. (1959) Studies on intraocular effect of the orbital parasympathetic II: Effect on the intraocular pressure. Arch. Ophthal. 62, 117-124

Arvidson, B. (1979) Retrograde transport of horseradish peroxidase in sensory and adrenergic neurons following injection into the anterior eye chamber. J. of Neurocytol. 8, 751-764

Arvidsson, J. and Grant, G. (1979) Further observations on transganglionic degeneration in trigeminal primary sensory neurons. Brain Res. $162,1-22$

Baljet, B., Groen, G.J., Boekelaar, A.B. and Los, J.A. (1987) Orbital neuroanatomy in the rat. Verh. Anat. Ges. $71,389-390$

Barany , E.H. (1962) Trancient increase in outflow facility after superior cervical ganglionectomy in rabbits. Arch. Ophthal. 67, 303-311

Bergmanson, J.P.G. (1977) The ophthalmic innervation of the uvea in monkeys. Exp. Eye Res. 24, 225-240

Bernard, C. (1858) Lecons sur la physiologie et la pathologie du systeme nerveux. Paris Vol.II 96 and 205

Brodal, A. (1981) The cranial nerves. In: Neurological anatomy in relation to clinical medicine. Oxford University Press, New York, Oxford. Pp. 448-578

Brooks-Fournier, R. and Coggeshall, R.E. (198॥) The ratio of preganglionic cells in the sympathetic nervous system of the rat. J. Comp. Neurol. 197, 207-216

Brubaker, R.F, and Gaasterland, D. (1984) The effect of isoproterenol on aqueous humor formation in humans. Invest. Ophthalmol. Vis. Sci. 25, 357-361

Bruce, L.L., McHaffie, J.G. and Stein, B.E. (1987) The organization of trigeminotectal and trigeminothalamic neurons in rodents: A double labeling study with fluorescent dyes. the J. Comp. Neurol. 262, 315-330

Budge, J.L. and Waller, A.V. (1851) Action de la partie cervicale du nerf grand sympathique et d'une portion de la moelle epiniere sur la dilatation de la pupille. C.R. Acad. Sici. (Paris) 33, 370-374

Butler, J.M., Unger, W.G. and Hammond, B.R. (1979) Sensory mediation of the ocular response to neutral formaldehyde. Exp. Eye Res. 28, 577-589

Cajal, S.R. (1909) Histologie de systeme nerveux. Ist ed. Maloine Paris, Pp.442452

Canon, W.B. and Rosenblueth, A. (1949) The supersensitivity of denerwated structures. A law of denervation. MacMillan New York

Carpenter, M.B. (1978) Gross anatomy of the brain. In: Core text of neuroanatomy. The Williams \& Wilkins Company Baltimore. Pp. 15-44

Chapman G.B. and Spelsberg, W.W. (1963) The accurence of myelinated and unmyalinated nerves in the iris angle of man and rhesus monkey. Exp. Eye Res. 2, 130-133

Chouchkov, C., Lazarov, N. and Davidoff, M. (1988) Serotonoin-like immunoreactivity in the cat trigeminal ganglion. Histochemistry $88,637-$ 639

Chung, J.M., Chung, K. and Wurster, R.D. (1975) Sympathetic preganglionic neurons of the cat spinal cord: horseradish peroxidase study. Brain Res. 
91, $126-131$

Clark, C.V. and Mapstone, R. (1985) Autonomic neuropathy in ocular hypertension. The Lancet 27 july Pp. 185-187

Cowan, W.M., Gottleb, D.I, Hendrickson, A.E., Price, I.L. and Woolsey, T.A. (1972) The autoradiographic demonstration of axonal connections in the central neryous system. Brain Res. 37, 21-51

Daul, W.G. and Barton, S. (1983) Structure and organization of mammalian sympathetic ganglia. In: Autonomic ganglia. Ed. Elvin, L.G. John Wiley \& Sons, New York. Pp. 3-26

Davson; H. (1984) The intraocular pressure. In: The eye. 3rd. Edition Academic Press Inc. Flarida $391-533$

Duke-Elder, S. and Wybar, 踏.W. (1961) System of ophthalmology. vol.II Mosby St. Lours $813-874$

Eakins, K.E. and Eakins, H.M.T. (1964a) Adrenergic mechanisms and the outflow of aqueous humour from the rabbit eye. J. Pharmacol. 144, 60-65

Eakins, K.E. and Ryan, S.J. (1964b) The action of stympathetic amines on the outllow opf aqueous humour from the eye. Brit. J. Pharmacol. 23, 374382

Eccles, J.C. (1935) Faclitation and inhibition in the superiorcervical ganglion. J. Physiol. 85, 207-238

Ehinger, B. (1966) Ocular and orbital vegetative nerves. Acta physiol. scand. (suppl.) $67, \quad 1-35$

Epstein, D.L. (1987) Open angle glaucoma. Why not a cure? Arch. Ophthalmol. $105,1187-1188$

Erickson-Lamy, K.A. and Kaufman, P.L. (1988) Effect of cholinergic drugs on outflow facility after ciliary ganglionectomy. Invest. Ophthalmol. Vis. Sci. $29,491-494$

Falls, W.M. (1984) The morphology of neurons in trigeminal nucleus oralis projecting to the medullary dorsal horn (trigeminal nucleus caudalis): A retrograde horseradish peroxidase and Golgi study. Neuroscience 13 , 1279-1298

Feeney, M.L. (1962) Ultrastructure of the nerves in the human trabecular region. Invest. Ophthalmol. I, 462-473

Geltser, A.r. (1969) Autonomic innervation of the cat iris. Arch. Ophthalmol. $81,70-83$

Gloster, J. and Greaves, D.P. (1957) Effect of diencephalic stimulation upon intraocular pressure. Brit. J. Ophthaimol. 41, 513-532

Gloster, J. (1961) Influence of the facial nerve on intra-ocular pressure. Brit. I. Ophthalmol. $45,259-278$

Greaves, D.P. and Perkins, E.S. (1952) Influence of the sympathetic nervous system on the intraocular pressure and vascular circulation of the eye. Brit. J. Ophthalmol. 36, 258-264

Greaves, D.P. and Perkins, E.S. (1953) Influence of the third cranial nerve on intraocular pressure. Brit. J. Ophthalmol. 37, 54-57

Greaves, D.P. and Perkins, E.S. (1956) The seventh cranial nerve and intraocular pressure. J. Physiol. 134, 393-398

Gregory, D.S., Awado, D.G. and Sears, M.L. (1985) Cervical ganglionectomy alters the eircadian thythm of intraocular pressure in New Zealand White rabbits. Current Eye Res. 4, 1273-1279

Grierson, (1986) Alterations in the outflow system in chronic simple glaucona. In: Glaucoma. Ed. McAllister, J.A. and Wilson, R.P. Butterworths London P p. $1-30$

Grillo, M. (1978) Ultrastructural evidence for a sensory innervation of some SIF cells in the rat superior cervicall ganglia. Anat. Rec. 190, 407 
Grimes, P. and Sallmam von, L. (1960) Comparative anatomy of the cillary nerves. Arch. Ophthalmol. 64, 81-91

Hara, S., Kobayashi, S., Sugita, K. and Tsukahara, S. (1982) Innervation of dog cillary ganglion. Histochemistry $76,295-301$.

Hartmann, E. (1924) La neurotomie retro-gasserienne. Doin Paris.

Henderson, E.E. and Starling, E.H. (1904) The influence of changes in the intraocular circulation on the intraocular pressure. J. Physiol. 31, 305-319

Hodes, R. and Magoun, H.W. (1942a) Pupillary and other responses from stimulation of the frontal cortex and basal telencephalon of the cat. $J$. Comp. Neurol. $76,461-473$

Hodes, R. and Magoun, H.W. (1942b) Autonomic responses to ellectrical stimulation of the forebrain and midbrain with special reference to the pupil. J. Comp. Neurol. 76, 169-190

Hogan, M.J., Alvarado, J.A. and Weddell, J.E. (1971) The cornea. In: Histology of the human eye. W.B. Saunders Company. Philladelphia $a_{y}$ London, Toronto Pp. $55-112$

Holland, M.G., von Sallman, L. and Collins, E.M. (1956) A study of the innervations of the chamber angle. Am. J. Ophthalmol. 42, 148 161

Holland, M.G., von Sallman, L. and Collins, E.M. (1957) A study of the innervation of the chamber angle. II: The origin of trabecular axons revealed by degeneration experiments. Am. J. Ophthal. 44, 206-22!

Hollwich, F. (1982) Augenheikunde. Georg Thieme Verlag Stuttgart, New York

Holzer, P. (1988) Lacal effector functions of capsaicin-sensitive sensory nerve endings: inwolvement of tachykinins, calcitonin gene-related peptide and other neuropeptides. Neuroscience 24,739-768

Horst ter G. (1986) Descending pathways from the lateral and ventromedial hypothalamic areas to the autonomic centers of medulla oblongata and spinal cord. In: The hypothalamus imtrinsic connections and outflow pathways to the pancreas. Stichting C. Regenboog. Groningen The Netherlands 103-127

Huerta, M.F., Hashikawa, T., Gayoso, M.J. and Harting, J.K. (1985) The trigeminal alivary projection in the cat: contributions of individual subnuclei. J. Comp. Neurol. 241, 180-190

Jacquin, M.F., Semba, K. Egger, M.D. and Rhoades, R.W. (1983) Organization of HRP labeled trigeminal mandibular primary afferent neurons in the rat. J. Comp. Neurol. 215, 397-420

Jaeger, R.J. and Benevento, L.A. (1980) A horseradish peroxidase study of the innervation of the internal structures of the eye. Evidence for a direct pathway. Invest. Ophthal \& Vis. Sci, 19, 575-583

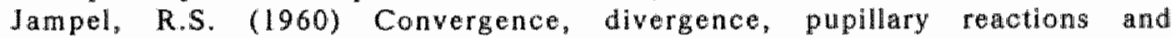
accomodations of the eye from foradic stimulation of the macaque brain. J. Comp. Neurol. 115, 371-399

Kai-Kai, M.A. and Keen, P. (1985) Localization of 5-hydroxytryptamine to neurons and endoneurial mast cells in rat sensory ganglia. J. Neurocytol. 14, $63-78$

Kanski, J.J. (1984) Glaucoma. In: Clinical ophthalmology. Buttersworth \& Co Pp. $7.1-7.37$

Katz, D.M., Markey, K.A., Goldstein, M. and Black, I.B. (1983) Expression of catecholaminergic characteristics by primary sensory neurons in the normal adult rat. Proc. Nat. Acad. Sci. USA 80, 3526-3535

Katz, D.M., Adler, J.E. and Black, I.B. (1987) Cathecholaminergic primary sensory neurons: autonomic targets and mechanisms of transmitter regulation. Federation Proc. 46, 24-29

Kerr, F.W.L., Kruger, L., Schwassman, H. and Stern, R. (1968) Somatotopic 
organization of mechmoreceptor units in the trigeminal nuclear complex of the macaque. J. Comp. Neurol. 134, 127-144

Koelle, G.B., Wolfand, L., Friedenwald, J.S. and Allen, R.A. (1952) Localization of specific cholinesterase in ocular tissues of the cat. Am. J. Ophthal. 35, $1580-1584$

Kolmer, W. (1914) Zur Histologie der Augenhate. Anat. Anz. 47, 417

Krootila, K, Uusitalo, H. Lebtosalo, I.I. and Palkama, A. (1987) Recovery of the blood-aqueous barrier after topical chemical irritation in the rabbit eye. Alb. Graef. Arch. Clin. Exp. Ophthalmol. 225, 272-276

Kuwayama, Y., Grimes, P.A., Ponte, B. and Stone, R.A. (1987) Autonomic meurons supplying the rat eye and the intraorbital distribution of wasoactive intestinal peptide (VIP)-like immunoreactivity. Exp. Eye Res. $44,907-922$

Lamers, W.P.M.A. (1962) De innervatie van het trabeculum corneosclerale. Nujmegen, Centrale Drukkerij

Landis, S.C. (1983) Factors which infuence the transmitter functions of sympathetic ganglion cells, In: Autonomic ganglia. Ed. Elfuin, L.G. John Wiley \& Sons, New York. Pp. 453-473

Langham, M.E. and Taylor, C.B. (1959) The effect of superior cervical ganglionectomy on the intraocular pressure. J. Physiol. 147, 58

Langham, M.E. and Taylor, C.B. (1960a) The influence of superior cervical ganglionectomy on intraocular dynamics. Brit. J. Ophthal. $35,445-458$

Langham, M.E. and Taylor, C.B. (1960b) The influence of pre- and postganglionic section of the cervical sympathetic on the intraocular pressure of rabbits and cats. J. Physiol. 152, 437-446

Langham, M.E. and Rosenthal, A.R. (1966) Role of cervical sympathetic nerve in regulating intraocular pressure and circulation. Am. J. Physiol. 210, $786-794$

Langham, M.E. (1978) Adrenoreceptor mechanisms in the outflow channels of normal and glaucomatous eyes. Glaucoma Update. Springer-Verlag Berlin Heidelberg New York Kriegstein G.K./ Leydhecker W. 19-23

Langley, J.N. (1900) The sympathetic and other related systems of nerves. In: Textbook of Physiology Ed. Schafer E.A., Pentland Edinburgh, Vol. 2 pp. 616-696

Langley, J.N. (1921) The autonomic nervous system, W. Heffner and Sons, Cambridge

Laties, A. and Jacobowitz, D.(1964) A histochemical study of the adrenergic and cholinergic innervation of the anterior segment of the rabbit eye. Invest. Ophthal. 3, 592-600

Latles, A. and Jacobowit, D. (1966) A comparative study of the autonomic Innervation of the eyo in monkey, cat and rabbit. Anat. Rec. 156, 383396

LaVaill, J.H. and LaVail, M.M. (1972) Retrograde axonal transport in the central nervous system. Science 176, 1416-1.417

Lehtosalo, J, Uusitalo, H., Uusitalo, R., Poranen, A. and Palkama, A. (1983) Electron microscopic identification of trigeminal nerve fibers in the cilliary body and the inis. Neurosci. Lett. 42, 239-242

Lehtosalo, J., Uusitalo, H. and Palkama, A. (1984) Sensory supply of the anterior uvea: a light and electron microscope study. Exp. Brain Res. 55, $562-569$

Lele, P.P. and Grimes, P.A. (1960) The role of neural mechanisms in the regulation of intraocular pressure in the cat. Exp. neurol. 2, 199-220

Ljeb, Wc.A, Guerry, D. and Eilis, LJ. (1958) Enfects of superior cervical ganglionectomy on aqueous humour dynamics. Afch. Ophthal. 60, 31-35 
Lieberman, A.R. (1976) Sensory Ganglia. In: The peripheral nerve. ed. Landon, D.N. London: Chapman and Hall. New York: John Wiley and Sons, Inc. $188-278$

Lin, T., Grimes, A. and Stone, R.A. (1988) Nerve pathways between the pterygopalatine ganglion and eye in cats. Anat. Rec. 222, 95-102

Loewy, A.D., Araujo, J.C. and Kerr, F.W.L. (1973) Pupillodilator pathways in the brainstem of the cat: anatomical and electrophysiological identification of a central autonomic pathway. Brain Res. 60, 65-91

Loewy, A.D. and Saper, C.B. (1978a) Edinger-Westphal nucleus: projection to the brain stem and spinal cord in the cat. Brain Res. 150, 1-27

Loewy, A.D., Saper, C.B. and Yamodis, N.D. (1978b) Re-evaluation of the efferent projections of the Edinger-Westphal nucleus in the cat. Brain Res. $141,153-159$

Macri, F.J. and Cevario, S.J. (1975) Ciliary ganglion stimulation. I Effects on aqueous humour inflow and outflow. Invest. Ophthal. 14, 28-33

Magendie, F. (1824) De l'influence de la cinquieme paire de nerfs sur la nutrition et les fonctions de l'oeil. J. Physiol. Exp. Pathol. 4, 176-200

Maldowsky, W. (1980) Die Nervenversorgung des Auges. In: Anatomie des Auges. Weberdruck Pforzheirn. Pp. 265-301

Malmfors, T. (1965a) Studies on adrenergic nerves. Acta physiol.scand. (suppl.) 64,248

Malmfors, T. and Sachs, Ch. (1965b) Direct demonstration of the systems of terminals belonging to an individual adrenergic neuron and their distribution in rat iris. Acta Physiol. Scand. 64, 377-384

Marfurt, C.F. (1981a) The somatotopic organization of the cat trigeminal ganglion as determined by the horseradish peroxidase technique. Anat. Rec. 201, 105-118

Marfurt, C.F. (1981b) The central projections of trigeminal primary afferent neurons in the cat as determined by the transganglionic transport of horseradish peroxidase. J. Comp. Neurol. 203, 785-798

Marfurt, C.F. and Turner, D.F. (1983) Sensory nerve endings in the rat orofacial region labeled by the anterograde and transganglionic transport of horseradish peroxidase: a new method for tracing peripheral nerve fibers. Brain Res. 261, 1-12

Marfurt, C.F., Zaleski, E.M., Adams, C.E. and Welther, C.L. (1986) Sympathetic nerve fibers in rat orofacial and cerebral tissues as revealed by the HRPWGA tracing technique: a light and electron microscopic study. Brain Res. $366,373-378$

Marfurt, C.F. and DelToro, D.R. (1987) Corneal sensory pathway in the rat: a horseradish peroxidase tracing technique, J. Comp. Neurol, 261 , 450-459

Marfurt, C.F. (1988) sympathetic innervation of the rat cornea as demonstrated by the retrograde and anterograde transport of horseradish peroxidase-wheatgerm agglutinin. J. Comp. Neurol. 268, 147-160

Maurice, D.M. (1954) Constriction of the pupil in the rabbit by antidromic stimulation of the trigeminal nerve. J. Physiol. $123,45 \mathrm{P}$

Morgan, C., DeGroat, W.C. and Jannetta, P.J. (1987) Sympathetic innervation of the cornea from the superior cervical ganglion. An HIR study in the cat. J. Autonomic Nervous System 20, 179-183

Nagano, S., Myers, J.A. and Hall, R.D. (1975) Representation of the cornea in the brain stem of the rat. Exp. Neurol. 49, 653-670

Nasution, I.D. and Shigenaga, Y. (1987) Ascending and descending internuclear projections within the trigeminal sensory nuclear complex. Brain Res. 425, 234-247

Nieuwenhuys, R. (1985) Survey of chemically defined cell groups and pathways. 
In: Chemoarchitecture of the brain. Springer Verlag. Berlin, Heidelberg, New York and Tokyo. Pp. 7-114

Nomura, T. and Smelser, G.K. (1974) The didentification of adrenergic and cholinergic nerve endings in the trabecular meshwork. Invest. Ophthal. $13, \quad 525-532$

Nord, S.G. (1967) Somatotopic organization in the spinall trigeminal nucleus, the dorsal column nuclei and related structures in the rat. $J$. Comp. Neurol. 130, 343-356

Olszewski, 1. (1950) On the anatomical and functional organization of the spinal trigeninal nucleus. J. Comp. Neurol. 92, 401-4l3

Opsahl, C. $A_{\text {. }}$ (1977) Sympathetic nervous system involvement in the lateral hypothalamic lesion syndrome. Am. J. Physiol. 232, R128-136

Palkama, A. Uusitalo, H. and Lethosalo, J. (1987) Innervation of the anterior eye segment of the eye: with special reference to functional aspects. Neurochemistry: Modern methods and applications, Alan R. Liss, Inc. pp. $587-615$

Panneton, W.M. and Burton, H. (1981) Cormeal and periocular representation within the trigeminal sensory complex in the cat studied with transganglionic transport of horseradish peroxidase. J. Comp. Neurol. 199, $327-344$

Patrick, G.W. and Robinson, M.H. (1987) Collateral projections from trigeminal sensory nuclei to ventrobasal thalamus and cerebellar cortex in rats. $J$. Morphol. 192, 229-236

Perkins, E.S. (1957) Influence of the fifth cranial nerve on the intraocular pressure of the rabbit eye. Brit. J. Ophthal. 41, 257-300

Petras, J.M. and Cummimgs, J.F. (1972) Autonomic neurons in the spinal cord of the rhesus monkey: a correlation of the findings of cytoarchitectonics and sympathectomy. J. Comp. Neurol. 146, 189-218.

Pfaller, K. and Arvidsson, $J$. (1988) Central distribution of trigeminal and upper cervical primary afferents in the rat studied by anterograde transport of horseradish peroxidase conjugated to wheatgerm agglutinin. J. Comp. Neurol. 268, 91-108

Price, J. and Mudge, A.W. (1983) A subpopulation of rat dorsall root ganglion neurons is catecholaminergic. Nature 301, 241-243

Quigley, H.A. (1980) Pathophysiology of the optic nerve in glaucoma. In: Glaucoma. Ed. McAllister, J.A. and Wilson, R.P. Butterworths London Pp.30-53

Rambourg, $A_{*}$, Clermont, $Y$. and Beaudet, A. (1983) Uitrastructural features of six types of neurons in rat dorsal root ganglia. J. Neurocyt. 21, 47-66

Rando, T.A., Bowers, C.W. and Zigmond, R.E. (1981) Localization of neurons in the rat spulual cord which project to the superior cervical ganglion. $J$. Comp. Neurol. 196, 73-83

Reiss, G.R. Lee, D.A., Topper, J.E. and Brubaker, R.F. (1984) Aqueous humour now during sleep. Invest. Ophthal. \& Vis. Sci. 25, 776-778

Roth, C.D. and Richardson, K.C. (1969) Electron microscopical studies on axonal degeneration in the rat iris following ganglionectomy. Am. $J$. Anat. $124,341-360$

Rozsa, A.I. and Beuerman, W. (1982) Density and organization of free nerve endings in the corneal epithelium of the rabbit. Pain 14, 105-120

Ruskell, Q.L. (1.965) The orbital distribution of the sphenopalatine ganglion in the rabbit. In: The structure of the eye, Vol. II: Eighth International Congress of Anatomists, Wiesbaden. Ed. Rohen, J.W., Schattauer, Stuttgart, Pp. $355-368$

Ruskell, G.L. (1970a) An ocular parasympathetic nerve pathway of facial nerve 
origin and its influence on intraocular pressure. Exp. Eye Res. 10, 319-330 Ruskell, G.L. (1970b) The orbital branches of the pterygopalatine ganglion and their relationship with internal carotid nerve branches in primates. $\mathscr{X}$. Anat. 106, 323-339

Ruskell, G.L. (1971) Facial parasympathetic innerwation of the choroidal bloodvessels in monkeys. Exp. Eye Res. 12, 166-172

Ruskell, G.L. (1974a) Peripheral nerve analysis using Wallerian degeneration: nerves relating to the ciliary ganglion. Exp. Eye Res. 18, 417-418

Ruskell, G.L. (1974b) Ocular fibres of the maxillary merve in monkeys. J. Anat. 118, $195-203$

Ruskell, G.L. (1976) The source of nerve fibres of the trabeculae and adjacent structures in monkey eyes. Exp. Eye Res. 23, 449-459

Saper, C.B., Loewy, A.D., Swanson, L.W. and Cowan, W.H. (1976) Direct hypothalamo-autonomic connections. Brain Res. 117, 305-312

Schimmelpfennig, B. (1982) Nerwe structures in human central corneal epithelium. Graefe's Arch. Clin. Exp. Ophthal. 218, 14-20

Schmerl, E. and Steinberg, B. (1950) Seperation of diencephalic centers concerned with pupillary motility and ocular tension. Am. J. Ophthal. 33, $1379-1381$

Sears, M.L. and Sherk, T.E. (1964) The trabecular effect of noradrenaline in the rabbit eye. Invest. Ophthal. 3, 157-163

Shigenaga, $Y$. , Okamoto, T., Nishimori, T. Suemune, $S$. Nasution, $\mathbb{I}$, Chen, $\mathbb{K}$., Tsuru, A., Yoshida, K., Tabuchi, M. and Tsuru, H. (1986) Oral and facial representation in the trigeminal principal and rostral spinal nuclei of the cat. J. Comp. Neurol. 244, 1-18

Shimazu, T. (1979) Nervous control of peripheral metabolism. Acta Physiol. Pol. $30,1-18$

Shimazu, T. (1981) Central nervous system regulation of liver and adipose tissue metabolism. Diabetologica $20,343-356$

Shimazu, T. (1983) Reciprocal innervation of the liver: its significance in metabolic control. In: Advances in metabolic disorders Vol.10 (CNS Regulation of Carbohydrate metabolism) Szabo, A.J. Ed. Academic Press, New York 355-384

Shimazu, T. (1987) Neuronal regulation of hepatic glucose metabolism in mammals. Diabetes/Metabolism Reviews vol.3, 185-206

Stjernschantz, J. Geyer, C. and Bill, A. (1979) Electrical stimulation of the fifth cranial nerve in rabbits: effects on ocular blood flow, extravascular albumin content and intraocular pressure. Exp. Eye Res. 28, 229-238

Stone, R.A. and Laties, A.M. (1987) Neuroanatomy and neuroendocrinology of the chamber angle. Glaucoma Update III Ed. G.K. Krieglstein, Springer Verllag Berlin Heldelberg pp. $1-16$

Sugimoto, T., Itoh, K. and Mizuno, N. (1.977) Localization of neurons giving rise to the oculomotor parasympathetic outflow: a HRP study in cats. Neuroscience Letters 7, 301-305

Sugimoto, T., Itoh, K. and Mizuno, N. (1978) Direct projections from the Edinger-Westphal nucleus to the cerebellum and spinal cord in the cat: an HRP study. Neuroscience Letters $9,17-22$

Sugitta, A and Yoshioka, H. (1984) Nerwe fibers in trabecular meshwork surface. Jpn. J, Ophthal. $28,248-253$

Tamamaki, N. and Nojyo, Y. (1987) Intracranial trajectories of sympathetic nerwe fibers originating, in the superior cervical ganglion in the rat: WGA-HRP anterograde labeling study. Brain Res. 437, 387-392

Terenghi, G., Polak, J.M., Probert, L., McGregor, G.P., Ferri, G.L., Blank, M.A., Butler, J.M., Unger, W.G., Zhang, S., Cole, D.F. and Bloom, S.R. (1982) 
Mapping, quantititave distribution and origin of substance $\mathrm{P}$ - and WIPcontaining nerves in the wwea of guinea pig eye. Histochemistry $75,399-$ 417

Tewar, H.B. and Boume, G.H. (1963) Histochemical studies on the distribution of simple esterase. Specific and non-specific cholineterase in the trigeminal ganglia of the rat. Acte Anat. 53, 319-332

Torvik, A. (1956) Afferent connections to the sensory trigeminal nuclei, the nucleus of the solitary tract and adjacent structures. An experimental study in the rat. J. Comp. Neurol. 106, 51-142

Tower, S.S. (1940) Unit for sensory reception in the comea with notes on nerve impulses from sclera, iris and lens. I. Neurophysiol. 3, 486

Trzeciakowski, J.P. (1987) Review: Central control of intraocular pressure. J. Ocular Pharmacol. 3, 367-378

Tripathi, R.C. and Tripathi, B.J. (1982) Functional anatomy of the anterior chamber angle. In: Ocular anatomy, embryology and teratology. Jacobiec F.A. Harper \& Row, publishers Philadelphia 197-285

Uddman, R., Alumets, J., Ehinger, B., Hakanson, R., Loren, I. and Sundler, F, (1980) Vasoactive intestinal peptide nerves in ocular and orbital structures of the cat. Invest. Ophthal. \& Vis. Sci. 19, 878-885

Unger, W.G. Butler, J.M. and Cole, D.F. (1981) Prostaglandin and an increased sensitivity of the sympathetically denervated rabbit eye to laser induced irritation of the iris. Exp. Eye Res. 32, 699-707

Valu, L. (1966) Zur nervenversorgung des Uvea-Trabekel-Systems. A. won Graefes Arch. Clin. Exp. Ophthal. 1969, 150-159

Van der Tuig, J.G., Knehans, A.W, and Romsos, D.R.(1982) Reduced sympathetic nervous system actiwity in rats with ventromedial hypothalamic lesions. Life Sci. 30, 913-920

Von Hippel, A. and Gruunhagen, A, (1868) Ueber den Einfluss der Nerven auf die Hohe des intraocularen Druckes. v. Graefes Arch. Ophthal. 14, 219258

Von Sallmann, L., Fuortes, M.G.F., Macri, F.J. and Grimes, P. (1966) Study of afferent electric impulses induced by intraocular pressure chamges. Am. J. Ophthal. $45,211-220$

Wall, P.D. and Taub, A. (1962) Four aspects of trigeminal nucleus and a paradox. J. Neurophysiol. 25, 110-126

Warwick, R. (1954) The ocular parasympathetic nerve supply and its mesencephalic sources. J. Anat. 88, 71-93

Windle, W.F. (1926) Non-bifurcating nerve fibers of the trigeminal nerve. Comp. Neurol. 40, 229-240

Yoshimatsu, H., Niijima, A., Oomura, Y."Yamabe, K. and Katafuchi, T. (1984) Effects of hypothalamic lesion on pancreatic autonomic nerve activity in the rat. Brain Res. 303, 147-152

Zander, E. and Wedell, G. (1951) Observations on the innervation of the cornea. J. Anat. 85, 68-99 
CHAPTER II

BLOOD-GANGLION CELL BARRIER 
Neuronal damage by methyl-mercury intoxication especially affect the sensory parts of the nervous system.

Van Welsum, R.A. and De Wolff, F.A. (1988)

Ned. Tildschr. Geneeskd. 48, 2198-2201) 


\section{SATELLITE CELLS AS BLOOD-GANGLION CELL BARRIER \\ IN AUTONOMIC GANGLIA}

\section{SUMMARY}

In a preliminary study a difference in the uptake and transport of WGA-HRP between the trigeminal ganglion and the superior cervical ganglion was observed. After injection of WGA-HRP and HRP into the trigeminal ganglion, peroxidase was found in the space between the satellite cell processes and the ganglion cells. The ganglion cells showed pinocytosis and uptake of WOAHRP and HRP. In the superior cervical ganglion, WGA-HRP and HRP were found alongside the satellite cells but were absent in the space between satellite cells and ganglion cells. Intravenous injection revealed the presence of HRP in the space between sensory ganglion cells and their satellite cells of the trigeminal and nodose ganglion whereas HRP was absent in the space between autonomic ganglion cells and their satellite cells of the superior cervical, medial cervical and pterygopalatine ganglion, although HRP lined the satellite cell membranes. By means of electron microscopy satellite cell processes in the superior cervical ganglion were found to enwrap ganglion cells very tightly with a marginal space between both cell types. Satellite cells and their processes were mutually anchored by numerous tight jumctions. In the trigeminal ganglion, the extracellular space between ganglion cells and satellite cells was larger and satelite cells were found to be more loosely arranged around the ganglion cells. Satellite cell processes were only occasionally linked by tight junctions.

It is concluded that satellice cells in autonomic ganglia comprise an offective barrier for WGA-HRP and HRP and probably large molecules in general. This barrier is absent in sensory ganglia.

\section{INTRODUCTION}

In contrast to the situation in the brain, large proteins have access to the extracellular compartment of peripheral ganglia. This must be due to the absence of a blood-ganglion barrier in the peripheral nervous system. The difference in permeability of blood wessels in peripheral ganglia as compared to 
the bloodvessels composing the blood-brain batrier was shown by the presence of several proteins in the extracellular spaces of autonomic ${ }^{2,16}$ and sensory ganglia $2,3,4,8,13,14,17$ after intravenous injection. This ready access to the extracellular space of peripheral ganglia has been related to e.g. cadmium intoxication, experimental allergic neuritis, diphteritic polyneuritis and to methyl mercury intoxication ${ }^{2} 9$

In a preliminary study of the innervation of the anterior eye segment of the rat, using wheat germ agglutinin coupled to horseradish peroxidase [WGA-HRP] as a tracer, a puzzling difference between injections in the trigeminal (sensory) and the superior cervical (sympathetic) ganglion was observed. The uptake and transport of WGA-HRP appeared to be successful in the trigeminal ganglion but largely failed in the superior cervical ganglion. To explain the cause of this difference the fine structural localization of WGA-HRP in the superior cervical ganglion and the trigeminal ganglion was determined after injection into these ganglia. It appeared that in the trigeminal ganglion WGAMRP is present in the ganglion cells and in the space between ganglian cells and satellite cells whereas in the superior cervical ganglion the space between ganglion cells and satellite cells is free of WGA-HRP and the amount of WGAHRP in the ganglion cells is neglectable. This may indicate that these ganglia have distinct properties regarding the accessibility and uptake of large proteins. However, as these experiments were carried out with WGA-HRP with its specific binding properties of the WGA moiety to oligosaccharides on the plasmalemma ${ }^{5,6}$, the results may also reflect a difference in binding properties to this tracer only. In addition the results may also reflect a different reaction of these ganglia to manipulation and injection. To elucidate this, HRP was injected into the superior cervical and trigeminal ganglion and the distribution of systemically injected HRP was studied in antonomic (superior cervical, medial cervical and pterygopalatine) ganglia and in sensory (trigeminal and nodose) ganglia. "The results are in strong support of a fundamental difference of autonomic and sensory ganglia with respect to a blood-ganglion cell barrier. The possible ultrastructural differences between the satellite cell-ganglion cell complexes within these ganglia were studied to elucidate the distinct distribution patterns found. 


\section{MATERIALS AND METHODS}

The experiments were performed on adult male Wistar rats weighing between 200 and 300 grans. Prior to injection all animals were anesthetized with ethanol $(20 \%, 7.5 \mathrm{ml} / \mathrm{kg}, \mathrm{i} . \mathrm{p}$.$) and hypnorm (0.25 \mathrm{ml} / \mathrm{kg}, \mathrm{i} . \mathrm{m}$.$) and the rats were$ placed in a stereotactic frame. The hydraulic injections were made over a period of 10 minutes.

\section{Superior cervicall ganglion injections}

All injections were placed into the rostral pole of the superior cervical ganglion. The superior cervical ganglion, lying in the carotid bifurcation, was reached by blunt dissection.

WGA-HRP: About 3 HL of $2 \%$ WGA-HRP dissolved in double distilled water were injected in four animals with a Hamilton syringe (30 gauge needle). In 6 animals a $2 \%$ WGA-HRP solution in double distilled water was injected iontophoretically with an ejection current of $0.6 \mu \mathrm{A}$ during a period of 20 to 40 minutes using glass micropipettes with a $20 \mu \mathrm{m}$ tip diameter. In ten animals $3 \mu$ of $2 \%$ WGA-HRP dissolved in double distilled water were injected with glass micropipettes $(20 \mu \mathrm{m}$ tip diameter) connected to a $10 \mu \mathrm{ll}$ Hamilton syringe via a short length of polyethylene tubing.

HRP: $3 \mu$ of a $30 \%$ HRP (Sigma, type II) solution in double distilled water were injected by pressure with glass micropipettes $(20 \mu \mathrm{m}$ tip diameter $)$.

\section{Trigeminal ganglion injections}

The injections were placed in the antero-median part of the trigeminal ganglion, lying in the middle cranial fossa. After removall of a small part of the parietal bone a small part of the hemisphere covering the antarior part of the left trigeminal ganglion was removed by suction.

WGA-HRP: About $3 \mu 1$ of $2 \%$ HRP-WGA dissolved in double distilled water were delivered by pressure injection using glass micropipettes with a $20 \mu \mathrm{m}$ tip diameter.

HRP: About 3 , of $30 \%$ HRP dissolved in double distilled water were pressure injected with glass micropipettes (20 $\mu \mathrm{m}$ tip diameter). 


\section{Vascular injections}

HRP (Sigma, type 11 ), $8 \mathrm{mg} / 10 \mathrm{~g}$ body weight, dissolved in $2 \mathrm{ml}$ phosphate buffered saline was injected into the tail vein.

Table I

\begin{tabular}{|c|c|c|c|c|c|}
\hline & & \multicolumn{2}{|c|}{ WGA-HRP } & \multicolumn{2}{|c|}{ HRP } \\
\hline & & $\begin{array}{l}\text { number of } \\
\text { animals }\end{array}$ & $\begin{array}{l}\text { survival } \\
\text { time(hr) }\end{array}$ & $\begin{array}{l}\text { number of } \\
\text { animals }\end{array}$ & $\begin{array}{l}\text { survival } \\
\text { time(hr) }\end{array}$ \\
\hline s.c.g. & injections & $\begin{array}{r}12 \\
8\end{array}$ & $\begin{array}{r}48-72 \\
4-12\end{array}$ & 3 & $4-112$ \\
\hline $\begin{array}{l}\text { tr.g. } \\
\text { vascular }\end{array}$ & $\begin{array}{l}\text { injections } \\
\text { injections }\end{array}$ & 10 & $4-72$ & $\begin{array}{l}2 \\
4\end{array}$ & $\begin{array}{l}4-12 \\
3-12\end{array}$ \\
\hline
\end{tabular}

s.c.g.: superior cervical ganglion; tr.g.: trigeminal ganglion

The number of animals and the survival times are indicated in Table I. All animals were killed with pentobarbital following 1000 IU thromboliquine. The animals were perfused through the ascending aorta with $500 \mathrm{ml} 0.9 \% \mathrm{NaCl}$ in distilled water containing $0.003 \%$ heparin, followed by $500 \mathrm{ml}$ of fixative containing $1 \%$ paraformaldehyde $-4 \%$ glutaraldehyde in $0.1 \mathrm{M}$ phosphate buffer, pH 7.3, and, finally, with $500 \mathrm{ml}$ of ice cold $0.1 \mathrm{M}$ phosphate buffer containing $10 \%$ sucrose. In the animals in which the trigeminal or the superior cervical

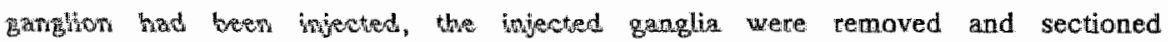
into small parts with a razor blade. The uninjected contralateral ganglion was used for a comparative check. After vascular injection, the superior cervical ganglia, the medial cervical ganglia, the pterygopalatine ganglia, the nodose ganglia and the trigeminal ganglia were removed and sectioned. The tissues were then incubated with a p-phenylenediamine-pyrocatechol [PPD-PC] mixture ${ }^{8}$. The specimens were postfixed in $\mathrm{OsO} 4$ and embedded in Epon 812. Ultrathin sections were cut and stained with uranyl acetate and lead citrate. In those animals where the superior cervical ganglion had been injected with WGA-HRP, the iris was removed to check peripheral WGA-HRP transport. When the trigeminal ganglion had been injected, the cornea was removed and checked for peroxidase transport. Both iris and comea were reacted for the 
detection of WGA-HRP with the TMB method ${ }^{11}$. The normal structure of ganglion cells and satellite cells was inwestigated in uninjected ganglia of three rats that were perfused with $250 \mathrm{ml} \mathrm{NaCl}$ and $1000 \mathrm{ml}$ of the fixative mentioned before. The specimens were left owernight in the same fixative, postfixed in 0 SO4, embedded in Epon 812 and stained in the same way.

\section{RESULTS}

\section{Superior cervical ganglion infections}

WGA-HRP and HRP were found in the endoneurium of the superior cervlcal ganglion four hours after injection. Peroxidase was bound to collagen fibres (Fig. IA,B). In the endoneurial space many WGA-HRP and HRP containing macrophages were present (Fig.2). Peroxidase lined the cell membranes of satellite cells (Fig.1A,B) and between the outermost satellite cell processes. The penetration of peroxidase between the satellite cell precesses, however, appeared to be blocked (Fig. 1A). A few ganglion cells in the immediate injection site and occasionally satellite cells (Fig.3) contained lysosome like bodies filled with WGA-HRP or HRP. Peroxidase was absent in the space between satellite cells and ganglion cells. From 24 hours onwards peroxidase was found only in macrophages. The method of injection appeared to have no influence on the distribution of WGA-HRP and HRP. In one animal, injected with a Hamilton syringe, anterograde transport of WGA-HRP to the iris was found.

The ultrastructure of the uninjected superior cervical ganglia revealed that ganglion cells and satellite cells are closely apposed leaving a small extracellular space as compared to the trigeminal ganglion (Fig.6). Satellite processes are closely packed around the ganglion cells. Between the satellito cell processess numerous axons, dendrites and terminals were found. Numerous tight junctions were found between the satellite cell processes (Fig.6). Especially those satellite cells enwrapping axons had many tight junctions in close vicinity to the axons. Many tight junctions were also found between satellite cell membranes covering the ganglion cells (Fig.6).

\section{Trigeminal ganglion injections}

WGA-HRP was found in the endoneurium of the trigeminal ganglion even 72 hours after the injection. The endoneurial distribution of the peroxidase was 
much the same as in the superior cervical ganglion. HRP-WGA and HRP, however, were additionally present in large quantities in the space between ganglion cells and satelite cells (Figs.7B,C). Peroxidase not only lined the cell membranes of satellite cells but also lined the cell membranes of ganglion cells. Gangtion cells that were lined by peroxidase showed signs of pinocytotic activicy (Fig.4A). Many ganglion cells and satellite cells had taken up WGAHRP or HRP into lysosome like bodies (Fig.4B). Macrophages filled with peroxidase were present in the trigeminal ganglion but not as many as in the superior cervical ganglion. Most macrophages were present in the periphery of the ganglion. WGA-HRP transport to the cornea was found in all experiments (Fig.5).

Uitrastructural study of uninjected trigeminal ganglia showed a large Intercellular space between ganglion cells and satellite cells (Fig.7A). Satellite cells were not closely packed around the ganglion cells. The satellite cells and ganglion cells had projections into the intercellular space. Satellite cells were only occasionally linked by tight junctions.

\section{Vascular injections:}

In all ganglia studied HRP was found in large amounts in the subcapsular and cortical parts. The trigeminal and superior cervical ganglion showed a distribution of HRP similar to that after intraganglionic injection. HRP lined the satellite cells of the superior cervical ganglion and was present in the extracellular space between the outermost satellite cell processes. It was not found in the space between ganglion cells and satellite cells. In the trigeminal ganglion, HRP lined the ganglion cells, and was found in the space between

Figure 1.

Ganglion cell-satellite cell complexes in the superior cervical ganglion 6 hours afier injection of WGA-HRP. WGA-HRP is bound to collagen. It tines the cell nembranus of sarellite cells (arrows in $A$ and $B$ ) and is present in the extracellular space between the outermost satellite cell processes where its penetration appears to be blocked (open arrow in A). Peroxidase is absent in the space between the satellite cell and the ganglton cell. The scale bars. represent 0.5um. gc: ganglion cell, sc: salellite cell

Figure 2.

Macrophages in the superior cervical ganglion 24 hours after injection of WGA-HRP. The macrophages have taken up large amounts of WGA-HRP. The scale bar represents lum.

Figure 3.

Satellite cell in the superior cervical ganglion \& hours after injection of WGA-HRP into the ganglion. The satellite cell processes have taken up HRPWGA. Arnows: axoms and dendrites that are enwrapped by the satellite cell. Scale bar represents $1 \mu \mathrm{m}$. sc: satellite cell 

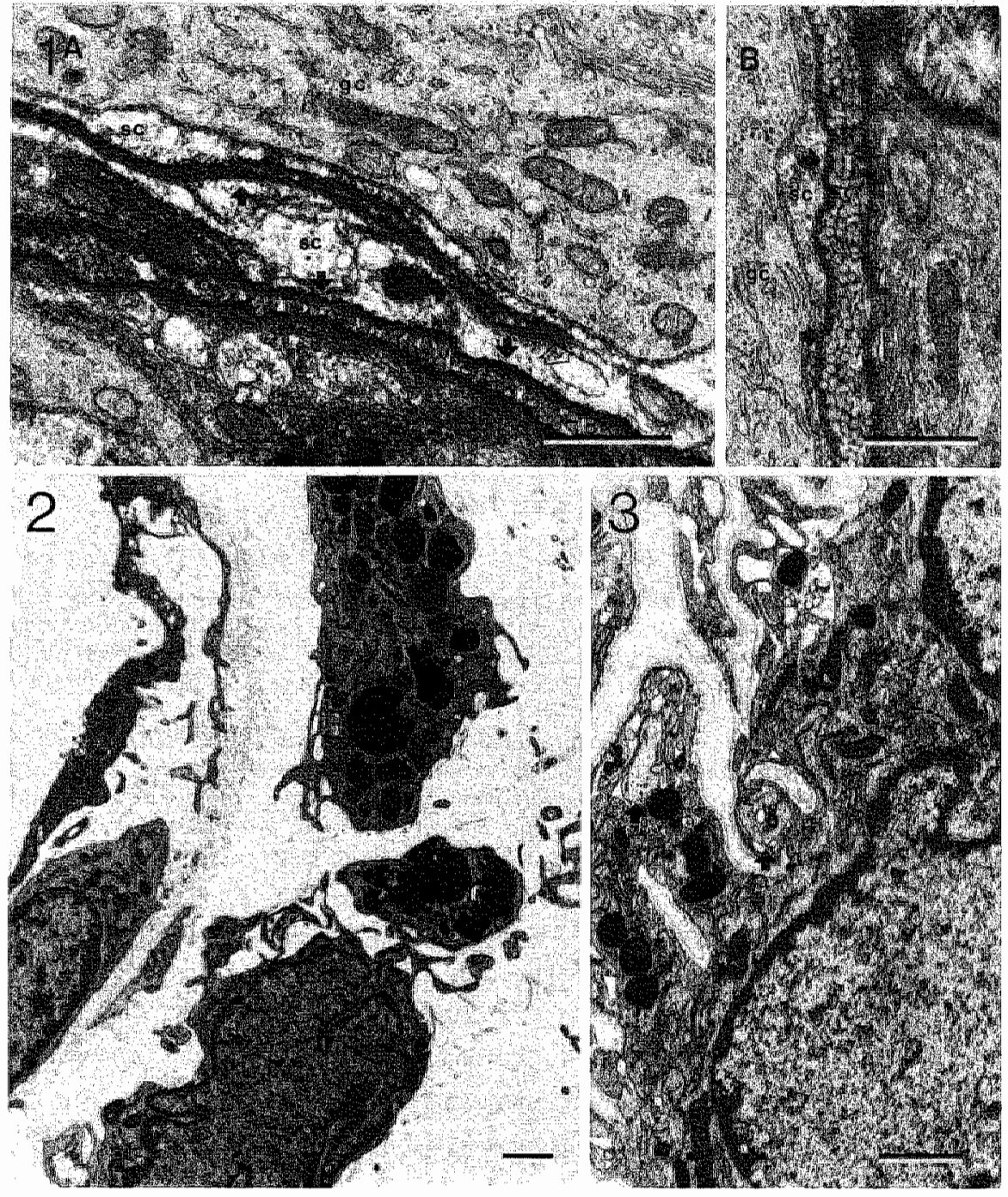

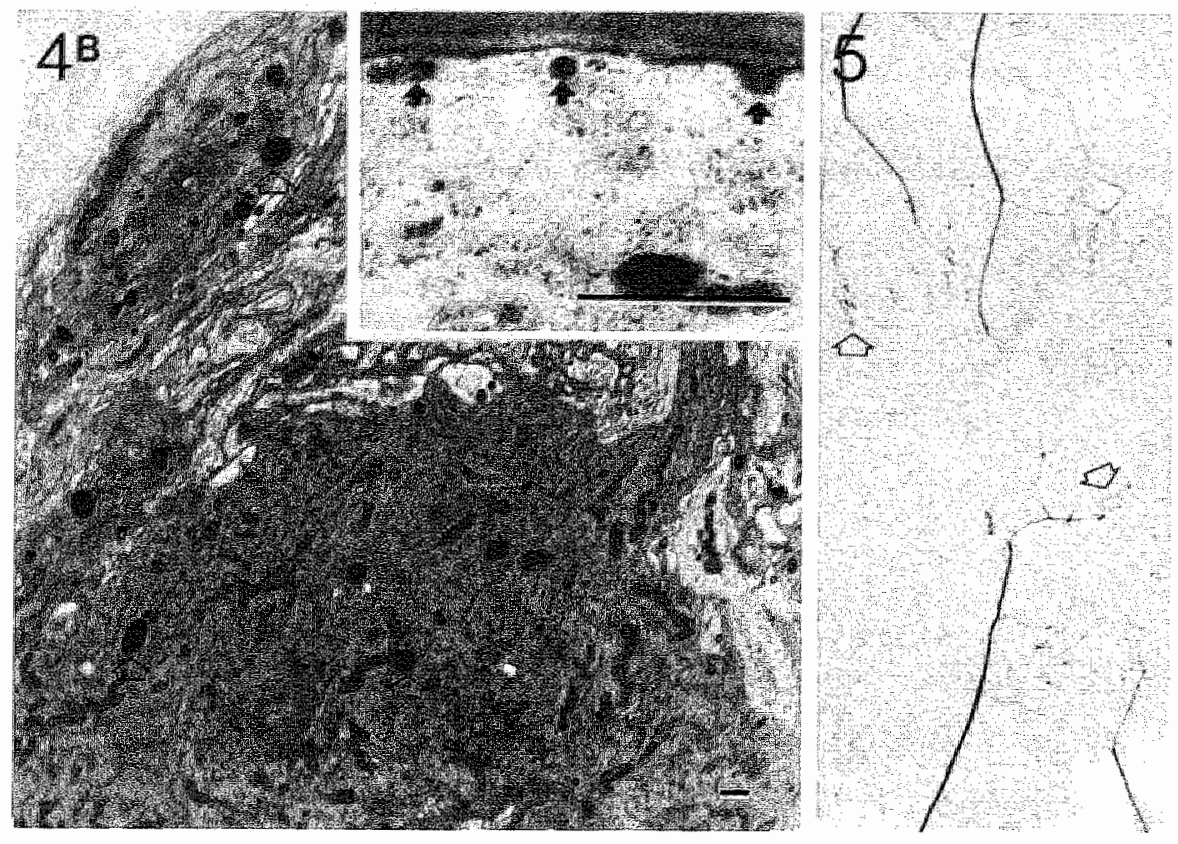

\section{Figure 4.}

Trigeminal ganglion 48 hours after injection of WGA-HRP. A: Ganglion cell showing signs of pinocytosis (arrows). B: Ganglion cell and satellite cell showing lysosome-like-bodies (open arrows) which have iaken up WGA-HRP. Scale bars: $0.5 \mathrm{\mu m}$. gc: ganglion cell, sc: satellite cell

Figure 5.

Light micrograph of a comea wholemount showing several WGA-HRP labelled nerves 48 hours after injection into the trigeminal ganglion. In the center of the corriea epithelial and sub-epithelial endings are present (open arrows) and in the periphery neuron bundles leave the cornea (arrows). Magnification: "13

ganglion cells and satellite cells. Few trigeminal ganglion cells, however, were not lined by HRP whereas their satellite cells were lined by HRP.

The sensory nodose ganglion showed a distribution of HRP similar to that of the trigeminal ganglion (Fig.8). The distribution of HRP in the sympathetic medial cervical ganglion and the parasympathetic pterygopalatine ganglion (Fig.9) was the same as in the superior cervical ganglion with absence of HRP in the space between satellite cells and ganglion cells, whereas the satellite cells and the extracellular space between the outermost satellite cell layers were bordered by large quantities of HRP. In addition, the occurrence of tight junctions in the nodose ganglion appeared to be similar to the trigeminal 
ganglion whereas the large number of tight junctions found in the superior cervical ganglion was comparable to the distribution of tight junctions in the medial cervical ganglion and the pterygopalatine ganglion. Although in all ganglia studied ganglion cells had taken up HRP, the number of ganglion cells which had taken up HRP in the autonomic ganglia was extemely small in comparison to the number in sensory ganglia.

\section{DISCUSSION}

HRP and WGA-HRP were found to be transported from the superior cerwical ganglion to the eye of cats and rats ${ }^{10,12}$. However, in the present experiments only one out of twelve injections into the superior cervical ganglion resulted in the transport of WGA-HRP to the iris whereas all injections into the trigeminal ganglion resulted in the transport of WGA-HRP to the cornea. In the superior cervical ganglion WGA-HRP and HRP did not gain access to the small space between ganglion cells and satellite cells, meither after intraganglionic injection nor after vascular injection. Moreover, vascular injection of HRP revealed that HRP had no access to this space in the medial cervical and pterygopalatine ganglion as well, even in areas where large amounts of HRP lined the satellite cell membranes. The ganglion cells and satellite cells in the superior cervical ganglion appeared to be closely apposed leaving only a small extracellular space. The satellite cells and their processes were mutually connected by numerous tight junctions. Apparently these tightly linked satellite cells prevent the access of endoneurial proteins to the ganglion cells. Tight junctions seal neighboring cells together to create a continuous sheet of cells between which even small molecules are unable to pass 1 . This barrier appeared not to be effective for tritiated leucine. Tritiated leucine, injected into the superior cerwical ganglion, was incorporated in proteins and transported in large amounts to the iris in eight rats that were injected with $750 \mu \mathrm{Ci}{ }^{3} \mathrm{H}$ Leucine (manuscript submitted). Hence, the barrier seems only effective for larger molecules.

In addition it was observed that WGA-HRP and HRP were very quickly removed from the endoneurial compartment by macrophages. This rapid response of macrophages in the superior cervical ganglion was also noted by Arvidson $(1979)^{2}$. Jacobs et al. $(1976)^{8}$ described a similar response within sensory ganglia. Yet there seems to be a difference in the removal of 
peroxidase from the trigeminal and the superior cervical gangion. In the superior cerwical gangtion no free WGA-HRP was found 24 hours after the injection whille it was still found 72 hours after injection into the trigeminal ganglion. In the trigeminal ganglion macrophages were mostly present in the periphery whereas the macrophages in the superior cervical ganglion were evenly distributed throughout the ganglion.

In the trigeminal ganglion WGA-HRP and HRP were present within the space between ganglion cells and satellte cells, lining the cell membrames of both ganglion cells and satellite cells. After vascular injection HRP appeared to line the ganglion cells of the nodose ganglion as well. Signs of pinocytosis were found all along the plasmalemma of the ganglion cells. The ganglion cells are less well separated from the endoneurial space by their satellite cells. Satellite cells are less tightly packed. Ganglion cells and satellite cells protrude into the space between these cells. As these differences in the arrangement of satellite cells between the trigeminal and superior cervical ganglion were observed in the same animal, it can not be due to a fixation effect. Only a few tight junctions were found between the cell membranes of satellite cells in the trigeminal ganglion.

The incidental uptake of WGA-HRP and HRP by ganglion cells in the superior cervical ganglion may partly be due to axonal damage or destruction of the junctions present between the enveloping satellite cells during injection. Transport across the satellite cell barrier and transcytotic transport may have resulted in the uptake of HRP of a few ganglion cells in the autonomic ganglia after vascular injection. However, the number of ganglion cells which bad taken up WGA-HRP or HRP was very small in comparison to the sensory ganglia.

Figure 6. Ganglion cell-satellite cell complexes in an uninjected stuperior cervical ganglion. Tight junctions (arrows) are present between the satellite cell processes which enwrap the ganglion cell. The intercellular space between the ganglion cell and the satellite cell is narrow. Scale bar: $0.25 \mathrm{~km}$. gc: ganglion cell, sc: satellite cell

Flgure 7.

Ganglion cell-satellite cell complexes in the trigeminal ganglion. A: A large extra-cellular space is present between the ganglion cell and the satellite cell ist an uninjected trigeminal ganglion. Both cells protrude into the extra-cellular space. B,C: Peroxidase lines the satellite cells but also the ganglion cells (arrows), 48 hours afier injection of WGA-HRP. The scale bar in A represents 0.5 mm. Scale bar in B: 0.25 fum. Scale bar in C: $0.125 \mu \mathrm{m}$. gc: ganglion celi, sc: satellite cell, $s$ : space between the ganglion cell and the satellite cell. 


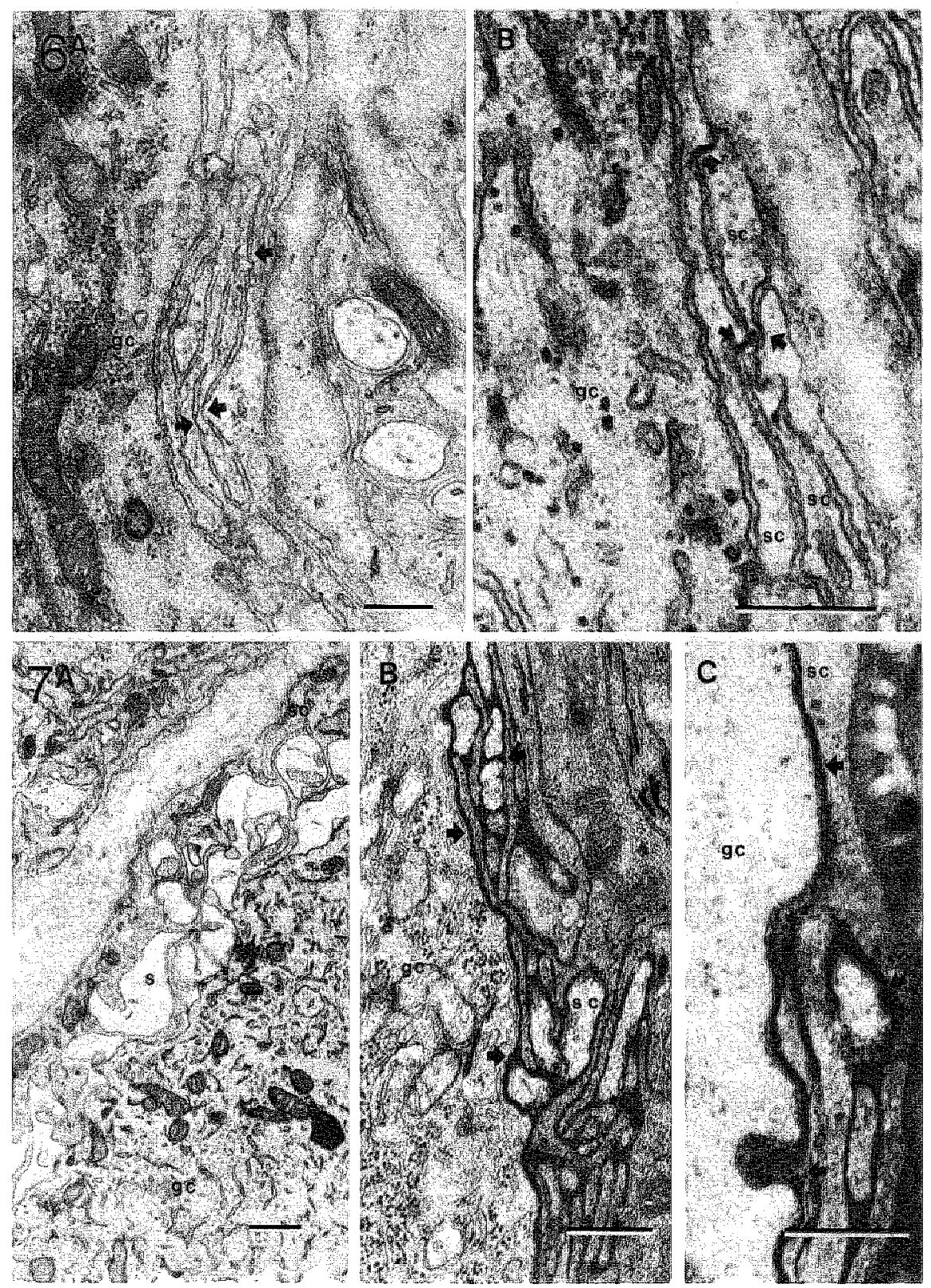



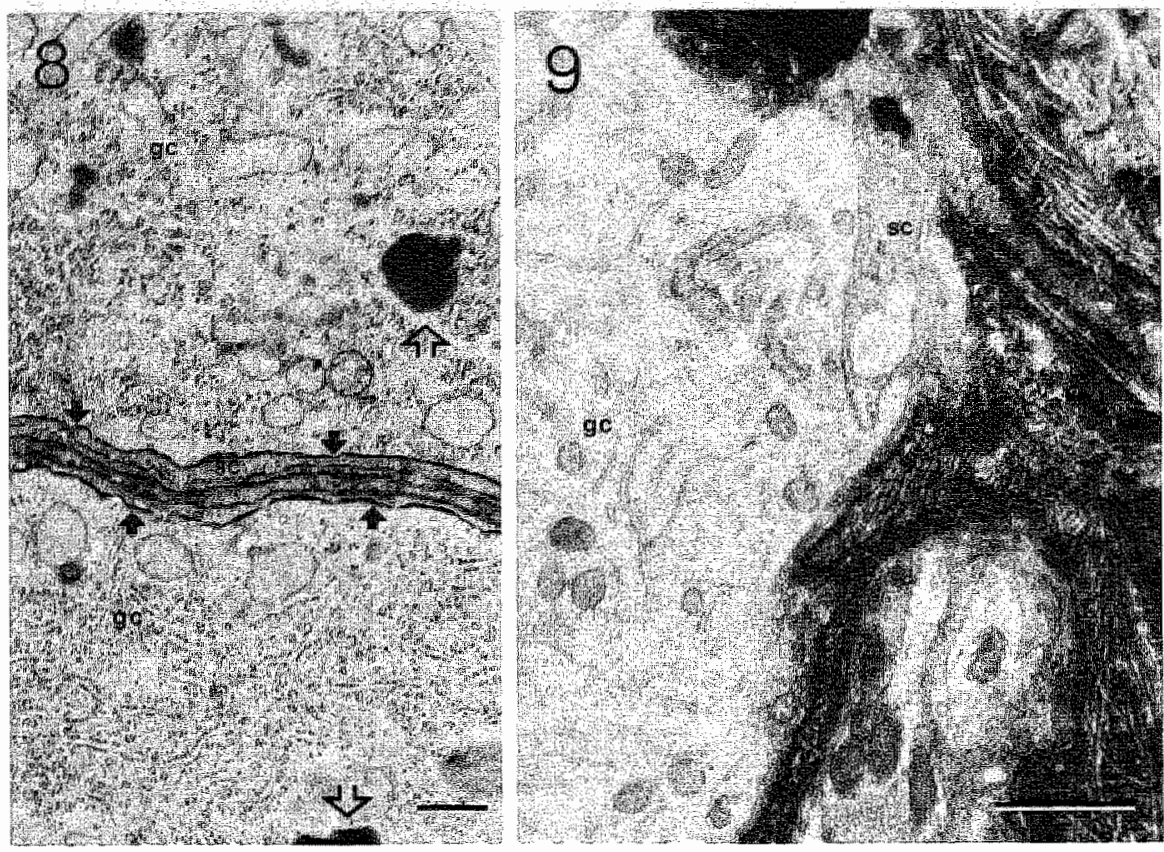

\section{Figure 8.}

Ganglion cells in the nodose ganglion 4 hours after injection of HRP into the tail wein. The ganglion cell membranes are lined by HRP (arrows) whereas the endoneurial space appears to be free of HRP. Both ganglion cells have takent up HRP (open arrows). gc: ganglion cell" sci satellite cell. Scale bar: 1 lam.

Figure 9.

Ganglion cell-satellite cell complex in the pterygopalatine ganglion 4 hours after intravascular injection of HRP. HRP is not present in the space between the gangllon cell and the satellite cell whereas a large amount of HRP is present in the endoneurial space lining the satellite cell. gc: ganglion cell, sc: satellite cell. Scale bar: $1 / \mu \mathrm{m}$.

The present study confirms the rapid access of circulating proteins to the endoneurial space of both sensory and autonomic ganglia, meaning that the capillary walls have no barrier function. The access of proteins to the ganglion cells has been studied ultrastructurally only in sensory ganglia ${ }^{2,8}$. Our results support this ready access of proteins to the space between ganglion 
cells and satellite cells and therefore to the ganglion cells in sensory ganglia indicating that in sensory ganglia the satellite cells have no barrier fumotion either.

In contrast, however, satellite cells in the autonomic ganglia form an effective barrier to WGA-HRP and HRP and possibly to large molecules in general. The presence of numerous tight junctions between the satellite cell processes seems to be responsible for this barrier as has been shown for the perineurium of the sciatic nerve in rabbits. 
1.Alberts, B., Bray, D., Lewis, J., Rafi, M. Roberts K. \& Watson, J.D., Molecular biology of the cell. Garland Publishing, Inc. New York \& London. (1983) 674-718

2. Arvidson, B., Distribution of intravenously injected protein tracers in peripheral ganglia of adult mice, Exp. Neurol.y 63 (1979) $388-410$

3.Arvidsson, $\mathbb{B}$., Kristensson, $K . \&$ Olsson, $Y$., Wascular permeability to fuorescent protein tracer in trigeminat nerve and Gasserian ganglion. Acta Neuropath., 26 (1973) 199-205

4.Brierly, J.B., The sensory ganglia. Recent anatomical, physiological and pathological contributions. Acta Psychiatr. Neurol. Scand., 30 (1955) 553576

5.Broadwell, R.D. and Balin, B.J., Endocytic and exocytic pathways of the neuronal secretory process and transsynaptic transfer of wheatgerm agglutinin-horseradish peroxidase in vivo. J. Comp. Neurol., 242 (1985) $632-650$

6.Gonatas, N.K. \& Avrameas, S., Detection of plasma membrane carbohydrates with lectin peroxidase conjugates, J. Cell Biol., 59 (1973) 436-443

7.Hanker, I.S., Yates, P.E., Metz, C.B.\& Rustioni, A., A new specific, sensitive and non-carcinogenic reagent for the demonstration of horseradish peroxidase. J. Histochem., 9 (1977) 789

8.Jacobs, J.M., Macfarlane, R.M.\& Cavanagh, J.B., Vascular leakage in the dorsal root ganglia of the rats studied with horseradish peroxidase. $J$. Neurol. Scl, 29 (1976) 95-107

9.Lieberman, A.Rn, The peripheral nerve. ad. Landon, D.N. John Wiley\& sons inc. New York (1976) 188-278

10.Marfurt, C.F., Zaleski, E.M., Adams, C.E. \& Welther, C.L., Sympathetic nerve fibers in rat orofacial and cerebral tissues as revealed by the HRPWGA tracing technique: a light and electron microscopic study " Brain Research 366 (1986) 373-378

11.Mesulam, M.M., Tracing neural connections with horseradish peroxidase (IBRO handbook series: methods in neurosciences) ed. Smith A.D. I.Willey and sons Ltd. (1982) 3-247

12.Morgan, C., Degroat, W.C. \& Jannetta, P.J., Sympathetic innervation of the connea from the superior cervical ganglion. An HRP study in the cat. J. Autonom. Nery. Syst., 20 (1987) 179-183

13.Olsson, Y., Topographical differences in the vascular permeability of the peripheral nervous system. Acta Neuropath. 10 (1968) 26-33

14.Olsson, Y., Studies on vascular permeability in peripheral nerves. Acta Neuropath. 17 (1971) 114-126

15. Reale, E., Luciano, L.\& Spitznas, M., Freeze-fracture faces of the perineurial shoath of the rabbilt sciatic nerve, J. Neurocytol. 4 (1975) 261-270

16.Tschetschujeva, T., Uber die Speicherung ron Trypan blau in Ganglien verschledener Giobiete des Nervensystems, Z. Ges. Exp. Med. 69 (1929) 208219

17. Waksman, B.H., Experimental study of diphteritic polyneuritis in the rabbit and guinea pig, J. Neuropath. Exp. Neurol., 20 (1961) 35-77 
CHAPTER III

THE ANTERIOR EYE SEGMENT INNERVATION

-as revealed by retrograde tracing -

III.1 COMPARATIVE ANATOMY OF THE FILTRATION ANGLE

III.2 THE INNERVATION OF THE RABBIT"S ANTERIOR EYE SEGMENT

III.3 THE INNERVATION OF THE RAT'S ANTERIOR EYE SEGMENT 



\section{1 COMPARATIVE ANATOMY OF THE FILTRATION ANGLE}

The anatomy of the site of outflow of aqueous humour differs substantially between distinct mammals. Three types of filtration angles are recognized in mammals: the anthropoid type of filtration angle, the carnivorous type of filtration angle and the herbivorous type of filtration angle. The variations found are characterized by differences in the localization and extent of the cilliary muscle and the splitting of the ciliary body. The herbivorous type is characterized by a ciliary muscle which Iocalization is restricted to the outer part of the ciliary body. The inner part of the cillary body and the iris are seperated from the outer part of the ciliary body by a triangular space, which is called the ciliary cleft. In rodents the ciliary muscle may even be rudimentary or lacking. The pectinate ligament, by which the ciliary body and the iris are anchored to the limbus, connects the inner part and the outer part of the ciliary body in the herbivorous type of filtration angle. In the camivorous type the ciliary muscle is present in both the inner part and the outer part of the ciliary body. This type also has a deep ciliary cleft. The iris and ciliary body, however, are supported by the cillary muscle. In the anthropoid type of filtration angle which is present in primates the ciliary cleft is almost obliterated by the massive development of the ciliary muscle. Figure 1 examplifies a herbivorous type of filtration angle and an anthropoid type of filtration angle. These differences in the anatomy of the site of outflow bear upon the interpretation of experiments concerning the outflow tract.

Figure 1: (page 64) This figure shows an anthropoid type of filtration angle (A) and a herbivorous type of filtration angle (B). A: shows the large cillary muscle (arrows) and the shallow trabecular mestwork (open arrow) in an anthropoid type. B: shows the deep ciliary cleft (open arrow) and the small cilliary muscle (arrows) in the herbiworous type of filtration angle. (Courtesy of W.P.M.A. Lamers) 


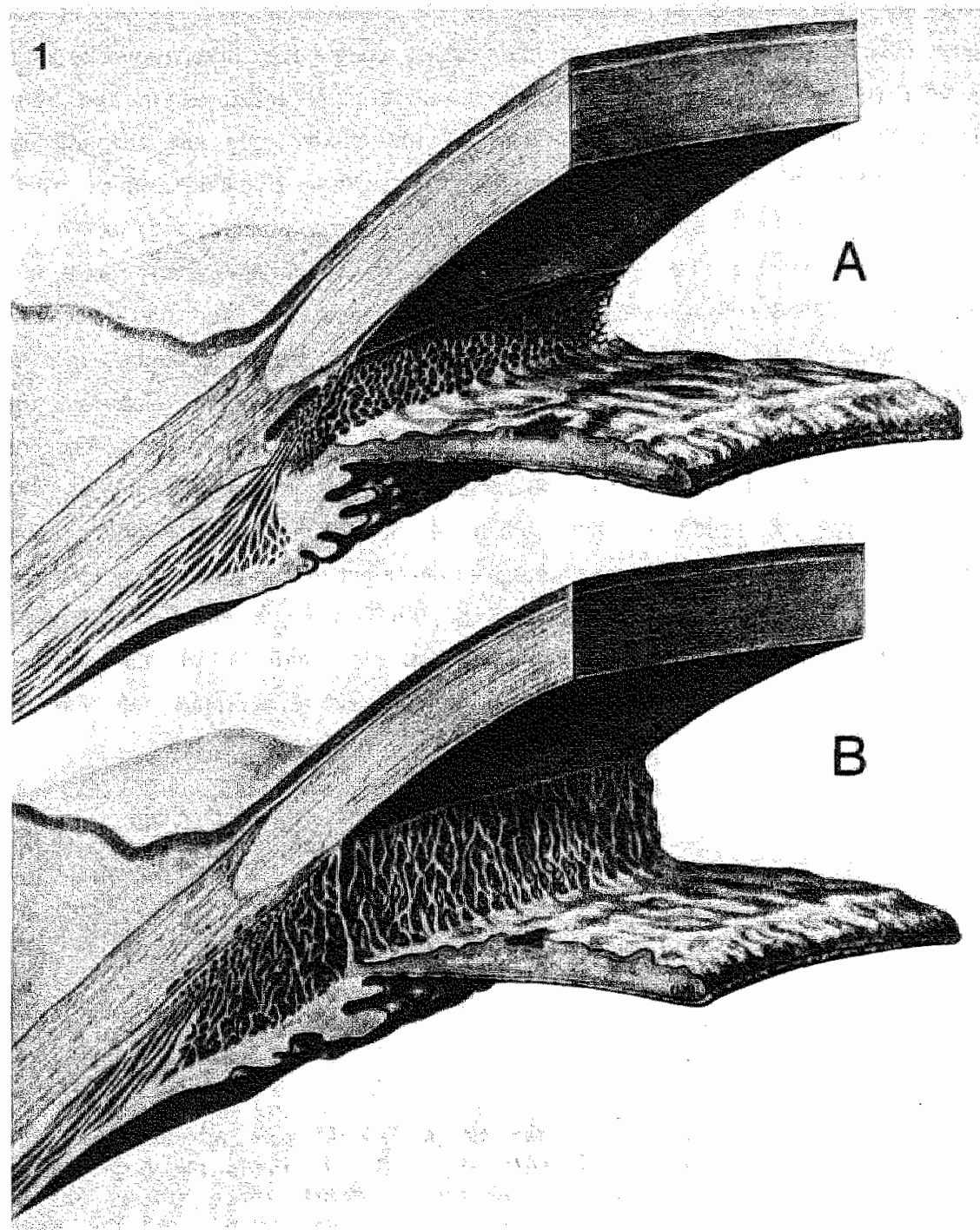




\section{III.2 THE INNERVATION OF THE RABBITS ANTERIOR EYE SEGMENT}

-a retrograde tracing study-

\section{SUMMARY}

The differential innervation of the distinct elements of the anterior segment of the rabbit-eye, i.e. cornea, conjunctiva, cillary body, iris and trabecular meshwork, was studied using horseradish peroxidase-wheatgerm agglutinin (WGA-HRP) as a tracer. WGA-HRP was injected into the anterior chamber, the conjunctiva, or the comea, and the animals were killed after 6 to 96 hr. The WGA-HRP localization was studied at the light and electron microscopic level. Injection into the anterior chamber led to an ubiquitous spread of the tracer in all elements of the anterior segment, resulting in a consistent retrograde labelling of neurons in the trigeminal (sensory), superior cervical(sympathetic) and ciliary (parasympathetic) ganglion. Neurons in the proximal part of the pterygopalatine ganglion (parasympathetic) were labelled only when the injected tracer was present in the conjunctiva. Varying survival-times after comeal injection were used to establish restricted comeal uptake. $U_{p}$ to 16 hr after corneal injection, WGA-HRP was limited to the cornea and led to the exclusive labelling of neurons in the trigeminal ganglion, indicating that the central cornea has an almost exclusive sensory innervation. The trigeminal sensory neurons projecting to the cornea were restricted to a small antero-medial part of the trigeminal ganglion. Electron microscopy revealed four different cell types in the trigeminal ganglion. However, distinct elements of the anterior segment did not project to specilic cell types.

\section{INTRODUCTION}

The sensory innervation of the cornea has recently been demonstrated in cats $^{27,28}$ and rats ${ }^{2,29}$ by means of horseradish peroxidase (HRP) tracing studies. HRP was applied to transsected comeal nerwes and retrogradely labelled ganglion cells were found in the antero-medial part of the trigeminal ganglion $^{28}$. HRP was also injected into the trigeminal ganglion and cormeal terminals were anterogradely labelled 29 .

On the basis of formaldehyde induced fluorescence studies by which catecholamines are detected $8,9,19,20,43,44,45,48$, a degeneration experiment ${ }^{46}$, 
an anterograde tracing study ${ }^{30}$ and the influence of epinephrine on the rabbit comeal epithelium $^{17}$, it was proposed that sympathetic nerves are present in the comea of subprimates and primates 48 . In contrast to the large amount of proof for an adrenergic innervation there are only a few studies conceming the cholinergic innervation. Histochemical identification of cholinergic corneal nerves based on the acetylcholine esterase reaction $18,19,20,36$, combined with degeneration experiments led to the proposition of a dual autonomic innervation of the comea. However, adrenergic nerves and cholinergic nerves are not exclusively sympathetic ${ }^{15,16}$ or parasympathetic ${ }^{47}$ respectively. Acetylcholinesterase containing corneal nerves were observed to degenerate after ophthalmic neurotomy 42 . In addition anterograde tracing studies with HRP and HRP conjugated with wheatgerm-agglutinin (WGA-HRP), and degeneration studies, have the disadvantage that passing fibres are also labelled and therefore these experiments cannot give definite proof for the existence of an autonomic innervation of the cornea.

The first aim of the present study was to elucidate the autonomic innervation of the cornea more definitely using the method of retrograde labelling with WGA-HRP combined with optimal survival times. Using the same method, we also aimed at discriminating between the trigeminal sensory imnervation of the cornea and other structures of the anterior segment, and investigating the ultrastructure of the differentially projecting trigeminal ganglion cells. Finally, the parasympathetic facial nerve innervation of the anterior eye segment mediated by the pterygopalatine ganglion was investigated.

\section{MATERIALS AND METHODS}

The experiments were performed on 28 adult male Dutch belled rabbits (weight: about $2 \mathrm{~kg}$ ).

\section{Retrograde tracing experiments (light microscopy)}

The animals were sedated by an intramuscular injection of fentanyl. A local anaesthetic (tetracaine $2 \%$ ) was used. The injections of WGA-HRP were performed with a Hamilton syringe (30 gauge needles) using a dissection microscope. After the injection, the eyes were properly rinsed with isotonic saline. 
(1) CORNEA. Approximately $10 \mu$ of $8 \%$ WGA-HRP, dissolwed in distlled water, were injected in 2 or 3 fragments into the centre of the comea.

(2) ANTERIOR CHAMBER. Twenty-five microlites of $4 \%$ WGA-HRP, dissolved in distilled water, were injected transcomeally into the anterior chamber of the eye.

(3) CONJUNCTIYA. Animals were injected with $25 \mu$ of $4 \%$ WGA-HRP under the conjunctiva of the right eye.

The number of animals, the injection in one or both eyes, the survival-times and the histological procedures used are summarized in Table 1 . After the indicated survival times, sedation and analgesia were produced in all animals with an intramuscular injection of fentanyl, after which 1000 1.U. thromboliquine were injected intravenously. The atnimals were killed with a mixture of ketamine $\mathrm{HCl}$ and acepromazine (1\%) which was injected into the ear vein. Perfusion fixation was carried out through the ascending aorta and started with 1.5 litre $0.9 \% \mathrm{NaCl}$ in distilled water to which $0.06 \%$ sodiumnitrate was added. This was followed by 2 litres of the fixating solution, consisting of $4 \%$ glutaraldehyde and $1 \%$ paraformaldehyde in $0.1 \mathrm{M}$ phosphatebuffer, pH 7.3. The perfusion was finished by one litre of $10 \%$ sucrose in $0.1 \mathrm{M}$ phosphatebuffer, $\mathrm{pH} 7.3$ at $4^{\circ} \mathrm{C}$. The rate of perfusion was about $300 \mathrm{ml} / \mathrm{min}$.

Both eyes, the trigeminal ganglia, the superior cervical ganglia, the pterygopalatine ganglia and the ciliary ganglia were dissected immediately after perfusion. The tissue was sectioned on a freezing microtome at $18 \mu \mathrm{m}$. The sections were mounted on chrome-alum-gelatin-coated slides. All specimens were reacted according to the tetramethylbenzidine [TMB] method for the demonstration of WGA-HAPP ${ }^{3 !}$. The sections were examined using bright- and dark-field microscopy.

\section{Electron microscopic procedure}

For electron microscopy three animals were injected into the right cornom with $10 \mu 1$ of $8 \%$ WGA-HRP, dissolved in distilled water and killed 15 hr after injection. Three other animals were injected into the right anterior eye 
Summary of the experiments performed

\begin{tabular}{llccl} 
Retrograce tracing experiment & $\begin{array}{c}\text { No. of } \\
\text { animals }\end{array}$ & $\begin{array}{c}\text { Survival } \\
\text { times } \\
\text { (hr) }\end{array}$ & $\begin{array}{l}\text { Histological } \\
\text { procedure }\end{array}$ \\
\hline 1. Intracorneal & OD & 3 & $06-48$ & TMB/LM \\
Intraconeral & OD+ OS & 7 & $06-48$ & TMB/LM \\
Intracomeal & OD & 3 & 15 & PPD-PC/EM \\
2. Anterior chamber & OD & 4 & $06-96$ & TMB/LM \\
Anterior chamber & OD+ OS & 6 & $06-96$ & TMB/LM \\
Anterior chamber & OD & 3 & 18 & PPD-PC/EM \\
3. Conjunctiva & OD & 2 & 24 & TMB/LM \\
\hline
\end{tabular}

LM: Light microscopical evaluation; EM: electron microscopical evaluation; TMB: tetramethyl-benzidine; PPD-PC: p-pherylenediamime-pyrocatechol

chamber with 25 Hil of $4 \%$ WGA-HRP dissolved in distilled water and killed 18 hr (see Table 1). The fixation procedure was identical to that described for light microscopy, except that the animals were artificially respirated with halothane in a mixture of $70 \%$ nitrous oxide and $30 \%$ oxygen. The trigeminal ganglia were dissected and incubated with a p-phenylenediamine- pyracatechol (PPD.PC) mixture (Hanker, Yates, Metz and Rustioni, 1977). The specimens were postlixed in $\mathrm{OsO} 4$ and embedded in Epon. Ganglion cells containing peroxidase were lacalized in unstained semithin sections, after which ultrathin sections were cut and stained with uranyl acetate and lead citrate. Sections were studied in Phillips EM 400 and EM 201 electron microscopes.

\section{RESULTS}

Retrogirade tracing experiments (Light microscopy)

Injection of WGA-HRP into the cornea resulted in immediate diffuse labelling of the centre of the comea. From 16 hr onwards small quantities of WGA-HRP could be demonstrated in the trabecular meshwork, iris, cillary body and conjunctiva. After $48 \mathrm{hr}$ these anterior segment structures were heavily labelled. Injections into the anterior chamber resulted already after 6 hr survival time in heavy labelling of the cornea, the ciliary body, 
The presence $(+)$ or absence $(-)$ of labelled neurons in different ganglia and the uptake of tracer within the anterior segment after intracorneal, anterior chamber and conjunctival injection of WGA-HRP and after varying survival times

\begin{tabular}{|c|c|c|c|c|c|}
\hline \multirow[b]{2}{*}{ Experiment } & \multirow[b]{2}{*}{$\begin{array}{l}\text { Uptake of } \\
\text { tracer }\end{array}$} & \multicolumn{4}{|c|}{ Ganglia } \\
\hline & & Trigeminal & $\begin{array}{l}\text { Superior } \\
\text { cervical }\end{array}$ & Cillary & $\begin{array}{l}\text { Pterygo- } \\
\text { palatine }\end{array}$ \\
\hline $\begin{array}{l}\text { 1. Intracorneal } \\
\text { (6) } 06-16 \mathrm{hr}\end{array}$ & cor & + & $=$ & - & $=$ \\
\hline $\begin{array}{l}\text { Intracorneal } \\
\text { (4) } 17-48 \mathrm{hr}\end{array}$ & as & + & + & + & $+1-$ \\
\hline $\begin{array}{l}\text { 2.Ant. chamber } \\
\text { (10) 6-96 brr }\end{array}$ & as & + & + & + & $+1-$ \\
\hline $\begin{array}{l}\text { 3. Conjunctiva } \\
\text { (2) } 24 \mathrm{hr}\end{array}$ & con, cor & + & + & - & + \\
\hline
\end{tabular}

The number of animals studied are indicated in parentheses. con: conjunctivat, cor: cornea, as: anterior segment

the iris, the trabecular meshwork and occasionally the conjunctiva. In addition to the conjunctiva, the cornea was labelled after a subconjunctival injection of WGA-HRP.

The results of the retrograde labelling experiments are summarized in Table II. In the animals injected unilaterally the labelling was only ipsilateral. At all survival times after comeal injection labelled ganglion cells and labelled nerves were observed in the trigeminal ganglion (Figs.2 and 3). After six hr, only a few ganglion cells were labelled, whereas after eight hr about one-third to one-half of the cells in the projection area were heavilly labelled. With longer survival times, the number of labelled cells did not increase further in this area. A survival time beyond $17 \mathrm{hr}$ showed additional labelling of cell bodies in the cillary, pterygopalatine and superior cervical ganglion. After 17 and 18 bix, only a few ganglion cells were labelled in the superior cervical and clliary ganglion. Although after $48 \mathrm{hr}$ more cells were labelled in the superior cervical ganglion, their number was relatively low in comparison to the unlabelled cells whereas in the ciliary ganglion they make up the majority of cells.

After injection into the anterior chamber, labelled ganglion cells were observed in the ciliary, superior cervical and trigeminal ganglion (Figs.4-9) in all animals. In the pterygopalatine ganglion, labelled ganglion cells were only 


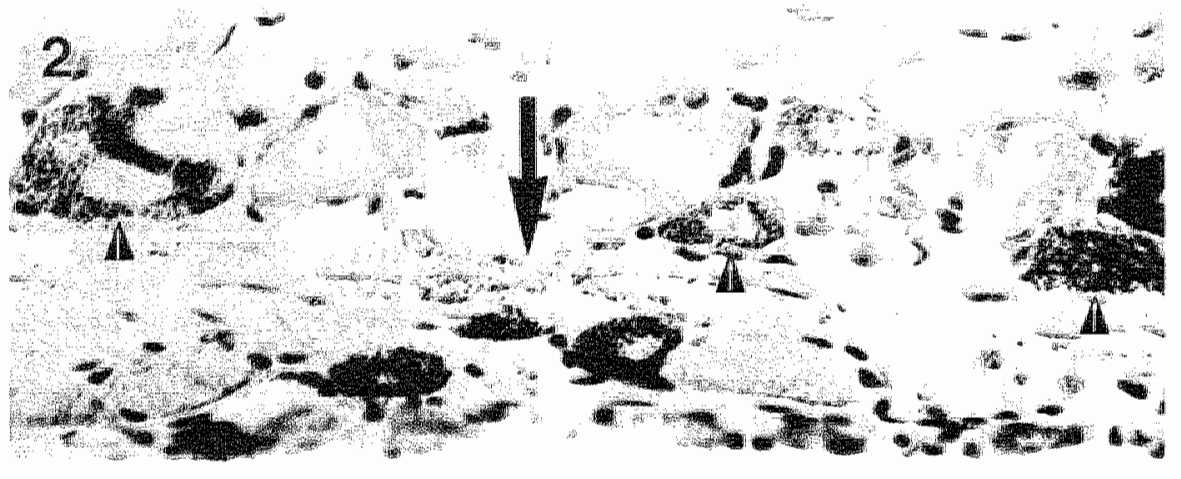

\section{3}
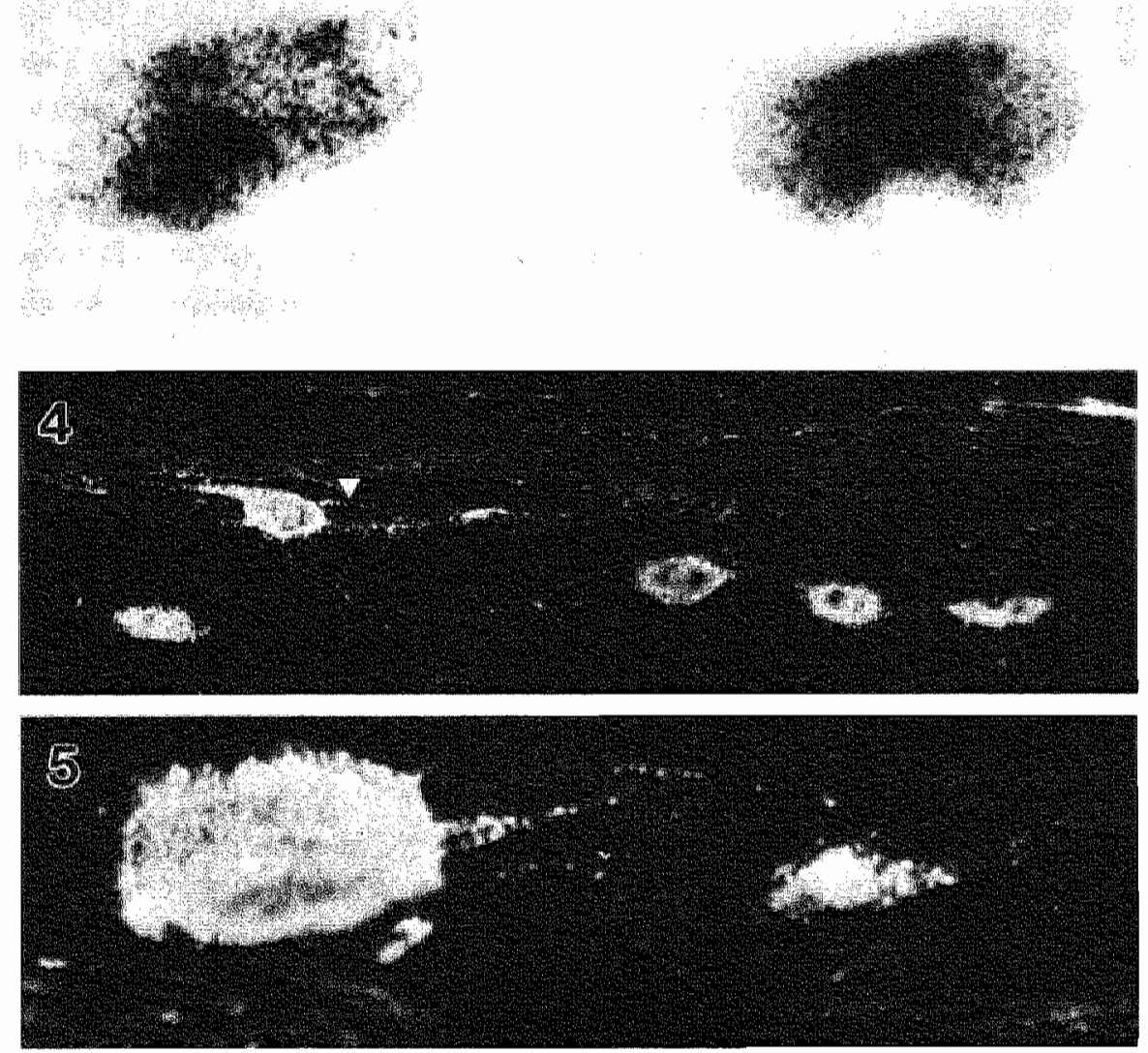
found in the experiments in which the conjunctiva was Labelled. After subconjunctival injection of WGA-HRP, peroxidase containing cells were found in the trigeminal, superior cervical and pterygopalatine ganglion. Though only a few cells were labelled in the pterygopalatine ganglion after injection into the anterior chamber, far more cells were labelled after sub-conjunctival injections.

In rabbits, the trigeminal ganglion has only two lobes: a mandibular and a maxillary-ophthalmic one. In the present experiments, labelled ganglion cells were always confined to the antero-medial part of the maxillary- ophthalmio lobe (Fig.10). After the anterior chamber injections, labelled ganglion cells were more laterally positioned than after short-term corneal injections (Fig.10). No preference in localization of labelled ganglion cells was observed along the superior-inferior axis of the trigeminal ganglion. The superior cervical ganglion consisted mostly of two parts. Nearly all labelled ganglion cells were confined to the proximal part of the ganglion. Within the proximal part, ganglion cells containing peroxidase were positioned at random independent of the site of injection.

Among animals a wide variation existed in the shape of the cillary ganglion (Figs.8 and 9). Most of the labelled ganglion cells were found to be located in the periphery of the ciliary ganglion (Fig.9).

A preferential localization of labelled ganglion cells was found in the

\section{Figure 2:}

Survey brightilld photomicrograph showing labelled nerve fibres (arrow) and labelled perikarya (arrowheads) in the trigeminal ganglion $48 \mathrm{hr}$ aftur injection of HRP.WGA into the cornea $\left(400^{*}\right)$.

Figure 3:

High magnificarion brightield photomicrograph of two labelled cell bodles in the trigeminal ganglion showing the even distribution of WGA-HRP in these cells $6 \mathrm{hr}$ after injection of WGA-HRP into the cormea (1000").

Figure 4:

Darkfield wiew of labelled cell bodies in the pterggopalatine ganglion $96^{\circ} \mathrm{hr}$ after injection of WGA-HRP into the anterior chamber. In additlon to labelled perikarya labelled nerwe fibres (arrowhead) are wisible (400").

Figure 5:

Darkfield photomicrograph showing a higher magnification of labelled cell bodies in the pterygopalatine ganglion $96 \mathrm{hr}$ after the injection of WGA-HRP into the anterior chamber (1500*). 

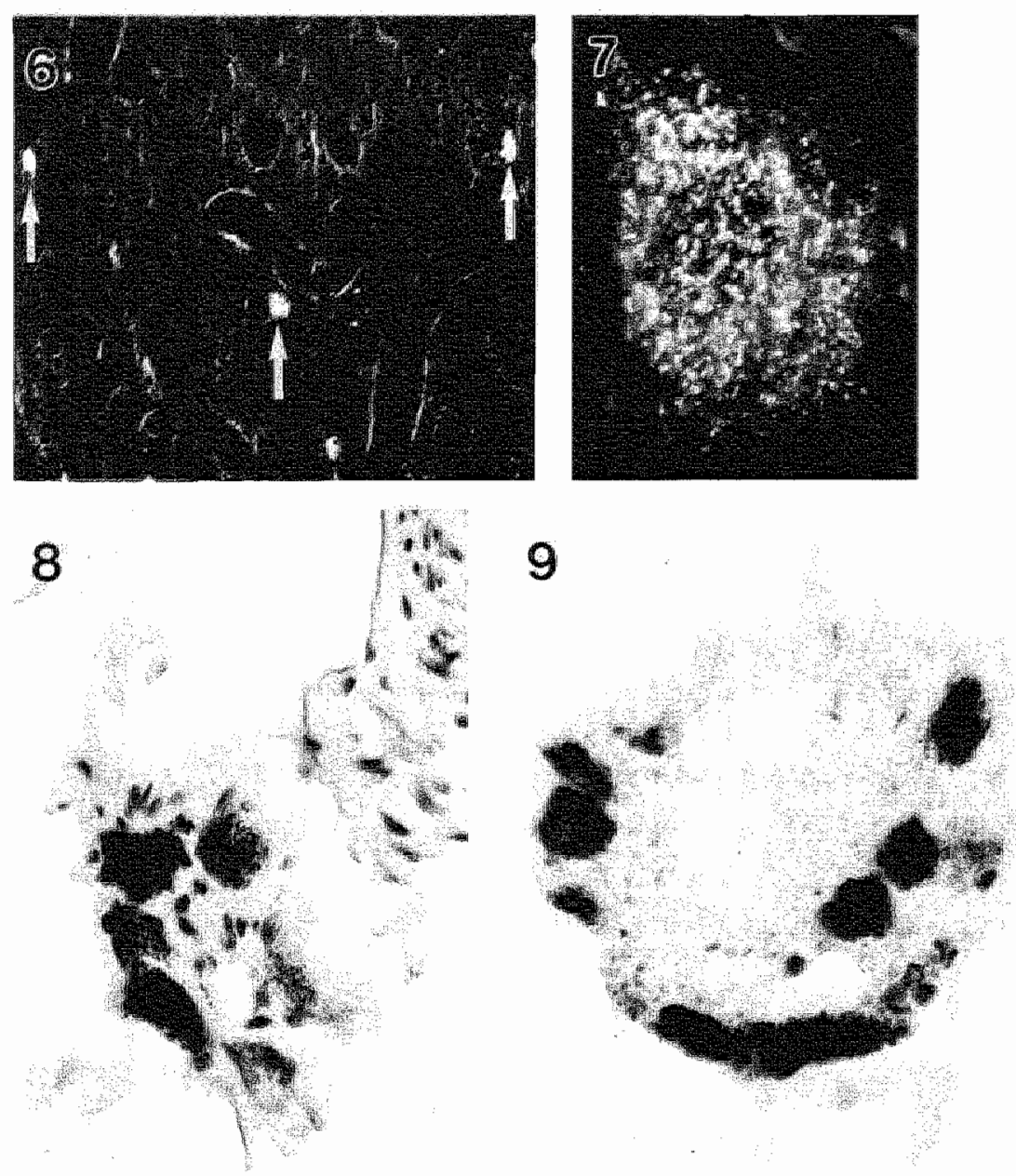

Flgure b:

lsolated labelled ganglion cells farrows] in the superior cervical ganglion 96 hr after injection of WGA-HRP into the anterior chamber. Darkfield photomicrograph (100*)

Figure $7:$

High magnification darkfield photonticrograph of a labelled cell body in the superior cervical ganglion $96 \mathrm{hr}$ after injection of

WGA-HRP into the anterlor chamber (1000").

Figure 8:

Brightfleld photomicrograph showing a cluster of cillary ganglion cells containing peroxidase $96 \mathrm{hr}$ after the injection of WGA-HRP into the anterior chamber $\left(250^{*}\right)$.

Figure $9:$

Brightfield view of the cillary ganglion $96 \mathrm{hr}$ after the injection of WGAHRP into the anterior chamber. Note that labelled neurons are lacalized in the periphery of the ganglion. (200*). 

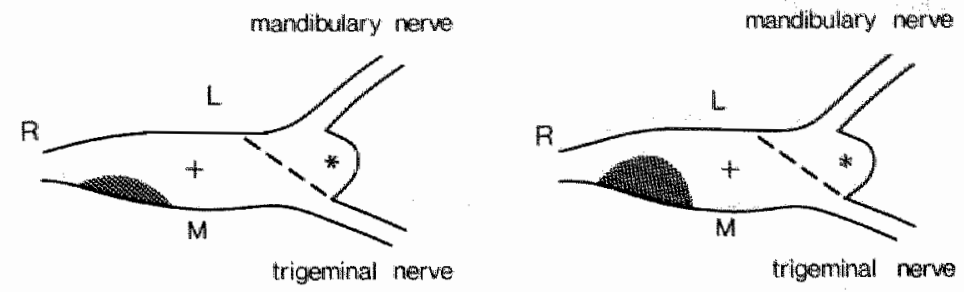

Figure 10:

Differences in localization of labelled ganglion cells in the right trigeminal ganglion. Left: the right trigeminal ganglion after injection into the cornea. Right: the right trigeminal ganglion after injection into the anterior chamber. The dots represent labelled ganglion cells. The figures are perpendicular to the superior-inferior axis.

R: Rostral (anterior), L: Lateral, M: Medial, +* Maxillary-ophthalmic lobe, *: Mandibular lobe

pterygopalatine ganglion as well. Almost all peroxidase-containing ganglion cells were confined to the posterior part of the pterygopalatine ganglion. No preference in localization was found along the superiot-inferior axis.

\section{Electron microscopic evaluation of trigeminal ganglion cells}

The clear-cut recognition of labelled ganglion cells in unstained semithin sections enabled a correlation of light and electron microscopic features of labelled and unlabelled cells. Labelled cells were characterized by electrondense bodies (lysosomes or related bodies) containing the $\mathrm{PPD}-\mathrm{PC}$ reaction product (Fig.11). These dense bodies displayed a wide range of sizes; were evenly distributed in the cytoplasm and were more numerous than comparable non-stained dense bodies in the unlabelled cells.

Independent of labelling two types of neurons could be distinguished: large neurons with pale cytoplasm containing rough endoplasmic reticulum ( $\mathrm{ERR}$ ) which was randomly distributed in small patches (Figs. 12A and B) and small neurons with dense cytoplasm containing randomly distributed $r E R$ in large patches of Nissl-body-like aggregates (Figs.12A and B). In addition, differences were observed in the appearance of mitochondria: mitocklondria with a pale matrix (Fig.13A) and mitochondria with a dense matrix (Fig.13B). 
So, on account of electron microscopic features, four cell types could be distinguished: 1) large pale neurons with pale mitochondria, 2) the same with dense mitochondria, 3) small dense neurons with pale mitochondria, and 4) the same with dense mitochondria.

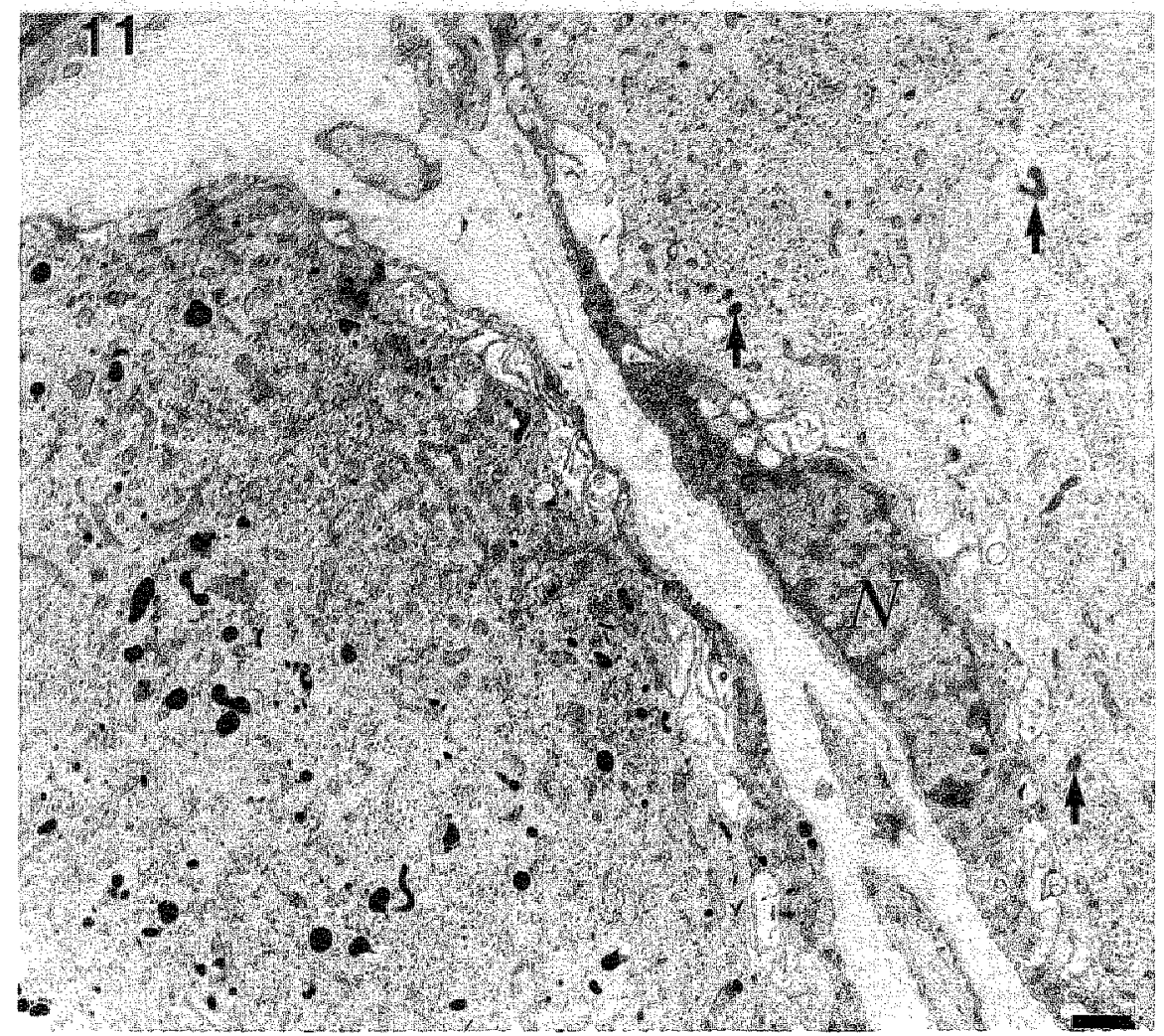

\section{Figure 11:}

Electronmicrograph showing a labelled neuron (left) and an unlabelled neturon(right) in the trigeminal ganglion 18 thours after injection of WGA-HRP into the anterior chamber. Note the difference in electron derse bodies in the left nouron compared to the right newron larrows]. N: Nucleus of a satellite cell (Scale bar represents I $\mu \mathrm{m}$ )

Cells labelled after anterior chamber or comeal injections were found among all four types of electron microscopic distinct neurons. However, in both conditions a slight tendency was noticed in favour of the small dense neurons with dense mitochondria. 

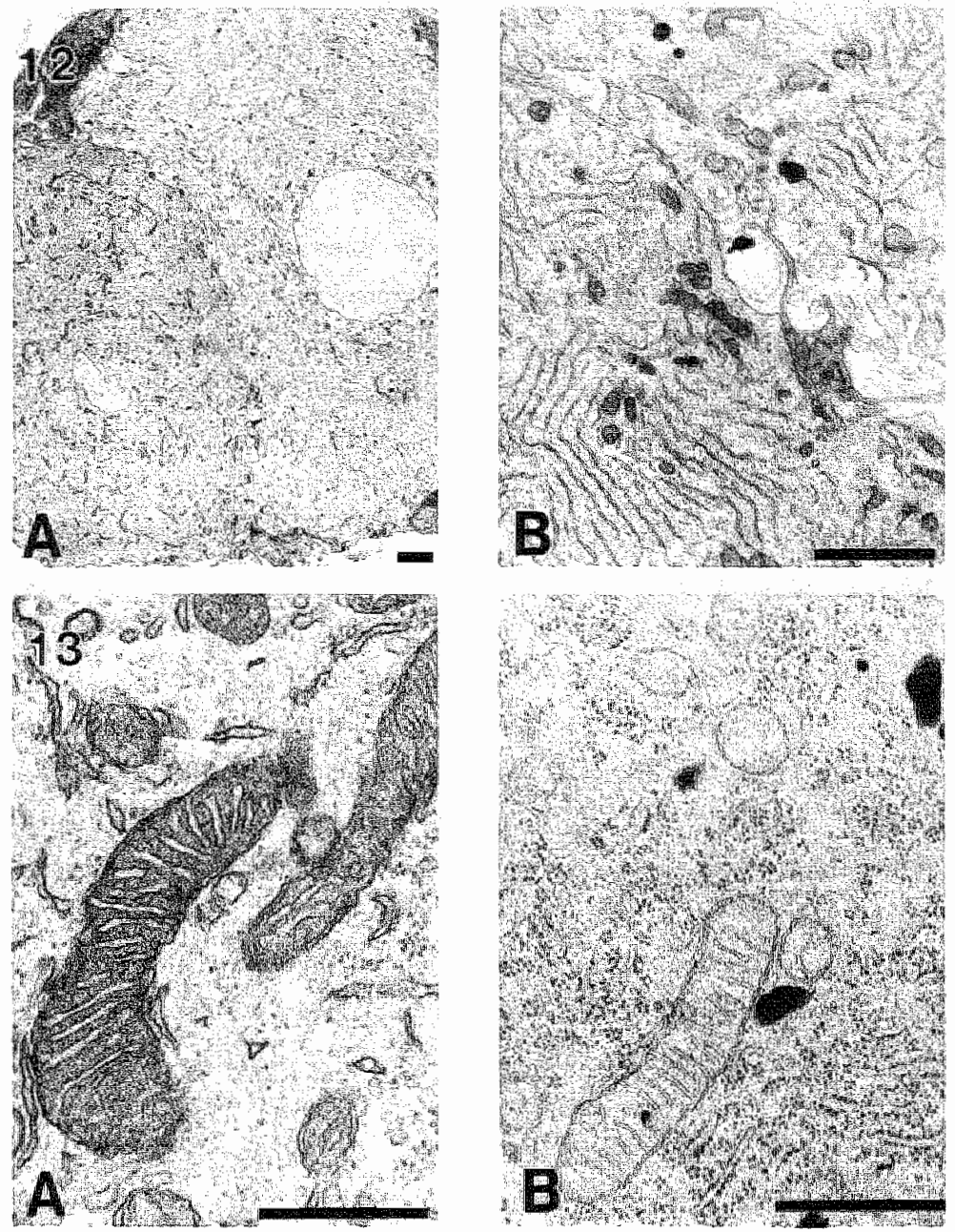

\section{Figure 12:}

Electronmicrographs showing the differences between light and dark newrons it the trigeminal ganglion. 12.4: The left neuron is more electron dense (Scale bar represents $2 \mathrm{Lm}$ ). 12B: A higher magnification showing the differences in rER (Scale bar represents $1 \mathrm{~mm}$ ). The dark neuron on the left shows Nissl-likeaggregates whereas the light neuron conalins small patches. In addition these cells show differences in mitochondria. The mitochondrla in the dark neuron have $a$ dense matrix while the mitochomdria in the light neuron have am electron lucent matrix.

Figure 13:

Electronmicrographs showing the differences between mitochondria in the trigeminal ganglion (Scale bars represent $0.5 \mathrm{\mu m}$ ). 13A: mitochondrio with an electron dense matrix 13B: mitochondria with an electron lucent matrix 


\section{DISCUSSION}

The results of the present investigation of retrograde labelling of ganglia after injection of WGA-HRP into the anterior chamber, the comea or the conjunctiva are summarized in Fig. 14 and Table II. The results on the innervation of the anterior chamber by the trigeminal, superior cervical and cillary ganglia confirm previous studies $3,14,23$. The present results, however, are inconsistent with previous studies on the corneal innervation and give additional information on the somatotopic organization of the trigeminal ganglion, the fine structural distinction between trigeminal ganglion-somata of sensory neurons of the anterior eye-segment and confirm the pterygopalatine innervation of the conjunctiva.

A main conclusion from this study, that in rabbits the central region of the cornea is innervated only by neurons of the trigeminal ganglion which are considered as exclusively sensory, is in contrast with literature. There is ample proof of the existence of adrenergic nerves in the cornea. Using formaldehyde induced fluorescence (FIF) adrenergic nerves were demonstrated in the corneal stroma and epithelium of cats $^{8,9,20}$, dogs ${ }^{9}$, guinea pigs ${ }^{8,9}$, mice $^{8}$, rabbits $8,9,19,20$ and rats $8,9,43,44$. Epithelial adrenergic fibres were found to disappear after birth and only stromal fibres remained. On accasion, adrenergic nerves were seen, using the FIF technique in the limbal stroma of monkeys ${ }^{20}$. By the glyoxylic acid fluorescence technique adrenergic nerves were demonstrated in the stroma of human corneas 48 . It was found that epinephrine influences the rabbit corneal epithelium by activating a chloride pump which was taken as pharmacological proof for an adrenergic corneal innerwation ${ }^{17}$. Degenerating nerve fibres in the cornea of rats were noticed after clliary ganglionectomy, superior cervical ganglionectomy, ophthalmic netrotomy and after maxillary neurotomy ${ }^{46}$. After the injection of WGA-HRP into the superior cervical ganglion, a few anterogradely labelled terminals were seen in the peripheral cornea of rats ${ }^{30}$. Cholinesterase-positive fibres were found in the cornea of rabbits ${ }^{18,19,36}$, cats and monkeys 20 . Although some cholinesterase-containing nerves did not degenerate after ophthalmic neurotomy in rabbits ${ }^{25}$. Tervo ${ }^{42}$ observed the disappearance of acetyl- cholinesterasecontaining nerves in rats only after ophthalmic neurotomy. As outlined by Tewari et al. ${ }^{47}$ cholinergic fibres are not exclusively parasympathetic but may also be sensory as was proven for the trigeminal ganglion. 


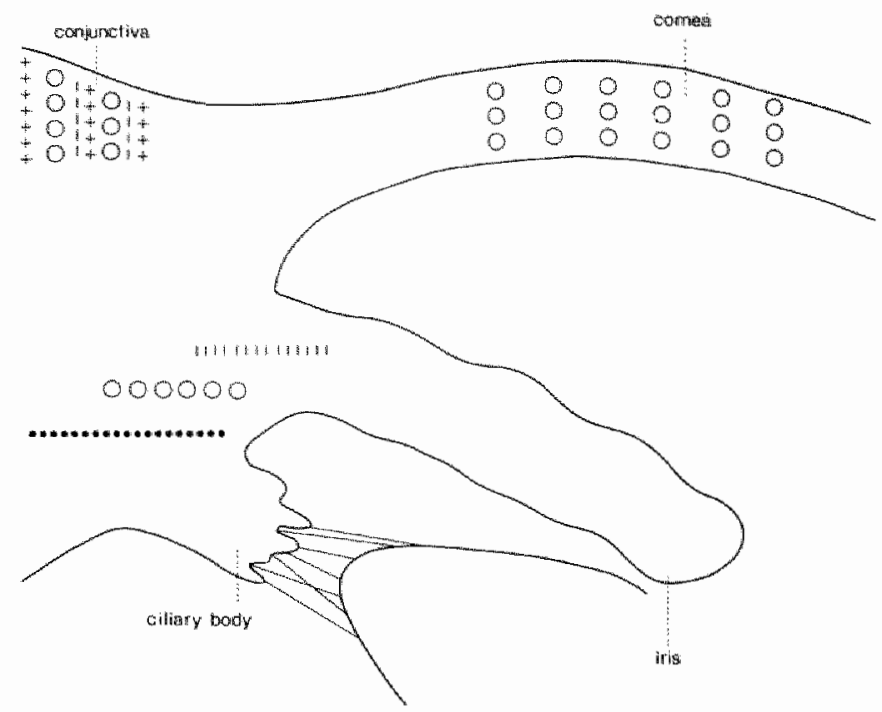

Figure 14:

In this figure the restults of the present study are summarized. The cornea is innervated only by nerve fibre terminals originating in the trigeminal ganglion. The conjumctiva is the sole projection site of the pterygopalatine ganglion. The iris, ciliary body and trabecular meshwork together are innervated by nerve fibre terminals with ganglion cells in the clliary. superior cervical and trigeminal ganglion.

00 : nerve fibre terminals of trigeminal ganglion cells

+ : nerve fibre terminals of pterygopalatine ganglion cells

II: nerve fibre terminals of superior cervical ganglion cells

.. : nerve fibre terminals of cillary ganglion cells.

In addition Katz et al. ${ }^{15,16}$ have shown that adrenergic nerves are not exclusively sympathetic but that primary sensory neurons in the periphery may also express catecholamine. This means that histochemical localization of adrenaline and cholinesterase are no definite proof for an autonomic innervation of the cornea. Degeneration and anterograde tracing studies with HRP and WGA-HRP have the inherent disadvantage that both ganglion cells and fibres traversing the ganglion are injured or take up the HRP or WGA- 
HRP, and consequently do not fully discriminate between ganglion cells and passing fibres. It has been shown that parasympathetic ganglia are muxed ganglia, like the pterygopalatine ganglion. Sympathetic and sensory nerves traverse this ganglion as well ${ }^{6}$. The superior cervical sympathetic ganglion may aiso contain other nerves besides its sympathetic fibres ${ }^{11}$. The method of retrograde tracing as used in this study theoretically enables the discrimination between peripheral nerves, provided the diffusion of the tracer can be restricted to the target site under investigation. Tonjum ${ }^{49,50}$ found diffusion of tracers out of the cornea into the anterior chamber despite the presence of the endothelial lining. From the anterior chamber WGA-HRP will be transported to the trigeminal ${ }^{3,23}$ " superior cervical ${ }^{3}$ and ciliary ganglion ${ }^{14}$. This problem can be circumvented by using short survival times. Due to the passive uptake of HRP, however, rather long survival times are needed to achieve sufficient labelling. WGA-HRP was used in the present study because the WGA moiety appears to stimulate the uptake of the complex resulting in a more intense labelling ${ }^{31}$. The difference in retrograde labelling between short-term (less than $17 \mathrm{hr}$ ) and medium-term corneal injections shows that the innervation of the central comea is of sensory trigeminal origin only. A minor autonomic innervation especially of the peripheral cornea below the sensitivity of this technique is not likely but cannot definitely be excluded. However, even when present, this minor autonomic component cannot account for the adrenergic and cholinergic nerves present in the central cornea.

The trigeminal nuclei are organized somatotopically ${ }^{4}$. The peripheral organization of the trigeminal nerve and the trigeminal ganglion is less well documented. After injection of HRP into the anterior chamber, labelled ganglion cells were found in the antero-medial part of the trigeminal ganglion $^{3}$. Noden ${ }^{32,33}$ found a somatotopic organization in the mandibular and maxillary but not in the ophthalmic part of the trigeminal ganglion of chickens. No attention was paid to the possible differences in projection to separate parts of the anterior segment. In the present study labelled ganglion cells were located in a limited projection area in the antero-mediall part of the maxillary-ophthalmic lobe of the trigeminal ganglion after comeal injection whereas labelled ganglion cells were positioned in a more extensive projection area after injection into the anterior chamber. Due to the fact that labelled ganglion cells always made up a minority within the limited corneal projection area $_{n}$ it cannot be concluded on account of these experiments whether this is 
an exclusive corneal projection area.

Light and electron microscopically different ganglion cell types were deseribed in sensory dorsal root ganglia based on account of the arrangement of

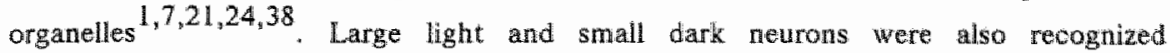
in the sensory trigeminal ganglion $10,32,33,35,41$. Several subdivisions have been proposed. These differences all relate to the arrangement and relative amount of rough endoplasmic reticulum and ribosomes. In the present study, differences in mitochondrial matrix were also taken into account, which leads to a subdivision into four cell types. Although it is not established that morphological differences represent functional differences, it has been suggested that cells of the different types subserve different sonsory modalities 24,37 . It was proposed that large light cells conduct proprioceptive impulses from the extraocular muscles to the trigeminal ganglion 37 . In the present study it was obserwed that both corneal and anterior chamber injections lead to labelling of all four cell types. This confirms the obserwation of Lele and Wedell ${ }^{22}$ that various modalities are transmitted from the cornea and anterior segment to the trigeminal ganglion.

It has been demonstrated that nerves from the pterygopalatine ganglion of facial nerve origin distribute to the eye in rabbits, monkeys and men 39,40 . Macintosh $^{26}$ has shown that the pterygopalatine ganglion projects to the conjunctiva. The results of sub-conjunctival injections of WGA-HRP in the present study are in agreement with this finding. In addition, injection of WGA-HRP into the anterior segment, or injection into the cornea combined with a long surwival time, gave rise to labelled ganglion cells in the pterygopalatine ganglion. However, labelled ganglion cells were occasionally observed, and their number was wery small. In the cases in which ganglion cells were labelled, the conjunctiva was found labelled as well. Hence it is most likely to be the result of difrusion to the conjunctiva or leakage into the inferior fornix. It was suggested by Uddman et al ${ }^{51}$ that VIP-immunoreactive nerves, present in the posterior third of the ciliary body of cats, originate in the pterygopalatine ganglion. After extirpation of this ganglion VIPimmunoreactive nerves disappeared on the operated side. Also on the basis of VIP-immunoreactivity, a facial innervation was suggested to the anterior uvea of rabbits ${ }^{5}$. In the present study, WGA-HRP might not or not always have reached the posterior third of the ciliary body but because of the ubiquitous accurrence of the neuronal peptide, VIP fibres passing through the 
pterygopalatine ganglion cannot be ruled out as a possible emplanation. Therefore, the present results strongly suggest that within the anterior segment of the rabbit the conjunctiva is the sole projection site from the pterygopalatine ganglion. Labelled ganglion cells in the pterygopalatine ganglion were confined to the posterior part of this ganglion, but no predilection of positioning was noticed allong the superior-inferior axis. 


\section{III.3 THE INNERVATION OF THE RAT'S ANTERIOR EYE SEGMENT}

-a retrograde traoing study-

In order to adjust to the ophthalmological literature the present study was started in rabbits. However, most neuroanatomical studies are performed in rats. In order to find out whether there are major differences between the innervation of the anterior eye segment of rabbits and rats, some of the retrograde tracing experiments performed in rabbits were repeated in rats. Whether the rat comea has a sympathetic innervation was not investigated by retrograde tracing but is dealt with in the anterograde tracing studies (Chapter V), which were all done in rats. The localization of labelled piterygopalatine ganglion somata after injection of WGA-HRP into the lacrimal gland, the conjunctiva and the anterior eye chamber was studied in detall and is discussed in Chapter VI.

In 4 rats, $2 \mu \rrbracket 4 \%$ WGA-HRP dissolved in double distilled water were injected into the anterior chamber of six eyes, using a Hamilton syringe (30 gauge needle).

2 ul $4 \%$ WGA-HRP dissolved in double distilled water were injected into the conjunctiva of six eyes of 4 rats.

After survival times of 24 to 48 hours the animals were killed and subsequently perfused through the ascending aorta with $500 \mathrm{ml} 0.9 \% \mathrm{NaCl}, 500$ ml $4 \%$ glutaraldehyde, $1 \%$ paraformaldehyde in $0.1 \mathrm{M}$ phosphate buffer, $\mathrm{pH} 7.3$ and $500 \mathrm{ml} 0.1 \mathrm{M}$ phosphate buffer containing $10 \%$ sucrose, $\mathrm{pH} 7.3$ at $4^{\circ} \mathrm{C}$. The ciliary ganglion, the pterygopalatine ganglion, the trigeminal ganglion and the superior cervical ganglion were dissected and sectioned at a freezing microtome at $15 \mu \mathrm{m}$, mounted and reacted according to the TMB method for the demonstration of WGA-HRP ${ }^{31}$.

The results of these experiments in rats were almost identical to the results obtained in rabbits. In all animals that had been injected into the anterior eye chamber the trigeminal ganglion, the superior cervical and the cilliary ganglion contained labelled ganglion cells. In four out of six injections into the anterior chamber labelled ganglion cells were found in the pterygopalatine ganglion as well. 
All injections into the conjunctiva revealled labelled ganglion cells in the trigerrinal ganglion, the superior cervical ganglion, the pteryopalatine ganglion and the clliary ganglion. Only 1 to 5 labelled ganglion cells appeared in the ciliary ganglion. The number of cells labelled in the ciliary ganglion after injection of WGA-HRP into the conjunctiva was much smaller than the number of labelled cillary ganglion somata after injection into the anterior eye chamber. In conclusion, the anterior eye segment of both rabbits and rats is supplied by nerve fores originating in all four ganglia. 


\section{REFERENCES}

1.Andres, K.H. (1961). Untersuchungen Ober den Feinbau von spinal-ganglien. Zeitschrift fOr Zellforschung $55,1-48$

2.Arvidson, B. (1977). Retrograde axonal transport of horseradish peroxidase from cornea to trigeminal ganglion. Acta Neuropathologica $38,49-52$

3.Arvidson, B. (1979). Retrograde transport of horseradish peroxidase in sensory and adrenergic neurons following injection into the anterior eye chamber.l. of Neurocytol. 8,751-764

4.Brodal, A. (1981). Neurological anatomy in relation to clinical medicine.Oxford University Press pp. 508-532

5.Butler, J.M., Ruskell, G.L., The Late Cole, D.F., Unger, W.G., Zhang, S.Q.,Blank, M.A., McGregor, G.P. and Bloom, S.R. (1984). Effects of vil th (facial) nerve degeneration on vasoactive intestinal polypeptide and substance $P$ levels in acular and orbital tissues of the rabbit. Exp. Eye Res. $39,523-532$

6.Christensen, K. (1934). The innervation of the nasal mucosa, with special reference to its afferent supply. Ann. Otomlaryngol. 43,1066-1083

7.Dawson, I.M., Hossack J. and Wyburn G.M. (1955). Observations on the Nissl's substance, cytoplasmic filaments and the nuclear membrane of spinal ganglion cells. Proc. of the Roy. Soc. of London, Series $B$ $144,132-142$

8. Ehinger, B. (1964). Distribution of adrenergic nerves to orbital structures.Acta Physiol. Scand. 62,291-292

9.Ehinger, B. (1966). Connections between adrenergic nerves and other tissue components in the eye. Acta Physiol. Scand. 67,57-64

10.Gaik, G.C. (1973). A morphological analysis of the neurons in the developing and adult chicken trigeminal ganglion. Anat. Rec. 175,326

11.Grillo, M. (1978). Ultrastructural evidence for a sensory innervation of some SIF cells in rat superior cervical ganglia. Anat. Rec. 190,407

12. Hanker, J.S., Yates, P.E., Metz, C.B and Rustioni A. (1977). A new specific, sensitive and non-carcinogenic reagent for the demonstration of horseradish peroxidase. Histochem. J. 9,789-792

13. Hess, A. (1955). The fine structure of young and old spinal ganglia. Anat. Rec. $123,399-424$

14.Jaeger, R.J. and Benevento, L.A. (1980). A horseradish peroxidase study of the innervation of the internal structures of the eye. Evidence for a direct pathway. Invest. Ophthalmol.\& Vis. Sci. 19,575-583.

15. Katz, D.M., Markey, K.A., Goldstein, $M$ and Black, 1.B. (1983). Expression of catecholaminergic characteristics by primary sensory neurons in the normal adult rat. Proc. Nall. Acad. Sci. USA 80,3526-35

16.Katz, D.M., Adler, J.E. nd Black, I.B. (1987). Catecholaminergic primary sensory neurons: autonomic targets and mechanisms of transmitter regulation. Federation Proc. 46,24-29

17.Klyce, S.D., Neufeld, A.H. and Zadunaisky, J.A. (1973). The activation of chloride transport by epinephrine and $\mathrm{Db}$ cyclic-AMP in the cornea of the rabbit. Invest. Ophthalmol. 12,127-139

18.Lassmann, G. (1961). Die Innerwation der Hormhaut. Alb. w. Graef. Arch. Ophthalmol. 162,565-609

19. Laties, A. and Jacobowitz, D. (1964). A histochemical study of the adrenergic and cholinergic innervation of the anterior segment of the rabbit eye. Invest. Ophthalmol. 3,592-600

20. Laties, A. and Jacobowitz, D. (1966). A comparative study of the autonomic innervation of the eye in monkey, cat and rabbit. Anat. Rec. 156,383-396 
21.Lawson, S.N., Caddy, K.W.T. and Biscoe, T.J. (1974). Development of rat dorsal root ganglion neurones. Studies of cell birthdays and changes in mean cell diameter. Cell Tiss. Res. 153,399-413

22.Lele, P.P. and Wedell, G. (1956). The relationship between neurohistollogy and comeal sensibility. Brain $79,119-154$

23. Lehtosalo, J.I., Uusitalo, H and Palkama, A. (1984). Sensory supply of the anterior uvea. $A$ light and electron microscope study. Exp. Brain Res. $59,562-569$

24.Lieberman, A.R. (1976). Sensory ganglia. The peripheral nerve. ed.Landon DN, London; Chapman and Hall. New York: John Wiley \& Sons, inc. pp 188-278

25.Lukas, Z, Smrcka, V., Dolezel, S. and Schroder R. (1975). Problem of double vegetative innervation of rabbit cornea. Acta Histochemica 53,93-96

26. Macintosh, S.R. (1974). The innervation of the conjunctival in monkeys. An electron microscopic and nerve degeneration study. Alb. v. Graef. Arch. kin. exp. Ophthalmol. 192,105-116

27. Marfurt, C.F. (1981a). The centrall projections of trigeminal primary afferent neurons in the cat as determined by the transganglionic transport of horseradish peroxidase. J. Comp. Neurol. 203,785-798

28. Marfurt, C.F. (198\#b). The somatotopic organization of the cat trigeminal ganglion as determined by the horseradish peroxidase technique. Anat. Rec. 201, 105-11.8

29.Marfurt, C.F and Turner, D.F. (1983). Sensory nerve endings in the rat oro-facial region labeled by the anterograde and transganglionic transport of horseradish peroxidase: a new method for tracing peripheral nerve nbers. Brain Res. 261,1-12

30.Marfurt, C.F., Zaleski, E.M., Adams, C.E and Welther, C.L. (198.6). Sympathetic nerve fibers in rat orofacial and cerebral tissues as revealed by the HRP.WGA tracing technique: a light and electron microscopic study. Brain Res. 366,373-378

31.Mesulam, M.M. (1982). Tracing neural connections with horseradish peroxidase (IBRO handbook series: Methods in the Neurosciences). ed. Smith AD John Wiley \& Sons Ltd. pp 3-247

32. Noden, D.M. (1980a). Somatotopic and functional organization of the avian trigeminal ganglion: An HRP analysis in the hatchling chick. J. Comp. Neurol. $\| 90,405-428$

33. Nodien, D.M. (19806). Somatotopic organization of the embryonic chick trigeminal ganglion. J. Comp. Neurol. 190,429-444

34.Panneton, W.M and Burton, H. (1981). Corneal and periocular representation within the trigeminal sensory complex in the cat studied with transganglionic transport of horseradish peroxidase. J. Comp. Neurol. $199,327-344$

35.Peach, R. (1973). Cellular differentiation in the mouse trigeminal ganglion. Anat. Rec. 175,408-409

36.Peterson, R.A., Lee, K. and Donn, A. (1965). Acetylcholinesterase in the rabbit comea. Arch. Ophthalmol, 73,370-377

37.Porter, J.D. and Spencer, R.F. (1982). Localization and morphology of cat extraocular muscle afferent neurons identified by retrograde transport of horseradish peroxidase. J. Comp. Neurol. 204,56-64

38. Rambourg, A., Clermont, Y. and Beaudet, A. (1983). Ultrastructural features of six types of neurons in rat dorsal root ganglia. J. of Neurocytology $12,47-66$

39. Ruskell, G.L. (1965). The structure of the eye, vol.it, ed. Rohen, J.W., 
Schattauer-Verlag, Stuttugart, pp.355-368

40.Ruskell, G.L. (1970). The orbital branches of the pterygopalatine ganglion and their relationship with internal carotid nerve branches in primates. I. Anat. 106,323-339

41.Sugiura, Y., Kitoh, I. and Sakai, H. (1983). A comparative ultrastructural study of the trigeminal ganglion in the rat and chicken. J. Morphol. $175,101-113$

42.Terwo, T. (1976). Histochenical demonstration of cholinesterase activity in the cornea of the rat and the effect of warious denervations on the corneal nerves. Histochemistry 47,133-143

43.Tervo, T. and Palkama, A. (1976a). Adrenergic innerwation of the rat comeal. epithelium. Invest. Ophthalmol. 15,147-150

44.Tervo, T. and Palkama, A. (1976b). Sympathetic nerves to the rat cornea. Acta Ophthalmol. 54,75-84

45.Tervo, K., Tervo, T. and Palkama A. (1978). Pre- and postnatal development of catecholamine-containing and cholinesterase-positive nerves of the rat cornea and iris. Anat. Embryol. 154,253-265

46.Tervo, T., Joo, F., Huikuri, K.T., Toth, I and Palkama, A. (1979). Fine structure of sensory nerves in the rat cornea: an experimental nerve degeneration study. Pain 6,57-70

47. Tewari, H.B and Bourne, G.H (1963). Histochemical studies on the distribution of simple esterase. Specific and non specific cholinesterase in the trigeminal ganglia of the rat. Acta Anat. 53,319-332

48. Toivanen, M., Tervo, T., Partanen, M., Vannas, A. and Hervonen, A. (1987). Histochemical demonstration of adrenergic nerves in the stroma of human cornea. Invest. Ophthalmol.\& Vis. Sci. 28,398-400

49.Tonjum, A.M. (1974). Permeability of horseradish peroxidase in the rabbit corneal epithelium. Acta Ophthalmol. 52,650-658

50.Tonjum, A.M. (1977). Movement of horseradish peroxidase in the cornea, sclera and the anterior uvea. Acta Ophthalmol. 55,771-779

51.Uddman, R., AJumets, J., Ehinger, B., Hakanson, R., Lorén, I. and Sundler,F. (1980). Vasoactive intestinal peptide nerves in ocular and orbital structures of the cat. Invest. Ophthalmol.\& Vis. Sci. 19,878-885. 



\section{CHAPTER IV}

THE SENSORY INNERVATION 



\section{PART I: THE SENSORY INNERVATION}

\section{SUMMARY}

The distribution of sensory trigeminal nerve fibres in the anterior eye segment and the autonomic eye related ganglia, i.e. the parasympathetic ciliary and pterygopalatine ganglia and the sympathetic superior cervical ganglion, was studied in rats. For this the trigeminal ganglion was injected with tritiated leucine and wheat germ agglutinin coupled to horseradish peroxidase (WGA-HRP).

After injection of WGA-HRP into the trigeminal ganglion, ganglion cell somata in the superior cervicall and the pterygopalatine ganglion were labelled. As labelling of these cell bodies with WGA-HRP is the result of retrograde transport it must be assumed that cell bodies in these ganglia project to the trigeminal ganglion. ${ }^{3} \mathrm{H}$-Leucine injection into the trigeminal ganglion revealed the presence of labelled nerve fibres in the pterygopalatine ganglion and the nodose ganglion i.e. the sensory ganglion of the vagus nerve. Labelled nerve fibres were absent in the ciliary and superior cervical ganglion. As ${ }^{3}$ H-leucine labelling of nerve fibres is the result of anterograde transport exclusively it can be concluded that trigeminal nerve fibres project to the modose ganglion and the pterygopalatine ganglion, but not to the ciliary and superior cervical ganglion.

In the retrobulbar structures, sensory nerve fibres occurred between the inferior oblique and the lateral rectus muscle and were present medial to the medial rectus muscle. Within the anterior eye segment, sensory nerve fibres were found in the cornea epithelium, stroma and adjacent to the endothelium. In addition, labelled fibres were found in the anterior stroma of the cilliary body, throughout the iris up to the pupilary border and in the conjunctiva. Most sensory nerve fibres which innervate the cornea, the iris and the ciliary body trawerse the ciliary cleft. 


\section{INTRODUCTION}

The anterior eye segment is supplied with sensory nerve fores by the ophthalmic nerve i.e. the first branch of the trigeminal nerve. A small maxillary projection to the eye was found in monkeys 25 . These sensory nerve fibres have free non-specialized endings in the comea, the iris, the ciliary body and the trabecular meshwork of primates and sub-primates $3,15,16,19$.

Retrograde tracing from the anterior eye segment with horseradish peroxidase (HRP) and wheatgerm-agglutinin coupled to HRP (WGA-HRP) revealed that the ganglion cell bodies of these sensory nerve fibres are located in the antero-median part of the trigeminal ganglion of rats, mice and rabbits $2,20,29$.

As to a possible projection of trigeminal nerve fibres to the three autonomic eye related ganglia, i.e. the parasympathetic ciliary and pterygopalatine ganglion and the sympathetic superior cervical ganglion, conclusive evidence is scarce. The ciliary ganglion of dogs $^{9}$ and primates ${ }^{25}$ and the pterygopalatine ganglion $^{6,25}$ are supposed to contain passing sensory nerve fibres. Whether the trigeminal ganglion projects to the superior cervical ganglion has not been studied.

In the present study trigeminal nerve fibres were labelled after injection of WGA-HRP or tritiated leucine ( ${ }^{3} \mathrm{H}$-Leucine) into the trigeminal ganglion followed by an optimal survival time. The innervation of the anterior eye segment and the distribution of sensory nerve fibres to the eye related ganglia were subsequently investigated using the TMB method for WGA-HRP and autoradiography for ${ }^{3} \mathrm{H}$-leucine..

\section{MATERIALS AND METHODS}

The experiments were performed on sixteen adult male wistar rats weighing between 200 and 300 grams. Prior to operation all animals were anesthetized with ethanol ${ }^{18}(20 \%, 7.5 \mathrm{ml} / \mathrm{kg}$, i.p.) and hypnorm $(0.25 \mathrm{ml} / \mathrm{kg}, 1 . \mathrm{m}$.) and the rats were placed in a stemeotactic frame.

After dissection of the calvarium and dura, a small part of the parietal cortex cowering the anterior part of the trigeminal ganglion was removed by suction. Injections were placed in the antero-median part of the left trigeminal ganglion. 


\section{WGA-HRP Injections}

1-2 HI, 2\% WGA-HRP, dissolved in double distilled water, were injected by pressure in \& rats using glass micropipettes (20um tip dianteri) connected via a short length of polyethylene tubing to a $10 \mu \mathrm{l}$ Hamilton syringe. In two animals WGA-HRP was applied directly on top of the trigeminal ganglion. The animals were killed 24 to 72 hours after surgery with pentobarbital following 1000 U thromboliquine. The animals were perfused through the ascending norta with $500 \mathrm{ml} 0.9 \% \mathrm{NaCl}$ in distilled water containing $0.003 \%$ heparin, followed by $500 \mathrm{ml}$ of fixative containing $1 \%$ parafomaldehyde- $4 \%$ glutaraldehyde in $0.1 \mathrm{M}$

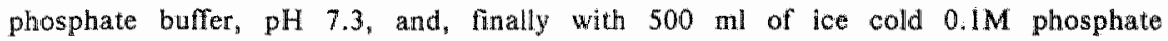
buffer containing $10 \%$ sucrose. The eyes and retrobulbar tissues containing the cilliary ganglion "the trigeminal ganglia, the pterygopalatine ganglia and the superior cervical ganglia were dissected immediately. In four animals the iris and comea were whole mounted while the remaining specimens were sectioned on a freezing microtome at $30 \mathrm{\mu m}$. The sections were mounted on chromealum-gelatin coated slides. The wholemounts and sections were reacted according the TMB method for the demonstration of WGA-HRP 21 . The sections were examined using bright-and dark-field microscopy. In the animals in which WGA-HRP was not injected but applied on the trigeminal ganglion only the superior cervical ganglion and the pterygopalatine ganglion were checked for transport of WGA-HRP.

\section{${ }^{3} \mathrm{H}$-Leucine Infections}

In six animals $3 \mu l^{3} \mathrm{H}$-Leucine (total activity $750 \mu \mathrm{Ci}$ ) were pessure injected into the left trigeminal ganglion. Following a 7 to 14 day survival period, the rats were killed with pentobarbital. The rats were perfused through the ascending aorta with $150 \mathrm{ml} 0.9 \% \mathrm{NaCl}$ in distilled water followed by $350 \mathrm{ml}$ fixative containing $4 \%$ glutaraldehyde- $1 \%$ paraformalidehyde in $0.1 \mathrm{M}$ phosphate bufTer, pH 7.3, or phosphate buffered 10\% formalin (Baker Chemicals). The heads were postixed in the same fixative (minimum 4 days). "The eyes and retrobulbar tissues, the trigeminal ganglia, the pterygopalatine ganglia and the superior cervical ganglia were removed. The tissues were rinsed in phosphate buffer and embedded in metacrylate, sectioned at $3 \mu \mathrm{m}$ and mounted. The slides were dipped in $\mathrm{G}-5$ enulsion (Kodak) diluted $1: 2$ with distilled water at $32^{\circ} \mathrm{C}$, dried, and stored in slide boxes for 6 to 12 weeks. Following exposure, the autoradiographs were developed in D $19 \mathrm{~b}$ and fixed in sodium thiosulfate $24 \%$ at 
$18^{\circ} \mathrm{C}$. The slides were then rinsed with tap water. The sections were stained with cresyl fast violet. The autoradicgraphs were examined with both bright and dark field microscopy.

\section{RESULTS}

No labelling was found on the side contralateral to the injection. The results after injection of WGA-HRP and ${ }^{3} \mathrm{H}$-Leucine injection were very similar and will be described together. In case there were differences the tracer used is indicated.

Injection site In the trigeminal ganglion large quantities of WGA-HRP and numerous autoradiographic silver grains were detected. Nearly all ganglion cells in the antero-median part were labelled.

Cornea Eight to fifteen labelled major branches were found in the cornea (Fig. IA). This wast innervation is best appreciated with WGA-HRP labelling of the whole mounted corneas and indicates effective labelling. Apart from these major branches several solitary nerve fibres were found in the periphery. The major branches divided towards the center of the cornea (Fig. IB). Centrally the individual nerve fibres dichotomized and formed a rich

Figure 1 Bright-field view of a wholemount of a cornea $48 \mathrm{hr}$ after injection of WGA-HRP into the trigeminal ganglion. A: Note the major nerve fibre bundles in the periphery (arrows). Magnification: "10 B: Enlargement of the central part of Fig. IA illustrating the dichotomisation of the fibre bundles (arrows) and the rich plexi (asterisk) between the collaterals. Magnification: 85

Figure 2 Bright-field views of sections of a cornea 14 days afier injection of tritiated leucine into the trigeminal ganglion. Magnification: $\$ 550 \mathrm{~A}$ : shows the subepithelial plexus with epithelial and subepithelial nerve fibres (arrows). B: shows a stromal nerve fobre (arrow). C: a labelled nerve fibre (arrows) directly adjacent to the corneal endothelium. End: endothelium: Ep. epithelium.

Figure 3 Bright-jleld view of a wholemount of the iris $48 \mathrm{hr}$ after injection of WGA-HRP into the trigeminal ganglion. Labelled nerve fibres (arrows) are present all over the irts, also adjacent to the pupillary border (small arrows). PB: pupillary border. Magnification: $" 85$

Figure 4 Bright-fleld view showing labelled nerve fibre (arrow) in the anterior stroma of the ciliary body 72 hr after injection of WGA-HRP into the trigeminal ganglion. CP: ciliary process. Magnification: *350

Figure 5 Dark-field view of the anterior eye segment 72 hr after injection of WGA-HRP into the trigeminal ganglion. Labelled nerve fibres (arrow) conting from the cornea course through the cillary cleft. co: comea: sc: sclera: cc: cillary cleft. Magnification: " 140 

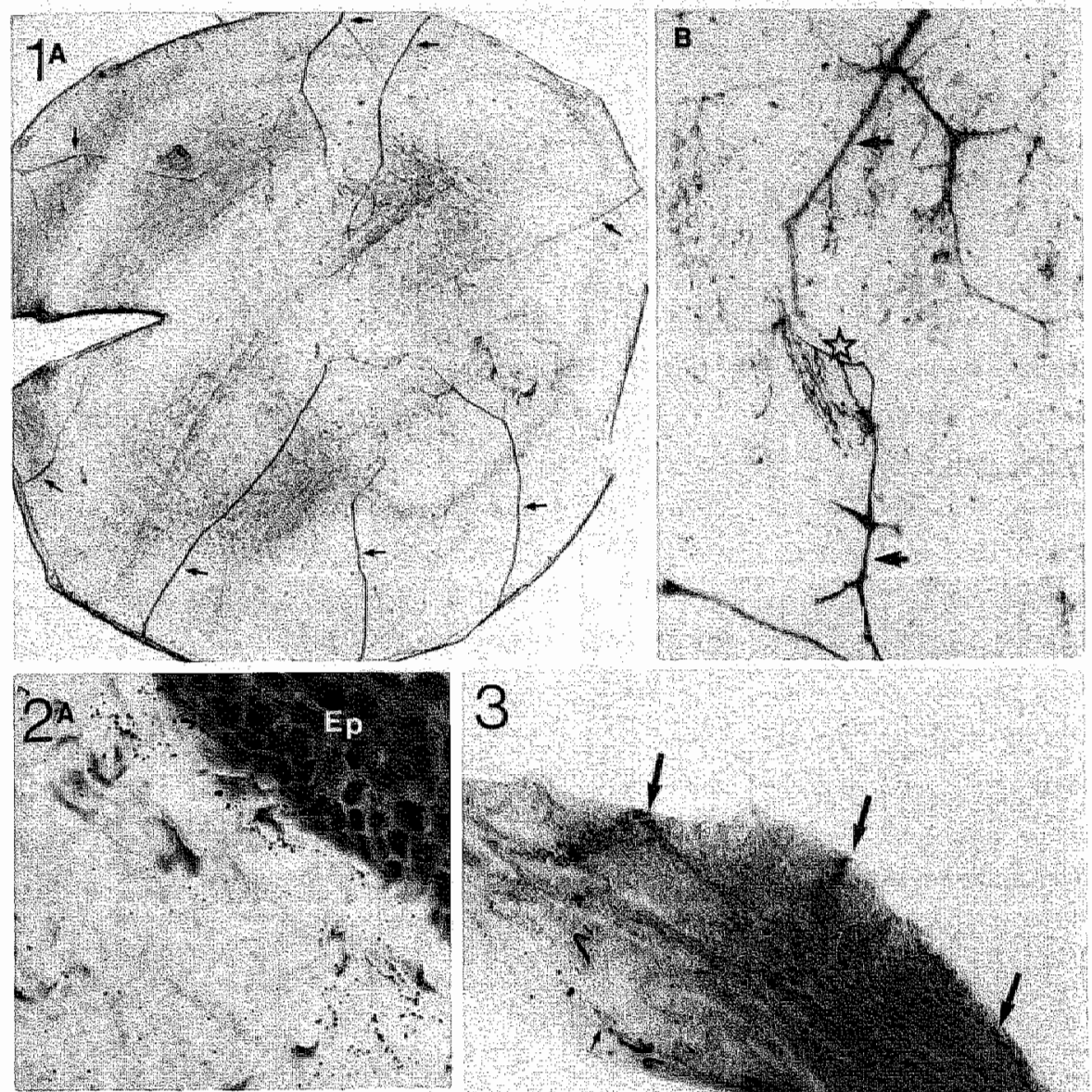

3
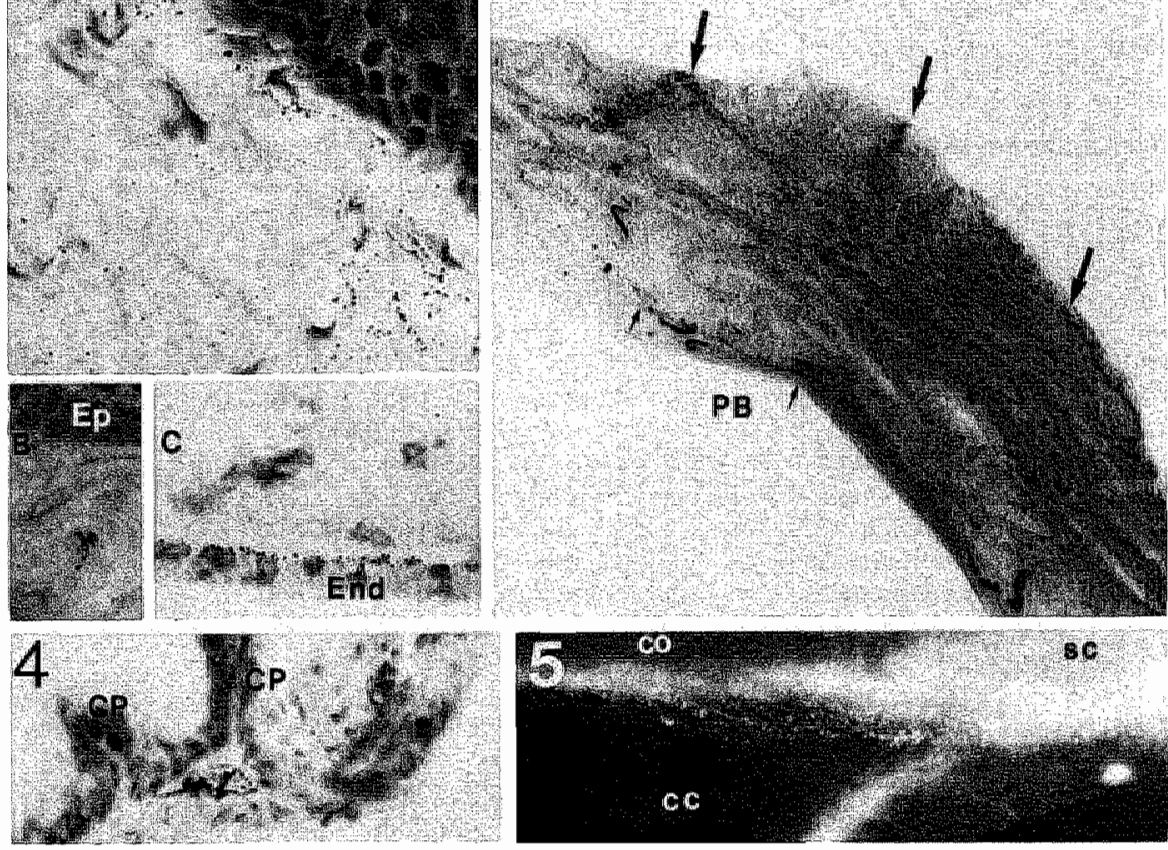
plexus with several epithelial and subepithelial nerve-endings. The histological distribution of the nerve endings is best illustrated in autoradiographs (Figs.2 A and B). In their course to the periphery, cormeal nerve fibres were found gradually more posterior in the comeal stroma even adjacent to the endothelium (Fig. $2 \mathrm{C})$,

Iris

Many labelled nerve fibres were found throughout the iris up to the pupillary border. Most nerve fibres coursed in a circular way (Fig.3). At the histological level labelled nerve fibres were fornd in the stromal part of the inis.

Cilliary body

Labelled nerve fibres were only present in the anterior stroma of the cilliary body (Fig.4). Labelled nerve fibres were not present in the cillary body epithelium.

Cilliary cleft By inspection of serial sections nerve libres from the cornea, the iris and the cillary body appeared to pass through the cillary cleft (Figs.5 and 6A-C). Most corneal nerve fibres passed through the outer part of the ciliary cleft and many nerve fibres actually traversed the ciliary cleft on their way to the suprachoroild (Fig.5). Some labelled nerve fibres that leave the iris were found to course through the pectinate ligament or one of the iris processes to the suprachoroid (Fig.6). Labelled nerve fibres from the ciliary body also traversed the ciliary cleft by way of the iris processes and thus coursed through the ciliary cleft to the suprachoroid (Fig.6). Nerweendings, however, could not be discriminated at the lightmicroscopic level.

Figure 6 Bright-field views of sections of the anterior eye segment $48 \mathrm{hr}$ after injection of WGA-HRP into the trigeminal gangllon showing the ciliary cleft. CB: cilliary body" CC: ciliary cleft. Magnification: "350

The figures $A, B$ and $C$ illustrate labelled nerve flbres in transit (deduced from serial sections) from the iris $(A)$, and the cillary body $\left(B_{*} C\right)$ to the sclera. Most of these in rransit fibres traverse the cillary cleft.

Figure 7 Dark-field view of the anterior eve segment $72 \mathrm{hr}$ after injection of WGA-HRP thito the trigeminal ganglion. Labelted nerve flbres (arrow) coming from the conjunctua (Conj) course through the limbus (Li) to the suprachoroid. Magnification: "150

Figure \& Bright-field view of the posterior segment of the eye 14 days after injection of tritiated letcine into the trigeninal ganglion. Labelled nerve fibres (arrows) are present in the suprachoroidal region. Ret: retina. Ch: chorold. Magnification: "550

Figure 9 Dark-field wew of the superior cervical ganglion $48 \mathrm{hr}$ after injection of WGA-HRP into the trigeminal ganglion exhibuting numerous labelled ganglion cell somata (arrows). Magnification: "350

Figure 10 Bright-field view of the pterygopalatine ganglion $48 \mathrm{hr}$ after injection of WGA-HRP into the trigeminal ganglion illustrating retrogradely labelled ganglion cell somata (arrows). Magnification." 350 


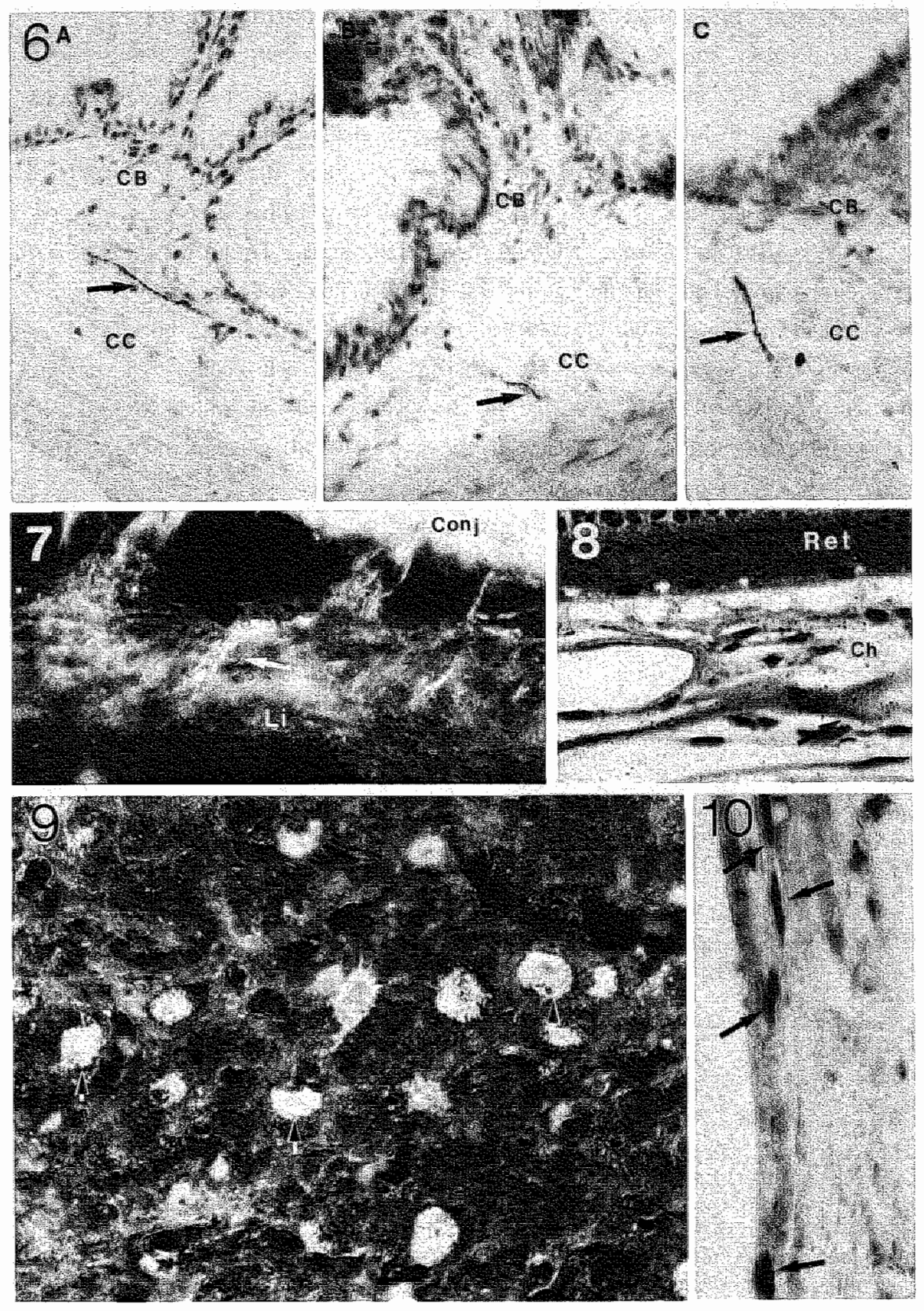


suprachoroid (Fig.8). Labelled nerve fibres from the conjunctiva joined the anterior segment nerwes directly behind the conjunctival insertion to the sclera (Fig.7). In the orbit behind the eye-ball labelled nerve fibres were found between the inferior oblique muscle and the lateral rectus muscle. In addition they were found medial to the medial rectus muscle. Labelled nerve fibres did not occur in the cillary ganglion (Figs.l1A and $\mathrm{B}$ ).

pterygopalatine ganglion The pterygopalatine ganglion is composed of a long posterior string of cells and a round cell mass. Tritium-labelled nerve fibres wete found both in the string of the ganglion and in the cell mass (Figs, I3A and B). In addition to labelled nerve fibres, WGA-HRP injection into the trigeminal ganglion revealed a few labelled ganglion cell bodies both in the string and in the cell mass (Fig. 10). In the two animals in which WGA-HRP had been applied upon the trigeminal ganglion labelled ganglion cell somata were not found in the pterygopalatine ganglion.

Superior cervical ganglion Numerous ganglion cell bodies in the rostral and caudal pole of the ganglion contained WGA-HRP (Fig.9). Application of WGA-HRP on the trigeminal ganglion did not reveal labelled ganglion cell

Figure 11 A: Bright-field photomicrograph of a labelled sensory nerve fibre bundle within the orbital region illustrated in black in Fig. B. Magnification: *350 B: Four camera lucida drawings showing the sensory nerve fibres in the retrobulbar structures after injection of tritiated leucine into the trigeminal ganglion. Black areas represent the labelled sensory nerve fibres. The striped areas represent nerwe fibres which did not contain labelling. The ciliary ganglion (arrow) did not contain labelled nerve fibres either. The optic nerve is indicated by small dots whereas the tear gland is indicated by large dots. ret: retha; rm: retractor miscle; li: lateral rectus muscle; io: inferior oblique muscle; mr: medial rectus muscle.

Flgure 12 A: Schematic representation of trigeminal nerve fibres (arrows) in the nodose garnglion' The shaded areas represent nerve fibre bundles whereas the white area represents ganglion cell somata. Labelling was present in the nerwe fibre bundle between the nodose ganglion and the jugular ganglion (jugular gl.) and berween ganglion cell somata within the nodose ganglion. $R$ : rostral; $C$ : caudal; $M$ : medial; L: lateral

B: Brightfeld whew of the nodose ganglion 8 days after injection of tritlated leucine into the trigeninal ganglion. Labelled nerve fibres encircle ganglion cell somata (arrows). Magnification: "550

Figure 13 A: Bright-field view of the pterygopalatine ganglion showing labelled nerve fibres between the ganglion cell somata 8 days after injection of tritiated leucine unto the trigeminal ganglion. Magnification: 350

B: Camera lucida drawing of the pterygopalatine ganglian showing the course of the labelled nerve fibres through the pterygopalatine ganglion. trig.g.: trigeminal ganglion; A: anterior: $P$; pasterior. 

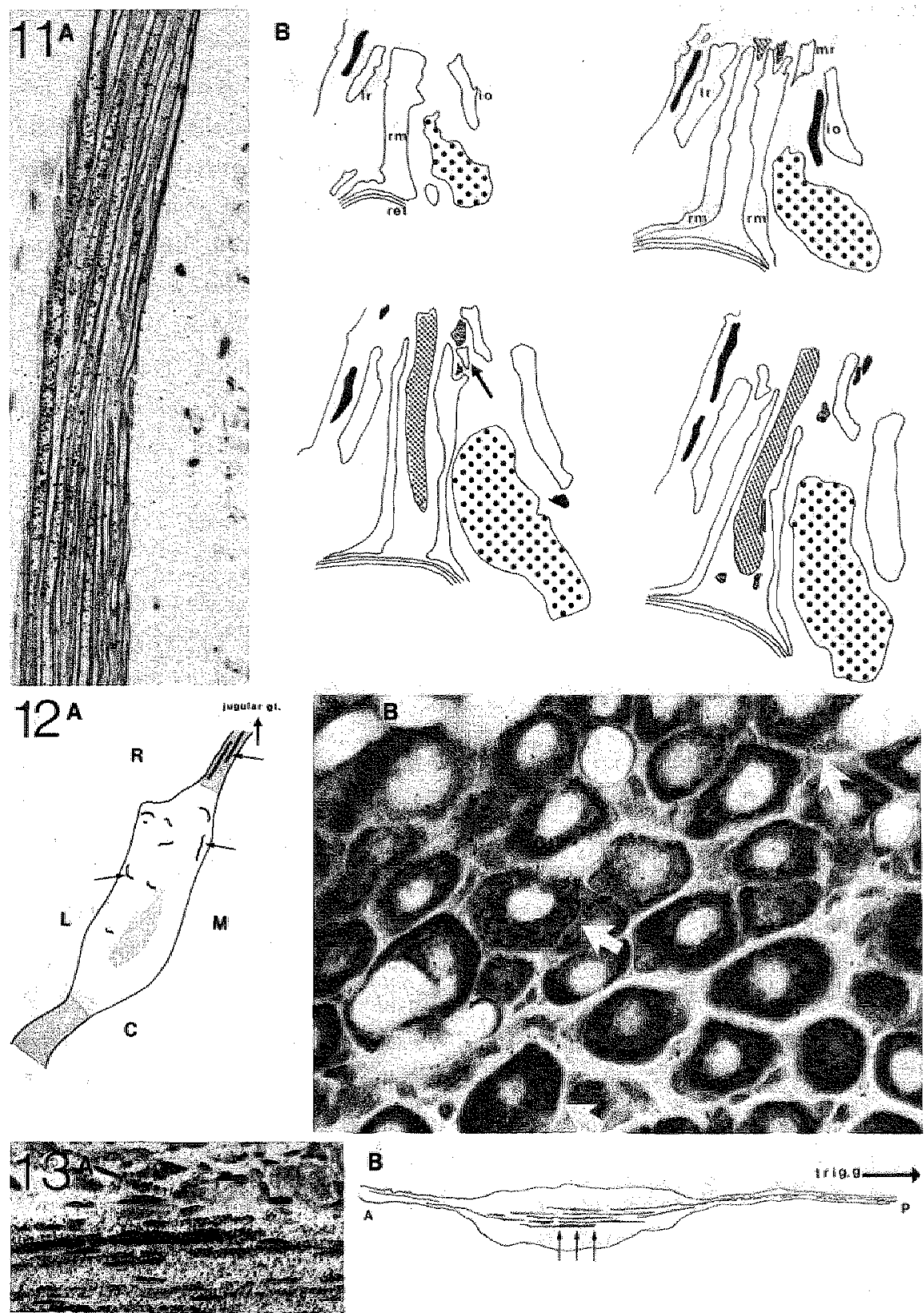
somata in the superior cervical ganglion. Labelled nerve fibres were found in the most rostral part of the ganglion. After injection of ${ }^{3} \mathrm{H}$-Leucine into the trigeminal ganglion, however, labelled nerve fibres did not occur in the superior cervicall ganglion.

Nodose ganglion

Lateral to the superior cervical ganglion lies the nodose ganglion. In the ipsilateral nodose ganglion labelled nerve fibres were present. These labelled nerve fibres were found between the nodose gariglion cells and appeared to run alongside the ganglion cell somata (Figs.12A and B). Nerwe fibres containing labelling were observed both in the medial and lateral part of the ganglion. Only a few labelled nerve fibres were found in the caudal part of the ganglion with the majority of labelled nerve fibres being observed in the rostral part of the ganglion. In addition, labelled nerve fibres were found in the fibre bundle running rostral to the nodose ganglion whereas labelling, was absent in the fibre bundle caudal to this ganglion (Fig. 12A).

\section{DISCUSSION}

The results of the present study are summarized in figure 14. After injection of WGA-HRP into the trigeminal ganglion numerous labelled ganglion cell bodies were found in the superior cervical ganglion and few in the pterygopalatine ganglion. Injection of tritiated leucine into the trigeminal ganglion revealed labelled nerve fibres in the pterygopalatine ganglion and the nodose ganglion whereas labelling was not observed in the superior cerwical ganglion and the ciliary ganglion. These different results of the WGA-HRP and ${ }^{3} \mathrm{H}-$ leveine injections can only be apprectated if we consider the distinct properties of these tracers. Labelling with tritiated leucine depends on the incorporatlon of the leucine into proteins. Since the neuronal soma is the only site of significant protein synthesis, the labelling observed after injection of tritiated leucine is the result of anterograde transport only 11,23 . In contrast, WGA-HRP is taken up by the neuronal soma, by nerve endings and by passing fibres 11,21 . From all these sites of entrance WGA-HRP is transported retrogradely and, or anterogradely. Since ganglion cell bodies were labelled in the superior cervical and the pterygopalatine ganglion after WGA-HRP injection into the trigeminal ganglion it must be assumed that retrograde transport from the trigeminal ganglion to these ganglia has taken place. This means that 


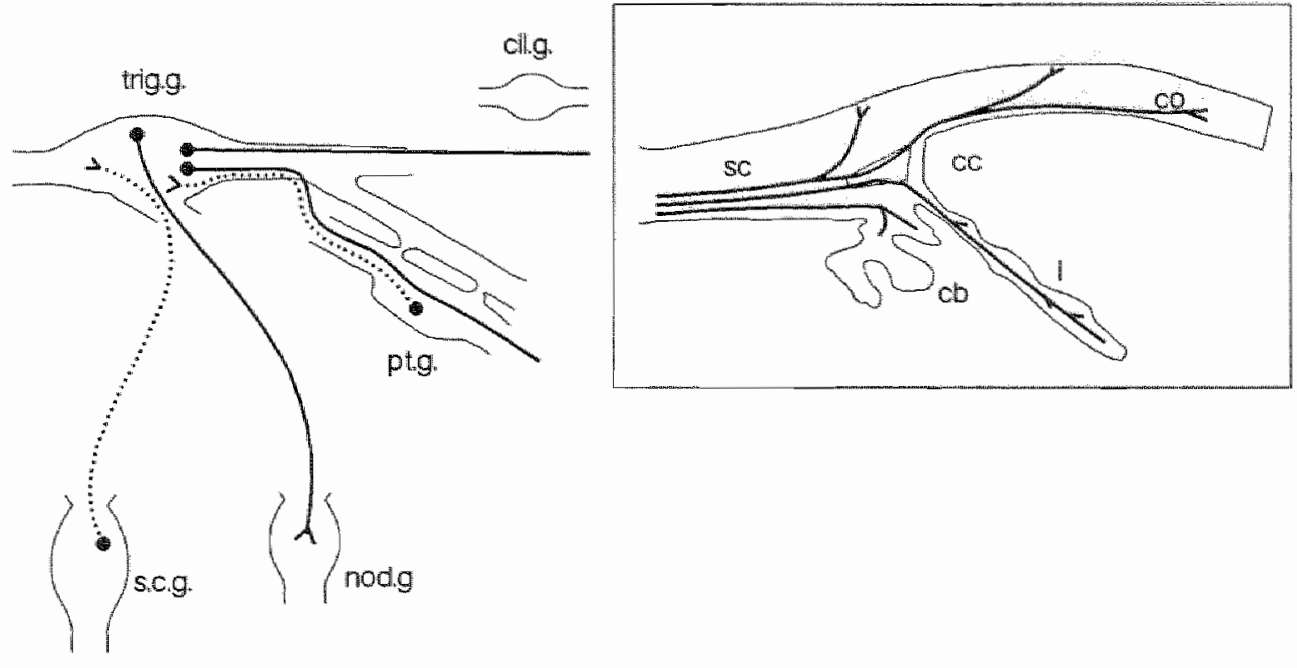

Figure 14 Summary of the results of the present experiments. Projections of the trigentinal ganglion (unimernupted lines) are present in the pterggopalathe ganglion (pt.g.) and the nodose ganglion (nod.g.). whereas they are absent in the ciliary ganglion (cil.g.) and the superior cervical ganglion (s.c.g.). WGAHRP injection into the trigeninal ganglion revealed that the prerygopalatine ganglion and the superior cervical ganglion project to the trigeminal gangllon (broken lines). Within the anterior eye segment (boxed area) trigeminal nerve fibres were present in the anterior stroma of the cillary body (cb). the iris (i), the cornea (co) and the conjunctiva. Most corneal, irideal and clliary body trigeminal nerve fibres traverse the clliary cleft (cc) on thetr way to the sclera (sc) and the suprachoroid.

passing nerve fibres or nerve fibre endings, which have their cell bodies in the superior cervical ganglion and the pterygopalatine garghlion, must be present in the trigeminal ganglion. The experiments in which WGA-HRP was applicated on top of the trigeminal ganglion lailed to label ganglion cell bodies. "These experiments are in support of the view that nerve fibres originating in the pterygopalatine and superior cervical ganglion are present in the trigeminal ganglion and not adjacent to it. Additional proof of the presence of nerve fibres from the pterygopalatine and superior cervical ganglion in the trigeminal ganglion can be obtained by anterograde tracing studies from these ganglia. As to the sympathetic nerve fibres in the trigeminal ganglion, this is investigated and discussed in an accompanying paper ${ }^{30}$. As the labelling observed after injection of tritiated leucine into the trigeminal ganglion is the result of anterograde transport, the labelled nerve fibres are of sensory trigeminal 
origin. Sensory trigeminal nerve fibres were found in the pterygopalatine ganglion and in the nodose ganglion. They were absent in the cillary and superior cervical ganglion.

On the basis of dissection studies and degeneration experiments sensory nevve fibres were found to be present in the pterygopalatine ganglion of primates 6,25 . The present study revealed the presence of trigeminal nerve fibres in the pterygopalatine ganglion of rats using the anterograde ${ }^{3} \mathrm{H}$ leucine method and thus corroborates these earlier findings. As to the presence of sensiory nerwe fibres in the ciliary ganglion, silver staining, cholinesterase studies and degeneration experiments revealed different results between species. These experiments showed passing sensory nerve fibres in the cilliary ganglion of dogs and primates 9,25 . In rabbits and cats, however, the ciliary ganglion only receives parasympathetic supply ${ }^{8}$. Since the trigeminal ganglion may contain passing sympattetic and parasympathetic nerve fibres, and since cholinesterase containing nerve fibres are not exclusively sensory definite proof of a projection from the trigeminal ganglion to the ciliary gangtion can only be obtained by anteroguade tracing studies. The present study defenitely proofs the absence of a trigeminal projection to the ciliary ganglion in rats. Whether or not trigeminal ganglion cell bodies project to the superior cervical ganglion and the nodose ganglion has never been studied. Therefore, the presenty described trigeminal nerve fibres in the nodose ganglion and their absence in the superior cervical ganglion are new and unprecedented findings. Cajal ${ }^{4}$ described pericellular baskets in the trigeminal ganglion. Similar baskets were found in the nodose ganglion of pigeons and rabbits and appeared to contain substance $\mathrm{P}^{28}$. Moreover, the number of substance $\mathbb{P}$ positive pericellular arborizations was markedly reduced after cervical vagotomy between the jugular and the nodose ganglion. Therefore, these baskets probably have an extraganglionic source. Since labelled nerve fibres were presently observed rostral to the nodose ganglion and not caudal to the ganglion, these trigeminal nerve fibres most likely end in the nodose ganglion. Many trigeminal ganglion somata and nerve fibres are known to contain substance-P $1,13,17$. So the pericellular arborizations found by South and Ritter ${ }^{28}$ may be of trigeminal origin. Our observations support this although more detailed electron microscopic analysis will be necessary.

The presently described corneal sensory innervation pattern confirms the results obtained by gold chloride staining of the cornea ${ }^{24,27}$. Sensory nerve 
fibres were distributed throughout the entire comea ever adjacent to the endothelium. The sensory nerve fibres adjacent to the endothelium support the experiments in which an endothelial innervation in rabbits was described ${ }^{3}$. Connection tracing studies and degeneration studies in monkeys and guirea pigs revealed a sensory imnerwation of the anterior stroma of the cillary body and the iris at the ultrastructural level $3,15,16$. Monkeys were found to have a small ophthallmic supply, concentrated near" the root of the iris and some monkeys lacked an ophthalmic innervation of the iris ${ }^{3}$. In the present paper sensory nerve fibres were visualised light microscopically in the anterior stroma of the ciliary body and the entire iris.

Many sensory nerve fibres innervating the cornea, the ciliary body and the iris course through the ciliary cleft. Kolmer ${ }^{12}$ suggested that nerve fibres in the trabecular meshwork are in transit to the cornea. Yet, nerve endings have repeatedly been demonstrated in the trabecular meshwork of primates $5,7,22,26$. Experiments on the ganglionic origin of these terminals were inconclusive. Adrenergic and cholinergic terminals were shown by Nomura and Smelser ${ }^{22}$. Degeneration experiments ${ }^{10}$ revealed the presense of sensory, sympathetic and parasympathetic merve fibres whereas Lamers ${ }^{14}$ only found sensory nerve fibres. Moreover, parasympathetic nerve fibres from the pterygopalatine ganglion were also found in the trabecular meshwork ${ }^{26}$. In the present WGAHRP experiments the actual course of the trigeminal nerve fibres could bo demonstrated. Many nerve fibres in transit to the cornea, the iris and the ciliary body appeared to traverse the ciliary cleft. Nevertheless, it cannot be excluded that these nerve fibres may also have boutons en passant or collaterals in the ciliary aleft. This could not be solved because of the limited resolution power of the present method. 
1.Anderson, S.E., Responses to antidromic trigeminal nerve stimulation, substance $P_{*}$ NKA, CGRP and capsaicin in the rat eye. Acta Physiol. Scand. $131(1987) 371-376$

2. Arvidson, B., Retrograde transport of horseradish perowidzse in sensory and adrenergic neurons following injection into the anterior eye chamber. I. of Neurocytol. 8 (1979) $751-764$

3.Bergmanson, I.P.G., The ophthalmic innerwation of the uvea in monkeys. Exp. Eye Res. 24 (1977) 225-240

4.Cajal, S.R. Histologie de systeme nerveux. I st ed. Maloine Paris, (1909) pp. $442-452$

5.Chapman, G.B. and Spelsberg, W.W., The occurence of myelinated and unmyalinated nerves in the iris angle of man and rhesus monkey. Exp. Eye Res. $2(1963) \quad 130-133$

6.Duke-Elder, S. and Wybar, R.W., System of ophthalmology. vol.il Mosby St. Louis 1961, pp. 813-874

7.Feney "M.L. Ultrastructure of the nerves in the human trabecular region. lnvest. Ophthal. I (1962) 462-473

8. Grimes, P. and won Sallmann, L., Comparative anatomy of the ciliary nerves. Arch. Ophthalmol. 64 (1960) 81-91

9.Hara, S., Kobayashi, S., Sugita, $\mathbb{K}$, and Tsukahara, S., Innervation of dog clliary ganglion. Histochemistry 76 (1982) 295-301

10. Holland, M.G., won Sallmann, L. and Collins, E.M., A study of the imnervation of the chamber angle. II: The origin of trabecular axons revealed by degeneration experiments. Am. J. Ophthal. 44 (1957) 206-221

11.Jones, E.G., Pathways to progress-the rise of modern neuroanatomical techniques. TINS 9 (1986) 502-505

12.Kolmer, W., Zur Histologie der Augenhaute. Anat. Anz, 47 (1914) 417

13. Kuwayama, $Y$., Terenghi, G., Polak, J.M. "Trojanowski, J.Q. and Stone, R.A., A quantitative correlation of substance $\mathrm{P}-$, calcitonine gene related peptide- and cholecystokinin-like immunoreactivity with retrogradely labeled trigeminal ganglion cells innervating the eye. Brain Research 405 (1987) $220-226$

14.Lamers, W.P.M.A., De innervatie van het trabeculum corneosclerale. Ph D thesis, Catholic University of Nijmegen, Centrale Drukkerij Nijmegen 1962

15.Lelatosalo, I., Uusitalo, H., Uusitalo, R. Poranen, A. and Palkama, A. Electron microscopic identification of trigeminal nerve fibers in the cillary body and the iris. Neuroscl. Leth. 42 (1983) $239-242$

16. Lehtosalo, J., Uusitalo, H. and Palkama, A., Sensory supply of the anterior uvea: a light and electron microscope sudy. Exp. Brain Res. 55 (1984) $562-569$

17. Lehtosalo, J.I., Substance P-like immunoreactive trigeminal ganglion cells supplying the cornea. Histochem. 80 (1984) $273-276$

18.Lumb, W.V. and Jones, E.W., Anestesia of laboratory and too animals. In: Veterinary Anestesia. Ed. Lea \& Febiger, Philadelphia, 1984 Pp. 413-493

19. Marfurt, C.F. and Turner, D.F., Sensory nerve endings in the rat orofacial region labeled by the anterograde and transganglionic transport of horseradish peroxidase: $a$ new method for tracing peripheral nerwe fibers. Brain Research 261 (1983) $\quad 1-12$

20. Marfurt, C.F. and DelToro, D.R., Corneal sensory pathway in the rat: a horseradish peroxidase tracing technique. J. comp. neurol. 261 (1987) 450- 
21.Mesulam, M.M., Tracing neural connections with horseradish peroxidase. In: IBRO Handbook Series: Methods in Neurosciences (Ed. Smith A.D.) John Wiley: New York 1982 pp.3-247

22. Nomura, T, and Smelser, G.K., The identification of adrenergic and cholinergic nerve endings in the trabecular meshwork. Invest. Ophthal. 13 (1974) $525-532$

23.Rogers, A.W., Techniques of autoradiography. Elsevier scientific publishing company: Amsterdam, London, New York 1973 pp. 1-372

24.Rozsa, A.J. and Beuerman, W., Density and organization of free nerve endings in the comeal epithelium of the rabbit. Pain 14 (1982) 105-120

25.Ruskell, G.L., Ocular fibres of the maxillary nerve in monkeys. I. Anat. 118 (1974) 195-203

26.Ruskell, G.L., The source of nerve fibres of the trabeculae and adjacent structures in monkey eyes. Exp. Eye Res. 23 (1976) 449-459

27.Schimmelpfennig, B., Nerve structures in human central corneal epithellum. Graefe's Arch. Clin. Exp. Ophthal. 218 (1982) 14-20

28.South, E.H. and Ritter, R.C., Substance P-containing trigeminal sensory neurons project to the nucleus of the solitary tract. Brain Research 372 (1986) 283-289

29.Tusscher ten, M.P.M., Klooster, J. and Vrensen, G.F.J.M., The innervation of the rabbit's anterior eye segment: A retrograde tracing study. Exp. Eye Res. 46 (1988) 717-730

30. Tusscher ten, M.P.M., Klooster, J., Want wan der, J.J.L., Lamers, W.P.M.A. and Vrensen, G.F.J.M., The allocation of nerve fibres to the anterior eye segment and peripheral ganglia of rats. Part 11: The sympathetic innervam tion. Brain Research, in press.

31. Wolter, J.R., Innervation of the corneal endothelium of the eye of the rabbit. Arch of Ophthalmol. 58 (1957) 246-250 

CHAPTER $V$

THE SYMPATHETIC INNERVATION 



\section{PART II: THE SYMPATHETIC INNERVATION}

\section{SUMMARY}

The sympathetic innervation of the peripheral ganglia related to the eye i.e. the trigeminal ganglion, the ciliary ganglion and the pterygopalatine ganglion, and of the anterior eye segment was studied in rats. Selective labellng of sympathetic nerves was obtained by means of injection of ${ }^{3} \mathrm{H}$-leucine into the superior cervical ganglion.

Bundles of sympathetic nerve fibres were found in the trigeminal ganglion and the pterygopalatine ganglion but were absent in the cillary ganglion. In addition individual sympathetic nerwe fibres, which may have contacts with trigeminal ganglion cells, were found between the ganglion cell bodies all over the trigeminal ganglion indicating a sympathetic innervation of this ganglion.

In the anterior eye segment, there appeared to be a sympathetic innervation of the ciliary cleft, the ciliary body and the iris. Within the ciliary body sympathetic nerve fibres innervate the central stroma and the stroma of the ciliary processes. Labelled sympathetic nerve fibres were also observed in the stroma of the iris and were most abundant in its periphery. Most sympathetic fibres reach the iris and cillary body by way of the base of the cillary body. Only few sympathetic fibres are present in the ciliary cleft. No sympathetic innervation of the corneal was found.

\section{INTRODUCTION}

The only known source of the sympathetic innerwation in the anterior eye segment is the superior cervical ganglion. Sympathetic nerve fibres reach the eye wia many pathways: e.g. the abducens nerve, the oculomotor nerve and the ophthalmic nerve 24,31 . Some of these fibres traverse other peripheral ganglia. The (parasympathetic) pterygopalatine and ciliary ganglion contain passing sympathetic fibres in dogs and primates $6,8,10,12$. Where sympathetic nerve fibres join the sensory branches coming from the eye is not yet definitely proved. Catecholaminergic nerve fibres, which are supposed to be 
of sympathetic origin, were found in the nasociliary nerve (the peripheral sensory branch) but not in the ophthalmic nerve of rats ${ }^{32}$. Sympathetic nerve fibres were observed in the ophthalmic nerve of rats a few millimeters rostral to the trigeminal ganglion after injection of wheatgerm agglutinin coupled to horseradish peroxidase (WGA-HRP) into the superior cervical ganglion 24,31 . Histochemically catecholaminergic fibres were identified on the dorsal surface of the trigeminal ganglion of rats ${ }^{28}$. Based on physiological evidence sympathetic nerve fibres were supposed to be present in the trigeminal ganglion of cats ${ }^{25}$. Connection-tracing with WGA-HRP from the trigeminal ganglion revealed the presence of sympathetic nerve fibres in the trigeminal ganglion 35

The targets of these sympathetic nerve fibres in the anterior eye segment have been studied extensively. By means of formaldehyde-inducedfluorescence, catecholaminergic nerve fibres were found in the cornea, the trabecular meshwork, the ciliary body and the iris of primates and subprimates $1,2,9,18,19,21,22$. Ganglion cells in the rostral pole of the superior cervical ganglion were found to be retrogradely labelled after injection of HRP and WGA-HRP in the anterior eye chamber of mice and rabbits ${ }^{3,33}$. Only nerve fibres in the cornea and iris were investigated after injection of HRP and WGA-HRP into the rostral pole of the superior cervical ganglion of rats and cats 23,24,27. However, as catecholaminergic fluorescence gives no definite proof of the sympathetic origin of fibres 7,17 and as retrograde labelling from the anterior eye segment is not selective for the distinct parts of this segment ${ }^{30}$, anterograde tracing from the superior cervical ganglion is the only conclusive experimental approach to unravel the sympathetic innervation of the anterior eye segment and the peripheral ganglia.

Since satellite cells in autonomic ganglia comprise a barrier for HRP and. WGA-HRP ${ }^{34}$ sympathetic nerve fibres were presently anterogradely labelled. with ${ }^{3} \mathrm{H}$-leucine. This radioactive aminoacid selectively labels cell bodies and consequently only sympathetic fibres are traced. Using this selective labelling we aimed at determining the course of sympathetic nerve fibres from the superior cervical ganglion to the eye related ganglia and the anterior eye segment. 


\section{MATERIALS AND METHODS}

The experiments were performed on eight male Wistar rats weighing berween 200 and 300 grams. The rats were anesthetized with ethanol ${ }^{20}\left(20 \%_{*} 7.5\right.$ $\mathrm{ml} / \mathrm{kg}, \mathrm{u}, \mathrm{p}$.$) and hypnorm \left(0.25 \mathrm{ml} / \mathrm{kg}_{*} \mathrm{i.m.}\right)$ and subsequenty placed upside down in a stereotactic frame. The superior cervical ganglion was reached by blunt dissection. All animals were injected into the left superior cervical ganglion. The injections were placed in the rostral pole of the ganglion. Three microlitres of ${ }^{3} \mathrm{H}$-leucine (total activity of $750 \mu \mathrm{Ci}$ ) were injected by pressure using glass micropipettes $(20 \mu \mathrm{m}$ tip diameter) connected with polyethylene tabing to a 10 Hl Hamilton syringe. Seven to fourteen days after injection, the animals were killed with pentobarbital, following 1000 IU thromboliquine. The animals were perfused through the ascending aorta with $1.50 \mathrm{ml} 0.9 \% \mathrm{NaCl}$ in distilled water containing $0.003 \%$ heparin, followed by 350 $\mathrm{ml}$ of phosphate buffered $10 \%$ formalin (Baker Chemicals). The heads were postfixed using the same solution for at least four days, and subsequently rinsed in saline for 24 hours. The eyes including the retrobulbar tissues, the superior cervical ganglia, the trigeminal ganglia and the pterygo- palatine ganglia were removed and rinsed in phosphate buffer. The eyes were embedded in metacrylate, sectioned transwersely at $3 \mu \mathrm{m}_{\text {, }}$ and mounted. The ganglia and retrobulbar tissues were sectioned longitudinally on a freezing microtome at 6 to $12 \mu \mathrm{m}$. The freeze sections were mounted on chrome-alumgelatin coated slides, dehydrated in ethanol, cleared in xylene for 1 hour and rehydrated subsequently. All slides were dipped at $32^{\circ} \mathrm{C}$ in $\mathrm{G}-5$ emulsion (Kodak), diluted $1: 2$ with distilled water, dried, and stored in slide boxes, at $4^{\circ} \mathrm{C}$, for 4 to 7 weeks. Following exposure, the autoradio graphs were developed in D $19 \mathrm{~b}$ and fixed in sodiumthiosulfate $24 \%$ at $18^{\circ} \mathrm{C}$. The slides were then rinsed with tap water. The sections were stained with cresyl fast violet. The autoradiographs were examined with both bright and darkfield microscopy.

\section{RESUILTS}

Injection site

After injection the superior cervical ganglia of all animals investigated 


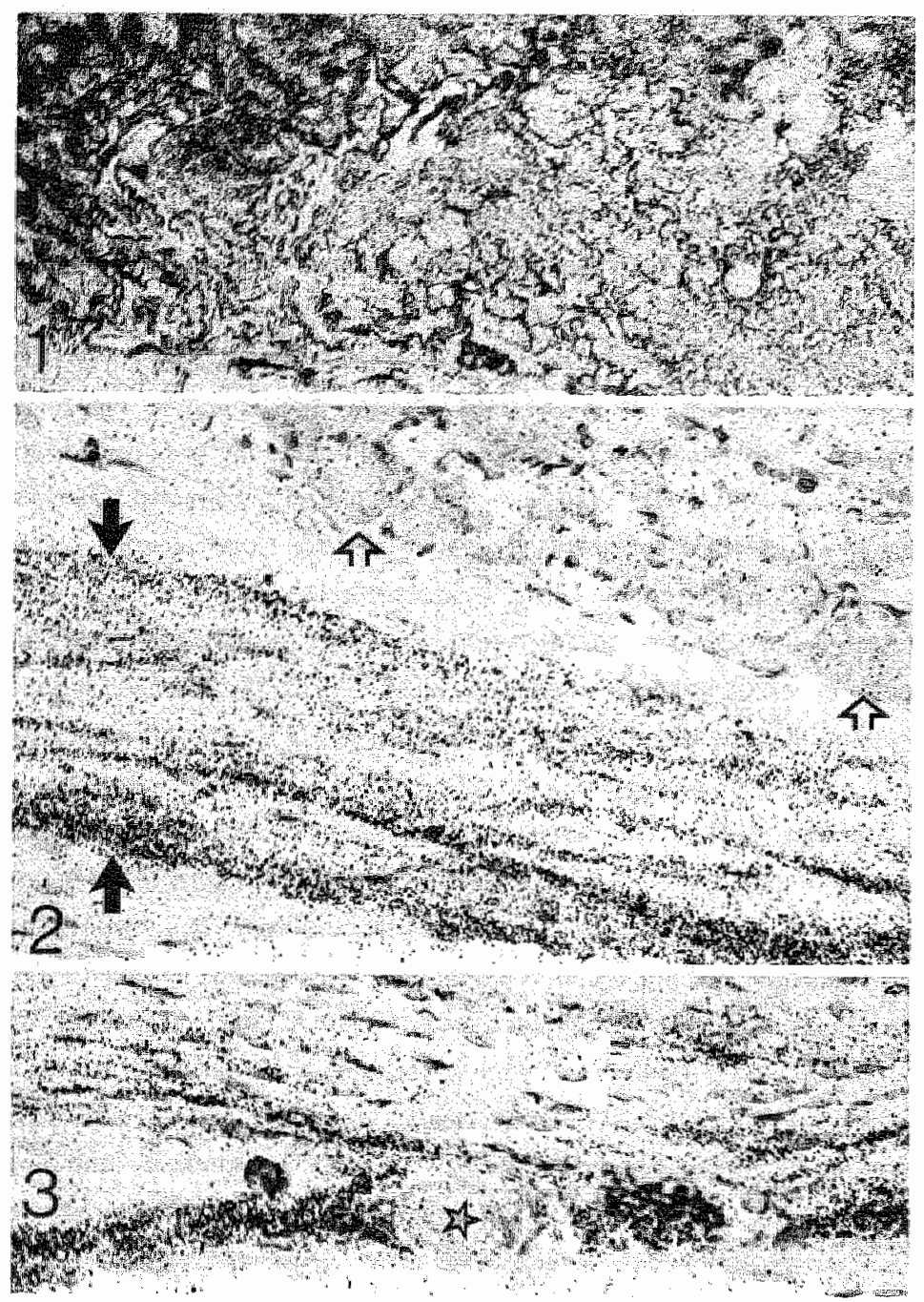

Figure 1 Brightield photomicrograph showing the superior cervical ganglion 14 days after injection of tritiated leucine. Silver gratis are present all over the gangllon. The density of the labelling is greater on the left side of the photomicrograph which represents the rostrat pole of the ganglion. Magnification: 85

Figure 2 Brightfeld wiew of the trigeminal ganglion. A large bundle of labelled nerve fibres (between the solid arrows) courses through the trigeminal ganglion. The labelled nerve fibres pass alongside the ganglion cell somata (open arrows). Magnification: " 350

Figure 3 A labelled nerve fibre bundle in the trigeminal ganglion. A ganglion cell soma (asterisk) lies in the course of these labelled nerve fibres and is surrounded by silver grains. Magnification: 350 

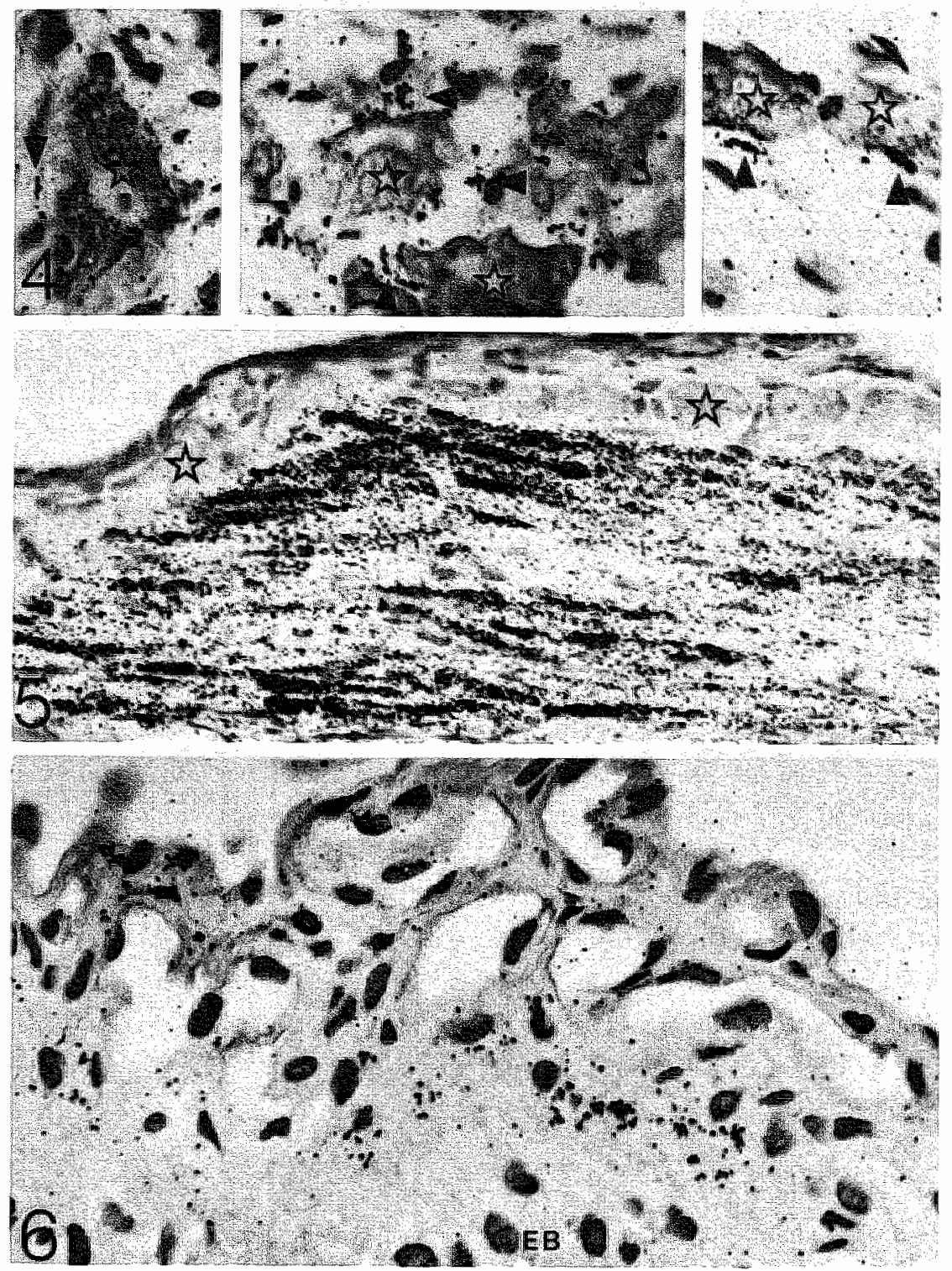

Figures \& $a-c$ Brightfield photomicrographs of the trigeminal ganglion showing individual labelled nerve fibres (arrowheads) in close proximity to gangllon cell somata (asterisk). Magnificaton: 350

Fitgure 5 Labelled sympathetic nerve fibre bundles in the cluster of cell somata of the pterygopalative ganglion. Labelled nerve flbres the in close proximity of the ganglion cell somata (asterisk). Magnification: "350

Figure 6 Labelled nerve fibres in the peripheral irideal stroma. Labelled nerve fibres lie in front of the epithellal bilayer. $E B$ : eplthellal bilayer. Magnification: $\$ 550$ 
showed an abundant autoradiographic labelling (Fig.l). Silver grains were present over cell bodies and the neuropil. In addition, labelling was abundant over axons leaving the superior cervical ganglion rostrally. The labelling was pressent both in the rostral and caudal pole of the ganglion. However, graindensity was greatest in the rostrall pole.

In all experiments profuse anterograde transport of ${ }^{3} \mathrm{H}$-proteins to the trigeminal ganglion, the pterygopalatine ganglion and the anterior eye segment was found. The cillary ganglion and the area surrounded by the retractor muscle were free of labelling. The labelling was restricted to the ipsilateral side.

\section{Trigeminal ganglion}

Large bundles of labelled nerve fibres were found in the trigeminal ganglion (Fig. 2). Most fibres entered the ganglion on the medial side and left the ganglion anteriorly. Ganglion cells were accasionally observed in the course of these fibre-bundles and were surrounded by numerous silver grains (Fig.3). Labelled nerve fibre-bundles were found both in the medial and lateral part of the ganglion. Besides these larger, heavily labelled, bundles, small isolated nerve fibres were labelled as well (Fig.4). These isolated labelled nerve fibres were found all over the ganglion, in close proximity to ganglion cell somata.

\section{Pterygopalatine ganglion}

In rats the pterygopalatine ganglion lies ventral to the maxillary nerve and is composed of a long string of perikarya and a cluster of perikarya. Numerous fibre bundles were labelled both in the cluster (Fig.5) and in the string of cell somata. Labelled isolated nerve fibres and associations with perikarya, as found in the trigeminal ganglion were not observed.

\section{Anterior eye segment}

Labelled nerve fibres were present in the iris and ciliary body. In the iris the labelling was found in the stroma (Figs. 6 and 7 ). The epithelial bilayer was largely free of labelling. The labelling gradually diminished from the base of the iris to its pupillary border. In the ciliary body the labelling was largely restricted to the stroma of the cillary body and the ciliary processes whereas, the cillary body epithelium did not contain labelled nerve fibres (Fig.8). At higher magnification, it proved that within the stroma of the iris and ciliary 


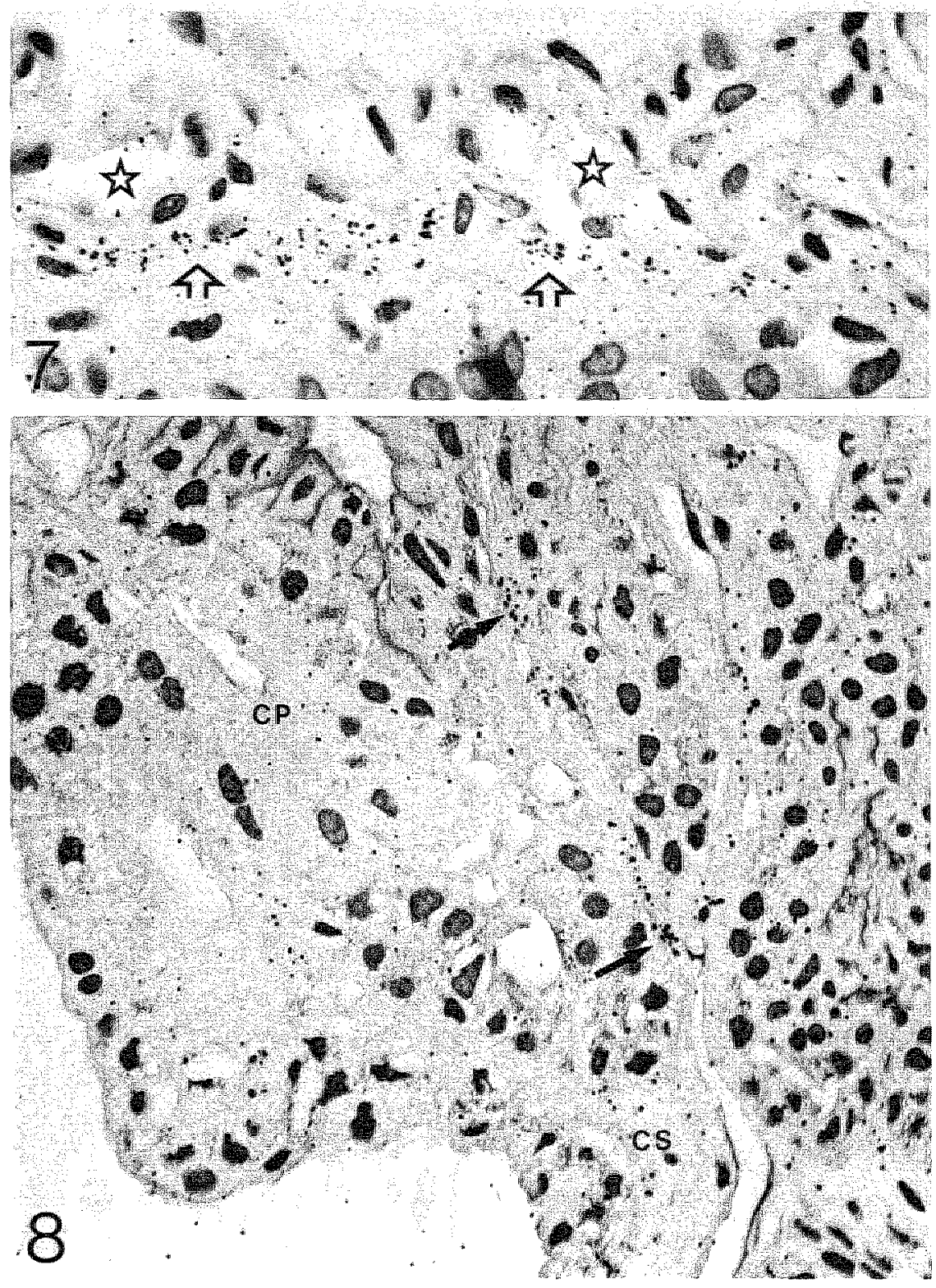

Figure 7 Photomicrograph of the central iris. Labelled sympathetic nerve fibres (open arrows) are located anterior to the epithelium and posterior to the blood-vessels (asterisk). EB: epithelial bilayer. Magnification: "\$50

Figure 8 Bright-field view of the cillary body with labelled sympathetic nerve fibres. The labelling is present in the central stroma and in the stroma of the chliary processes (solid arrows). CS: central stroma; CP: cillary process. Magnification:" 350 


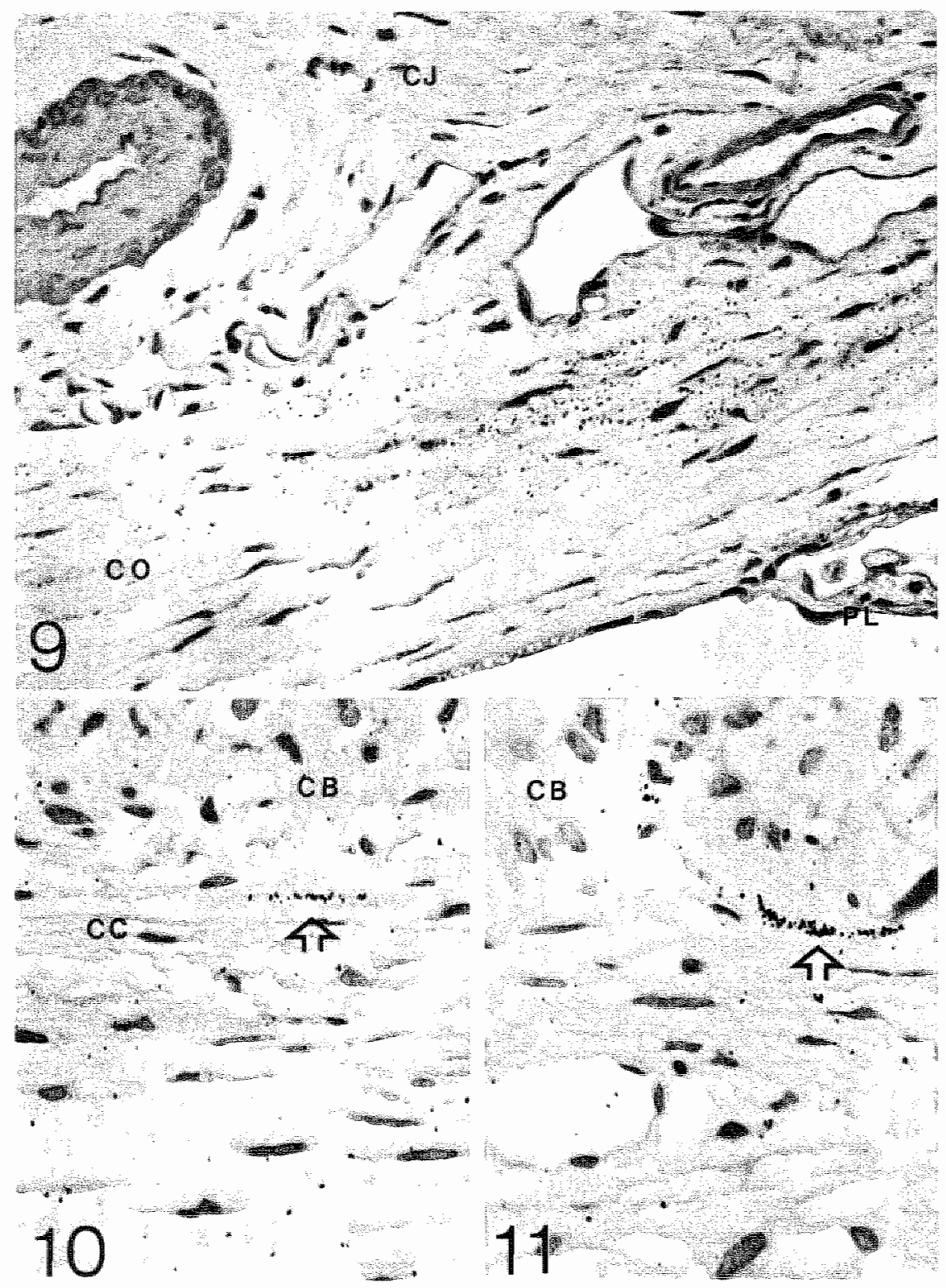

Figure 9 Brighufield photomicrograph showing the corneal/scleral border. Labelled sympathetic fibres are present in the scleral part but absent in the cornea. CO. cornea; PL: pectinate ligament: CJ: conjunctiva. Magnification: "140 Figure 10 A labelled sympathetic nerve fibre (open arrow) courses through a lamella of the ciliary cleft $C B$ : cillary body; $C C$ : ciliary cleft. Magnification: 550

Figure 11 A labelled nerve fibre (open arrow) in the base of the ciliary body just on top of the cillary cleft. CB: cillary body. Magnification: $" 550$ 
body labelled nerve fibres surround bloodvessels and lie adjacent to muscie cells. Several labelled nerve fibres were found in the limbus (Fig.9). No labelling, however, was found in the comea. A few labelled nerve fibres were found in the pectinate ligament and in the lamellae of the cillary cleft (Fig.10). Most labelled nerves, however, entered the cillary body and iris through the base of the cillary body, just above the ciliary cleft (Fig. LI).

\section{DISCUSSION}

The results of the present study are summarized in figure 12. In addition to a profuse sympathetic innervation of the iris and ciliary body a law sympathetic nerve fibres were found in the ciliary cleft, whereas the comea appeared to be devoid of a sympathetic innervation. The sympathetic innervation of the iris, ciliary body and ciliary cleft supports previous studies $1,2,9,18,19,21,22$. However, the absence of a sympathetic innervation of the cornea contradicts the findings of $\mathrm{Marfurt}^{24}$ and Morgan et all ${ }^{27}$. Using anterograde tracing with HRP and WGA-HRP from the superior cervical ganglion of rats and cats, these authors observed labelled merve fibres in the comea. The contradiction may be of methodological origin. Tract-tracing with HRP and WGA-HRP has the inherent draw-back that the tracer is not only taken up by nerve cell bodies but also by terminals and passing fibres at the injection site ${ }^{13,26}$. Hence, by this technique it is impossible to discriminate between these ganglionic elements. The labelling obtained with autoradiography, however, represents exclusive anterograde transport of ${ }^{3} \mathrm{H}$-proteins ${ }^{30}$ "The absence of corneal labelling also contradicts the results obtained by retrograde labelling with WGA-HRP ${ }^{24}$. Aftel application of WGA-HRP to the comea, and survival times of 48 to $72 \mathrm{hr}, 0$ to 3 labelled somata were found in the superior cervical ganglion. As outlined in a previous paper ${ }^{33}$ this retrograde labelling may be due to leakage into the anterior chamber and uptake by the iris, the cilliary body and the trabecular meshwork. Much shorter survival times, and consequently reduced or absent leakage into the anterior chamber showed the absence of labelling in the superior cervical ganglion. Formaldehyde-induced-nuorescence revealed catecholamine positive nerve fibres in the comea 9,18,19. These catecholaminergic nerve fibres were supposed to be of sympathetic origin. However, neither do all sympathetic nerve fibres contain catecholamine, nor are all catecholaminergic nerve fibres 


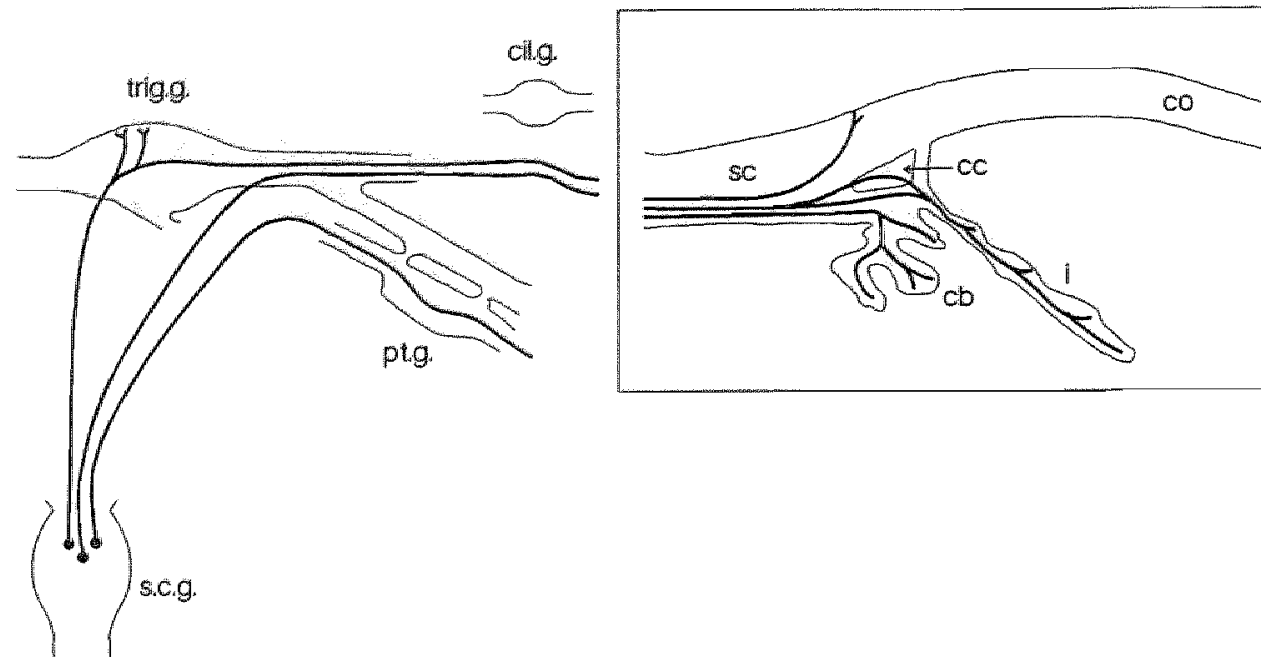

Figure 12 The resulis of the present study are outlined. Injection of ${ }^{3} \mathrm{H}-$ leucine into the superior cervical ganglion $(\mathrm{scg})$ revealed labelled sympathetic nerve fibres in the trigeminal ganglion (trig.g.), the pterygopalatine ganglion (pt.g.) and the anterior eye segment (boxed area). Labelled nerve fibres did not occur in the cillary ganglion (cil.g.). Apart from passing sympathetic nerve fibres, there may be sympathetic terminals in the tritgeminal ganglion. Only a few labelled sympathetic nerves were found in the ciliary cleft (co). Most sympathetic fibres reach the iris (i) and ciliary body by way of the base of the clliary body (cb). Sympathetic nerve fibres were found in the sclera (sc) but were absent in the cormea(co).

sympathetic $^{7,17}$. Moreover, catecholamines were demonstrated in sensory nerve fibres 14,15. In conclusion, the present and previous ${ }^{30}$ studies strongly indicate that the sympathetic innervation of the anterior eye segment, coming from the superior cervical ganglion, remains restricted to the ciliary body, the iris and the ciliary cleft and that the cornea is dewoid of this input.

A new and unprecedented outcome of the present study is the presence of labelled sympathetic nerve fibres in the trigeminal and pterygopalatine ganglion. The large labelled bundles of nerve fibres most likely traverse these gganglia. Besides these bundles, isolated labelled nerve fibres in close proximity to ganglion cell somata and pericellular accumulations of silver grains were observed in the trigeminal ganglion. The latter finding indicates that some of the sympathetic fibres may have terminals or other contacts in the trigeminal 
ganglion. The fact that WGA-HRP injected into the trigeminal ganglion leads to massive labelling of superior cetrical ganglion cell bodies is in strong support of this view ${ }^{35}$. The presence of sympathetio fibres and posisibly sympathetio contacts supports the observation of pericellular baskets around trigeminal ganglion cell somata by Cajal ${ }^{4}$. Chouchkow, Lazarov and Davidon ${ }^{5}$ described serotonin-like immunoreactive nerve fibres with varicosities surrounding nonimmunoreactive trigeminal cell somata. The ganglion tell somata did not display serotonin-like immunoreactivity at all. The immunoreactive nerve nbres must, therefore, have an extra-ganglionic source. The superior cervical ganglion appears to be a likely candidate except for the fact that only SIF cells in the superior cervical ganglion of adult rats contain serotonin ${ }^{29}$. Serotonin, however, could be demonstrated in principal nerve cells after pretreatment with colchicine or nialamide and $\mathrm{L}$-tryptophan or ligation of the postganglionic nerve trunks even after prior ligation of the preganglionic nerve nibres 11 . Hence, sensory ganglia, i.e. the trigeminal ganglion and the nodose gangllon ${ }^{35}$ contain nerve fibres and possibly nerve endings with an extramganglionic source. These results suggest that the sensory information arriving via the vagus nerve and arriving via the peripheral trigeminal branches can be modulated. As to the trigeminal branches, a modulating effect of sympathetic serotonergic fibres on the trigeminal sensory innervation dependent acute irritative response has been suggested previously 16 . Whether the modulation takes place by classical synapses or by another kind of release of peptides or neurotransmitters has to be found out at the ultrastructural levell.

In man the ciliary ganglion is supposed to contain oculomotor, trigeminal and sympathetic fibres 8,10 . By dissection and silwer staining the ciliary ganglion of rabbits and cats was found to contain solely oculomotor nerves 10 . Catecholaminergic nerves were found in the ciliary ganglion of dogs 12 . In the present experiments in rats sympathetic fibres were not found in the ciliary ganglion. These differences may be based on the techniques used. Moreover, Hara et al. ${ }^{12}$ observed that the catecholaminergic fluorescence in the cillary ganglion did not disappear after cervical sympathectomy. It is likely, however, that there are species differences.

In conclusion, this study shows bundles of sympathetic nerve fibres and indiwidual sympathetic fibres in close proximity to ganglion cell somata in the trigeminal ganglion. Sympathetic nerve fibres were found in the pterygopalatine ganglion but not in the ciliary ganglion. Conceming the 
anterior eye segment, sympathetic nerve ifbres were detected in the ciliary cleft, the cllary body and the iris. Sympathetic nerve fibres were not found in. the corned. 
1.Akagi, Y., Ibata, $Y$. and Sano, $Y .$, The sympathetic innervation of the ciliary body and trabecular meshwork of the cat. Cell Tissue Res. 173 (1976) 261 269

2.Akagi, Y., Sasamoto, K., Kodama, $Y$. and Tamura, K., Sympathetic innervation of the site of the aqueous secretion and outfow of the Japanese monkey (Macacus fuscatus); Fluorescent histochemistry and electron microscopy. Acta Soc. Ophthal. Jpn. 85 (1981) 1339-1349

3.Arvidson, B., Retrograde transport of horseradish peroxidase in sensory and adrenergic neurons following injection into the anterior eye chamber. $J$ of Neurocytol. \& (1979) 751-764

4.Cajal, S.R., Histologie de systeme nerveux. 1 st ed. Maloine Paris, 1909 pp. $442-452$

5.Chouchkov, C., Lazarov, N. and Davidoff, M., Serotonin-like immunoreactivity in the cat trigeminal ganglion. Histochemistry 88 (1988) $637-639$

6.Christensen, $K$, The innervation of the nasal mucosa, with special reference to its afferent supply. Ann. Otolaryngol. 43 (1934) 1066-1083

7.Dail, W.G. and Barton, S. Structure and organization of mammalian sympathetic ganglia. In: Autonomic ganglia. Ed. Elfvin, L.G. John Wiley \& Sons, New York, 1983 Pp. 3-26

8.Duke-Elder, S. and Wybar, R.W., System of Ophthalmology. Vol. II. Mosby St. Louis 1961 pp. $813-874$

9.Ehinger, B., Ocular and orbital vegetative nerves. Acta Physiol. Scand.(suppl.) 67 (1966) 1-35

10.Grimes, P. and Salimann von, L., Comparative anatomy of the cilliary merves. Arch. Ophthalmol. 64 (1960) 81-91

11. Happola, O., 5-Hydroxytryptamine-immunoreactive neurons and nerve fibres in the superior cervical ganglion of the rat. Neuroscience 27 (1988) 301307

12.Hara, S., Kobayashi, S., Sugita, K. and Tsukahara, S., Innervation of dog ciliary ganglion. Histochemistry 76 (1982) 295-301

13.Jones, E.G., Pathways to progress-the rise of modern neuroanatomical techniques. TINiS 9 (1986) 502-505

14.Katz, D.M., Adier, J.E. and Black, I.B., Catecholaminergic primary sensory neurons: autonomic targets and mechanisms of transmitter regulation. Federation Proc. 46 (1987) 24-29

15.Katz, D.M., Markey, K.A. Goldstein, M. and Black 1.B., Expression of catecholaminergic characteristics by primary sensory neurons in the normal adult rat. Proc. Nat. Acad. Sci. USA 80 (1983) 3526-3535.

16.Krootila, K., Uusitalo, H., Lehtosalo, J.I. and Palkama, A., Recowery of the blood-aqueous barrier after topical chemical irritation in the rabbit eye. Alb. Graef. Arch. Clin. Exp. Ophthalmol. 225 (1987) 272-276

17. Landis, S.C., Factors which influence the transmitter functions of sympathetic ganglion cells. In: Autonomic ganglia. Ed. Elfvin, L.G., John Wiley \& Sons, New York. 1983 Pp. 453-473

18.Laties, A. and Jacobowitz, D., A histochemical study of the adrenergic and cholinergic innervation of the anterior eye segment of the rabbit eye. Invest. Ophthal. 3 (1.964) 592-600

19.Laties, A and Jacobowitz, D. A comparative study of the autonomic innervation of the eye in monkey, cat and rabbit. Anat. Rec. 156 (1966) $383-396$ 
CHAPTER VI

THE FACIAL PARASYMPATHETIC INNERVATION 



\section{PRE- AND POST-GANGLIONIC NERVE FIBRES OF THE PTERYGOPALATINE GANGLION AND THEIR ALLOCATION TO THE EYEBALL OF RATS}

\section{SUMMARY}

Pre- and post-ganglionic neurons of the pterygopalatine ganglion of rats were investigated by acetylcholinesterase in toto staining and by connection tracing with wheat germ agglutinim coupled to horseradish peroxidase (WGAHRP) and tritiated leucine. The main results are summarized in Fig. 8.

The anterograde tracing with tritiated leucine revealed small parasympathetic nerve fibre bundles, originating in the pterygopalatine ganglion, in the retrobulbar structures adjacent to the optic nerve, passing through the clliary ganglion. Within the eyeball labelled nerve fibres appeared in the choroid, the limbal area and the conjunctiva whereas the ciliary body and iris were found to be devoid of this input.

The pterygopalatine ganglion consists of distal triangular cell mass and an proximal extension of somata up to the trigeminal ganglion. Retrograde tracing with WGA-HRP from the lacrimal gland resulted in the exclusive labelling of somata in the distal cell mass. Injection in the anterior eye chamber revealed exclusive labelling of somata in the proximal extension of the ganglion and after conjunctival injection somata were labelled in both the cell mass and the extension. It is concluded that the pterygopalatine ganglion is somatotopically organized along the rostral-caudal axis.

Application of WGA-HRP to the transected major petrosal nerve distall to the ganglionic extension revealed labelled preganglionic parasympathetic somata projecting to the pterygopalatire ganglion, in an ipsilateral discrete nucleus rostrolateral to the facial motor nucleus: the lacrimal nucleus. The possibility of a separate nucleus which projects to the ganglionic extension is discussed. Additionally, labelled somata appeared in the ipsilateral and contralateral superior cervical ganglion and the ipsilateral trigeminal ganglion, indicating a projection of these ganglia to the pterygopallatine ganglion.

\section{INTRODUCTION}

An ocular parasympathetic pathway of facial nerve origin, additional to the oculomotor supply through the ciliary ganglion, has been shown in cats 12 , rats 11 rabbits and monkeys ${ }^{16,17}$. The preganglionic nerve fibres of this 
lacrimal parasympathetic pathway originate in the superior sallwatory nucleus or lacrimal nucleus and the postganglionic lacrimal parasympathetic nerve fibres arise from the pterygopalatine ganglion (sphenopalatine ganglion). Superior salivatory neurong also supply the submandibular ganglion which postganglionic neurons innervate the submandibular and sublingual salivary glands.

As to the localization of the superior salivatory neurons different techniques revealed distinct results. One or two distinct cell groups near the rostral end of the genu of the facial nerve root, somata scattered in the medullary reticular formation or a cell column extending from the dorsolateral aspect of the facial motor nuclei to the solitary tract nucleus, either ipsilaterally or bilaterally all have been indicated as the localization of the superior salivatory nucleus ${ }^{4}$.

The pathway of postganglionic nerve fibres to the eyeball and their localization within the eye has been studied by the degeneration technique and by the distribution of vasoactive intestinal peptide (VIP)-like immunoreactive nerve fibres. Degeneration studies revealed parasympathetic fibres of pterygopalatine ganglion origin within the rami orbitalis innervating the eye in rabbits and monkeys ${ }^{16,17}$. In addition it was shown that these fibres innervate the choroidal blood vessels in monkeys ${ }^{18}$. Many somata in the pterygopalatine ganglion display VIP-like immunoreactivity ${ }^{6,25}$. Ocular VIP-like immunoreactive nerve fibres were found in the choroid, the posterior cilliary muscle and the clliary processes of cats ${ }^{25}$, as well as in the iris of rats $^{2}$.

It has been established that the pterygopalatine ganglion not only contains parasympathetic neurons. Anterograde tracing studies showed sympathetic nerve libres originating in the superior cervical ganglion and sensory nerve fibres originating in the trigeminal ganglion, passing the pterygopalatine ganglion of $\mathrm{rats}^{23,24}$. In addition, injection of wheatgerm agglutinin coupled to horseradish peroxidase (WGA-HRP) into the trigeminal ganglion showed labelled somata in the pterygopalatine ganglion indicating that these somata may project to the trigeminal ganglion ${ }^{23}$.

Connection tracing studies from the pterygopalatine ganglion have not yet been performed. In the present study, the pterygopalatine ganglion and its connections were studied by means of in toto staining of acetylcholinesterase 1 . Moreover, tritiated leucine was injected into the pterygopalatine ganglion to investigate the orbital and ocular distribution of nerve fibres originating in 
this ganglion. By the injection of WGA-HRP into the antertor eye chamber, the lacrimal gland and the conjunctiva, the localization of the pterygopalatine somata innervating these structures was sorted out. To study the localization of the superior salivatory somata and the peripheral ganglionic somata that project to the pterygopalatine ganglion, WGA-HRP was applied to the proximal part of the transected ganglionic nerve fibres.

\section{MATERIALS AND METHODS}

Male Wistar rats weighing $200-300 \mathrm{~g}$ were used.

The animals used in tracing experiments were anesthetized with $20 \%$ ethanol (10 ml/ $\mathrm{kg}$ body weight) and hypnorm $(0.35 \mathrm{ml} / \mathrm{kg}$ body weight) and placed in a stereotactic frame. The left pterygopalatine ganglion was reached from the dorsal side. The tracing experiments are indicated in figure 1 .

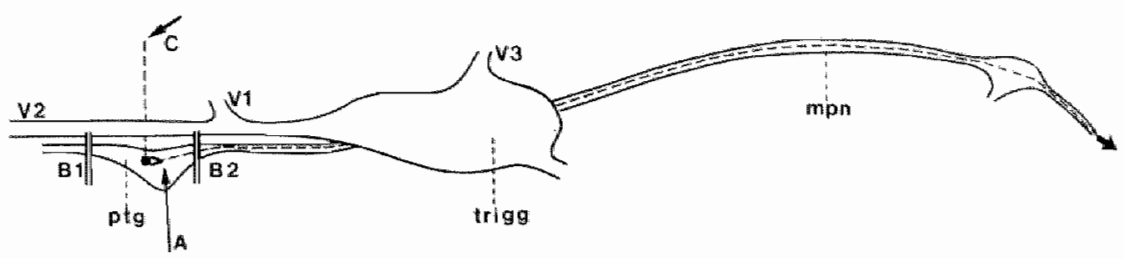

Figure 1 The performed experiments are indicated in this schematic drawing of the pterygopalatine ganglion (ptg). A: indlcates the anterograde tracing experiments with tritlated leucine from the pterygopalatine ganglion. $B$ : indicates the site of the ganglionic transection after which WIGA-HRP was applied to the proximal nerve fibres; BI: transection rostral to the ganglion, B2: transection of the major petrosal nerve (mpn). $C$ : indicates the retrograde tracing experiments with WGA-HRP from the lacrimal gland, the conjuncilva and the anterior eye chamber. trigg: trigeminal ganglion; VI: ophthalmic nerve; V2: maxillary merve; V3: mandibulary nerwe.

3 H-leucine injections (Fig. I (a))

After pulling the maxillary nerve aside, the distal part of the pterygopalatine ganglion of 4 animals was pressure injected with $3 \mu{ }^{3} \mathrm{H}$-leucine (total activity $750 \mu \mathrm{Ci})$, using glass micropipettes (20 $\mathrm{mm}$ tip diameter) connected with 
a polyethylene tubing to a $10 \mu$ Hamilon syringe. The animals were allowed to survive for 8 days, anesthetized with pentobarbital and transcardially perfused with $0.9 \%$ saline followed by phosphate buffered 10\% formalin (Baker Chemicads). The heads were postixed for 4 days, using the same solution, and subsequently rinsed in saline for 24 hrs. The eyes, including the retrobulbar tissues, the trigeminal and pterygopalatine ganglia were removed, embedded in metacrylate, sectioned at $3 \mu \mathrm{m}$ and mounted. The sides were dipped at $32^{\circ} \mathrm{C}$ in G-5 emulsion (Kodak) diluted 1:2 with distilled water, dried, and stored in slide boxes for 6 to 12 weeks. After exposure, the coated slides were developed in D $19 \mathrm{~b}$, fixed in $24 \%$ sodium throsulfate at $15^{\circ} \mathrm{C}$ and rinsed with tap water. The sections were stained with cresyl fast wiolet and examined with both bright and dark field microscopy.

\section{WGA-HRP experlments}

Transection (Fig. I(B))

A part of the maxillary nerve was removed. In 3 animals the nerve fibres rostral to the triangular distal part of the pterygopalatine ganglion were transected (Fig. $\Perp(B 1)$ ) whereas in 8 animals the major petrosal nerve was transected, caudal to the triangular distal part of the ganglion (Fig. 1(B2)). A solidified piece of WGA-HRP in Willospon (Willpharma), prepared by soaking a small piece of Willospon in 10\% WGA-HRP, was applied to the nerve fibres proximal to the transection. This was covered by another piece of Willospon not soaked in WGA-HRP and subsequently coated by Histoacryl Blue (Braun Melsungen $A G$ ) to prevent leakage of WGA-HRP to the surrounding tisswe.

Retrograde tracing (Fig. 1(C))

2 HI $4 \%$ WGA-HRP, dissolved in double distilled water, were pressure injected with a Hamilton syringe $(30$ gauge needle) into 4 lacrimal glands of 3 animals, into the conjunctiva of 4 eyes of 3 animals and into the anterior eye chamber of 4 eyes of another 3 animals.

After a surviwal time of 24 to 72 hrs the animals were anesthetized with pentobarbital following 1000 U thromboliquine. The animals were then perfused with $0.9 \%$ saline followed by $0.1 \mathrm{M}$ phosphate buffered $1 \%$ paraformaldehyde- $4 \%$ glutaraldehyde, $\mathrm{pH} 7.3$, and finally with ice cold $0.1 \mathrm{M}$ phosphate buffer containing $10 \%$ sucrose. In the experiments in which WGA-HRP was applied to transected nerve fibres, the brains $s_{\mathrm{p}}$ the trigeminal, the superior cervical and 
the pterygopalatine ganglia and the structures proximal to the pterygopalatine ganglia were dissected. The brains were sectioned transwersely from the superior colliculus to the spinal cord, at $50 \mu \mathrm{m}$, whereas the ganglia wert sectioned longitudinally at is $\mu \mathrm{m}$ on a freezing microtome. In the retrograde experiments the maxillary nerves and the adjoining pterygopalatine ganglia were dissected and sectioned longitudinally at $15 \mathrm{\mu m}$ on a freezing microtome. All sections were mounted on chrome-alum-gelatin coated slides and reacted according to the TMB method for the demonstration of WGA-HRP ${ }^{15}$ "The sections were examined using both bright and dark field microscopy. A rough estimate of the number of labelled preganglionic neurons was obtained by counting labelled WGA-HRP labelled somata.

\section{Acetylcholinesterase staining}

Twelve rats were used for the in toto staining of acetylcholinesterase 1 . After ether anesthesia, the animals were perfused with $400 \mathrm{ml}$ saline at $37^{\circ} \mathrm{C}$, containing 150 IU hyaluronidase (Hyason, Organon) and a sucrose-formol fixation medium at $4^{\circ} \mathrm{C}^{8}$. Skinned specimens were postfixed in the cold fixation nuid for 6-8 hours, rinsed and dissected in order to expose the orbital nerve bundles. The specimens were subsequently washed in double distilled water, transferred into the acetylcholinesterase incubation medium, containing $1 \%$ triton $\mathrm{X}-100$, rinsed in double distilled water, dehydrated in water glycerine series and stored in glycerine. In order to reveal even the smallest nerve fibre bundles and neuronal perikarya, some specimens were dissected further. The specificity of the reaction was tested by using $5.10^{-4} \mathrm{M}$ iso-OMPA (inhibition of pseudocholinesterase) and of $5.10^{-6} \mathrm{M} \mathrm{BW} 284 \mathrm{C} 5$ (inhibition of acetylcholinesterase) in the incubation medium.

\section{RESULTS}

\section{Acetylcholinesterase staining}

The pterygopalatine ganglion of rats is an elongated structure lying mediocaudal to the maxillary nerve. The rostral part of the ganglion had triangular shape of which basis many nerve fibre bundles entered the orbit (Fig. 2). At a higher magnification neuronal perikarya appeared not only in this triangular ganglionic part, but numerous additional perikarya appeared in the many nerve fibre bundles extending from the ganglion. The major petrosal 
nerve was also surrounded by perikarya even up to the level of the trigeminal geanglion (cf. Fig. 5).

Nerve fibres originating in the superior cervical ganglion reached the pterygopalatine ganglion by way of the inferior petrosal sirus (Fig. 2) through the nerve fibre plexus surrounding the internal carotid artery and the palatine portion of the pterygopalatine artery. Only nerve fibres from the perivascular nerwe plexus of the inferior petrosal sinus and nerve fibres from the pterygopalatine ganglion showed intense acetylcholinesterase staining. Nerve fibres from both sources intermingled within the orbit (Fig. 6A) and joined branches of the ophthalmic nerve, branches of the zygomatico-facial nerve or perivascular branches surrounding the ophthalmic artery (a branch of the pterygopalatine artery). Four to six distinct ciliary nerves were found within the retractor muscle of the orbit. All ciliary nerves, however, were inter- connected by way of nerwe fibre branches from the nasociliary nerve, the cillary and accessory cillary ganglia and the ophthalmic artery plexus (Fig. 6A).

\section{WGA-HRP experiments}

\section{Transection}

Application of WGA-HRP after rostral ganglionic transection (Fig. I(BI)) rewealed many labelled nerve fibres in the pterygopalatine ganglion. Only few somata, however, appeared to be labelled. Some maxillary nerve fibres contained WGA-HR.P.

Figure 2 In toto staining of acetylcholinesterase showing the triangular cell mass of the pterygopalatine ganglion (arrow) of which base numerous nerve fabres extend to the orbit (asterisk). The proximal part of the ganglion is not dissected out here. In the nerve plexus of the imferior petrosal sinus small ganglia are present (arrowheads). III: aculomotor nerve; VI: abducens nerve. Magnification: 30 *

Figure 3 Transverse sections through the pons showing labelled superior salivatory neurons 72 hours after application of WGA-HRP to the transected preganglionic neurons of the pterygopalatine ganglion. 3. The labelled neurons are located between the factal motor nuclews (VII) and the trigerninal nucleus (V). gf: the genu of the facial nerwe root. Magnification: $35^{*}$ 3B: A higher magnification of the labelled somata illustrated in $A$. In some experiments, facial motor meurons (arrows) were labelled in addition to the parasympathetic preganglionic neurons which are far smaller as compared to the facial motor neurons. Magnification: $140^{*}$

Flgure 4 The ipsilateral superior cervical ganglion is shown $48 \mathrm{hr}$ after application of WGA-HRP to the transected pterygopalatine ganglion. Somata in whe rostral part of the ganglion are preferentially labelled. $C:$ caudal $^{*} R$ : rostral. Magnification: $55^{*}$ 


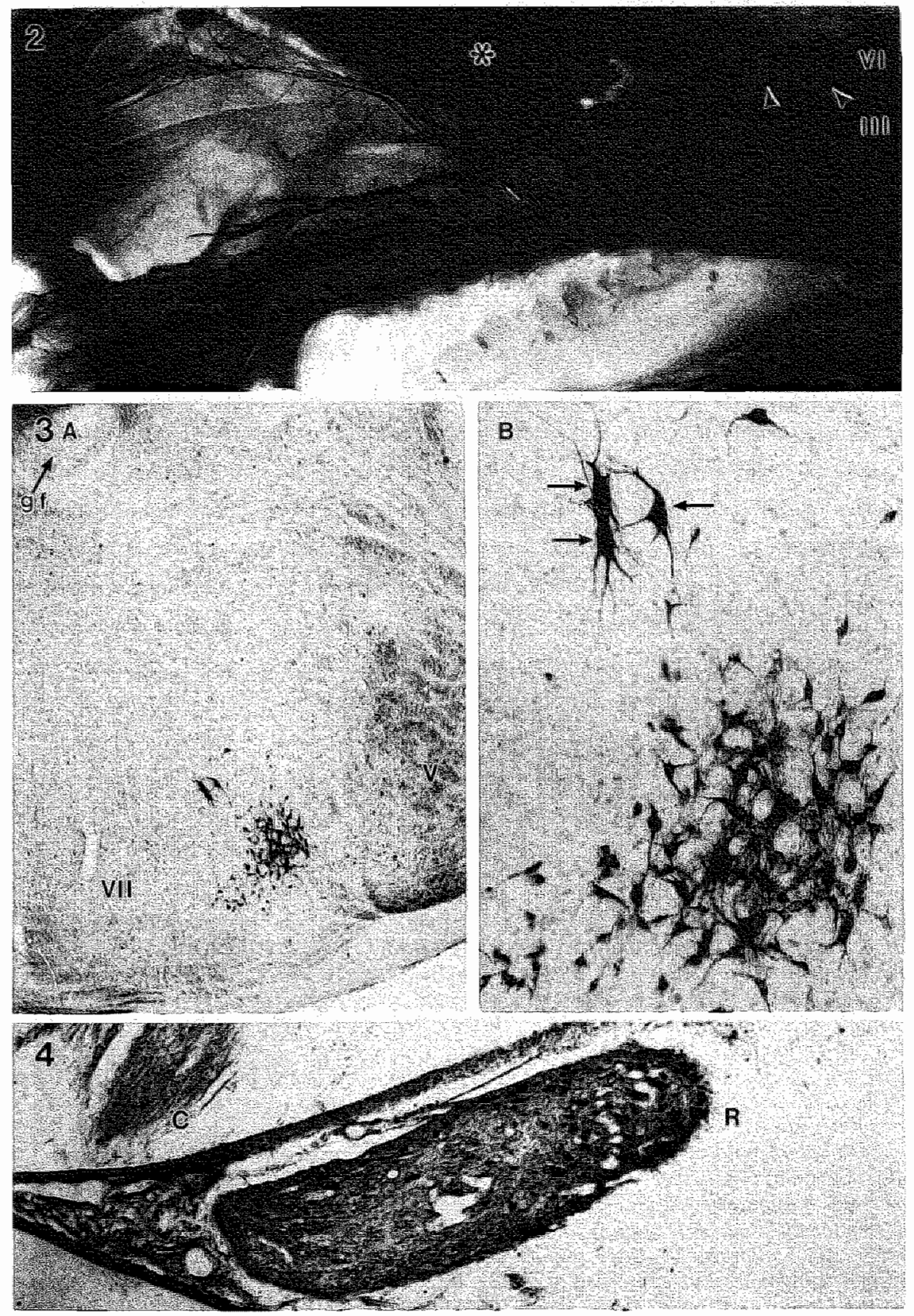


20.Lumb, W.V. and Jones, E.W., Anesthesia of laboratory and 200 animals. In: Veterinary Anestesia. Ed. Lea \& Febiger Philadelphia, 1984 Pp. 413-493

$21 \mathrm{Malmfors}, \mathrm{T}$., Studies on adrenergite nerves. Acta physiolscand. (suppl.) 64 (1965) 248

22. Malmfors, $T$. and Sachs, $C h$. Direct demonstration of the systems of terminals belonging to an individual adrenergic neuron and their distribution lin rat iris. Acta physiol. scand. 64 (1965) 377-384

23.Marfurt, C.F., Zaleski, E.M., Adams, C.E. and Welther, C.L., Sympathetic nerve fibers in rat orofacial and cerebral tissues as revealed by the HRP-WGA tracing technique: a light and electron microscopic study. Brain Research 366 (1986) 373-378

24. Marfurt, C.F., Sympathetic irinervation of the rat cornea as demonstrated by the retrograde and anterograde transport of horseradish peroxidasewheatgerm agglutinin. J. Comp. Neurol. 268 (1988) 147-160

25. Matthews, B. and Robinson, P.P.. The course of postganglionic sympathetic fibres distributed with the trigeminal nerve in the cat. J. Physiol. 303 (1980) $391-401$

26.Mesulam, M.M., Tracing neural connections with horseradishperoxidase. In: IBRO Handbook Series: Methods in Neurosciences (Ed. Smith A.D.) John Wiley: New York 1982 pp. 3-247

27.Morgan, C., DeGroat, W.C. and Jannetta, P.J., Sympathetic innervation of the cornea from the superior cervical ganglion. An HRP study in the cat. J. Auton. Nerv. Syst. 20 (1987) 179-183

28.Nojyo, $Y$., Tamamaki, N., Matsuura, $T$. and Sano, $Y .$, Histochemical and electron microscopical demonstration of the sympathetic nerve fibers joining to the fourth and sixth cranial nerwes in rats. Histochemistry 88 (1988) 557-561

29.Paiwarinta, H., Happola, O, Joh, T.H., Steinbusch, $H_{\text {. }}$ Watanabe, $T$. and Panula, P., Immunocytochemical colocalization of histamine, histidine decarboxylase, 5-hydroxytryptamine and tyrosine bydroxylase in the superior cervical ganglion of the rat. Histochem. J. 19 (1987) 319-326

30.Rogers, A.W., Techniques of autoradiography. Elsevier scientific publishing company: Amsterdam, London, New York 1973 pp. 1-372

31. Tamamaki, N. and Nojyo, $Y_{.,}$Intracranial trajectories of sympathetic nerve fibres originating in the superior cervical ganglion in the rat: WGA-HRP anterograde labeling study. Brain Research 437 (1987) 387-392

32.Tervo, T., Demonstration of adrenergic nerve fibres in the nasociliary but not the ophthalmic merve of the rat. Exp. Eye Res. 27 (1978) 607-613

33.Tusscher ten, M.P.M., Klooster, J. and Vrensen, G.F.J.M., Theinnervation of the rabbit's anterior eye segment: A retrograde tracing study. Exp. Eye Res. 46 (1988) 717-730

34.Tusscher ten, M.P.M., Klooster, J, and Vrensen, G.F.J.M., Satellite cells as blood ganglion cell bartier in autonomic ganglia. Brain Research" in press.

35. Tusscher ten, M.P.M., Klooster, ل, Want van der, J.J.L., Lamers, W.P.M.A. and Vrensen, G.F.J.M., The allocation of nerve fibres to the anterior eye segment and peripheral ganglia of rats. Part $I$ : the sensory innervation. Brain Research, in press. 
Caudal ganglionic transection (Fig. 1(B2)) and application of WGA-HRP resulted in profuse labelling of the preganglionic nerve fibres.

Superior salivatory nucleus: In all caudal transection experiments a discrete area dorsolateral to the ipsilateral facial motor nucleus which extends somewhat caudally and rostrally contained labelled somata (Fig. 3). These labelled somata were located medial to the descending faciall nerve root. Labelled neurons in this area could easily be distinguished from the facial motor neurons, since the labelled neuronis were far smaller $(20-35 \mu \mathrm{m})$ and have less prominent dendrites (Fig. 3B). The area containing labelled neurons measured about $500 \mu \mathrm{m}$ in diameter and is comparable to the wentral nucleus described by Contreras et al. ${ }^{4}$. Based on semi quantitive counting this area contained 250 to 350 labelled neurons. Within the parvicellular reticular formation, rostral to this area a few neurons (never more than 10) were labelled as well. After rostral transection this area did not contain labelled somata. In all experiments ${ }_{\text {}}$ both after caudal and rostral transection, sensory trigeminal nerve fibres appeared to be labelled in the whole trigeminal brainstem nuclear complex (TBNC). In one third of the experiments labelled neurons appeared in the trigeminal motor nucleus and the trigeminal mesencephalic nucleus. In these experiments motor neurons in the dorsal subnuclei of the facial motor nucleus were also labelled both ipsi- and contra-laterally (Fig. 3). Besides the labelling that appeared in the TBNC, the facial motor nucleus, the trigeminal motor nucleus, the trigeminal mesencephalic nucleus and the discrete nucleus dorsolateral to the facial motor nucleus, labelling was not found in other brain areas.

Figure 5 Labelled somata in the pterygopalatine ganglion 24 hr after infection of WGA-HRP in the lacrimal gland $(5 A)$ and in the anterior eye chamber (5B). Labelled somata were exclusively found in the distal triangular cell mass of the pterygopalatine ganglion after injection in the lacrimal glandcontaining (5A). whereas labelled somata only appeared in the ganglionic proximal extension after injection of WGA-HRP into the anterior eye chamber (5B). Magnification: 140"

Fipure 6 6A: Specimen after in toto staining of acetylcholinesterase showing branches of the ophthalmic nerve (on) and the pterygopalatine artery (ppa). The nerwe pleatus in the apex of the orbit (open arrow), consisting of branches from the pterygopalatint ganglion and the nerve plexts of the superior petrosal sinus, distibutes to the nasociliary nerve (arrowheads) "the ophthalmic artery (oa) and the cillary nerves (cn). The cillary ganglion is indicated by the arrow. ocn: oculomotor nerve. Magnification: 40*

$6 B-D:$ Autoradiographs after injection of tritiated leucine into the pterygopalatine ganglion. Labelled nerve fibres (arrowheads) pass through the ciliary ganglion $(\sigma B)$ and pass along nerve fibre bundles $(6 C, n f b)$ and blood vessels (6D, bv). Magnification: $350^{*}$ 


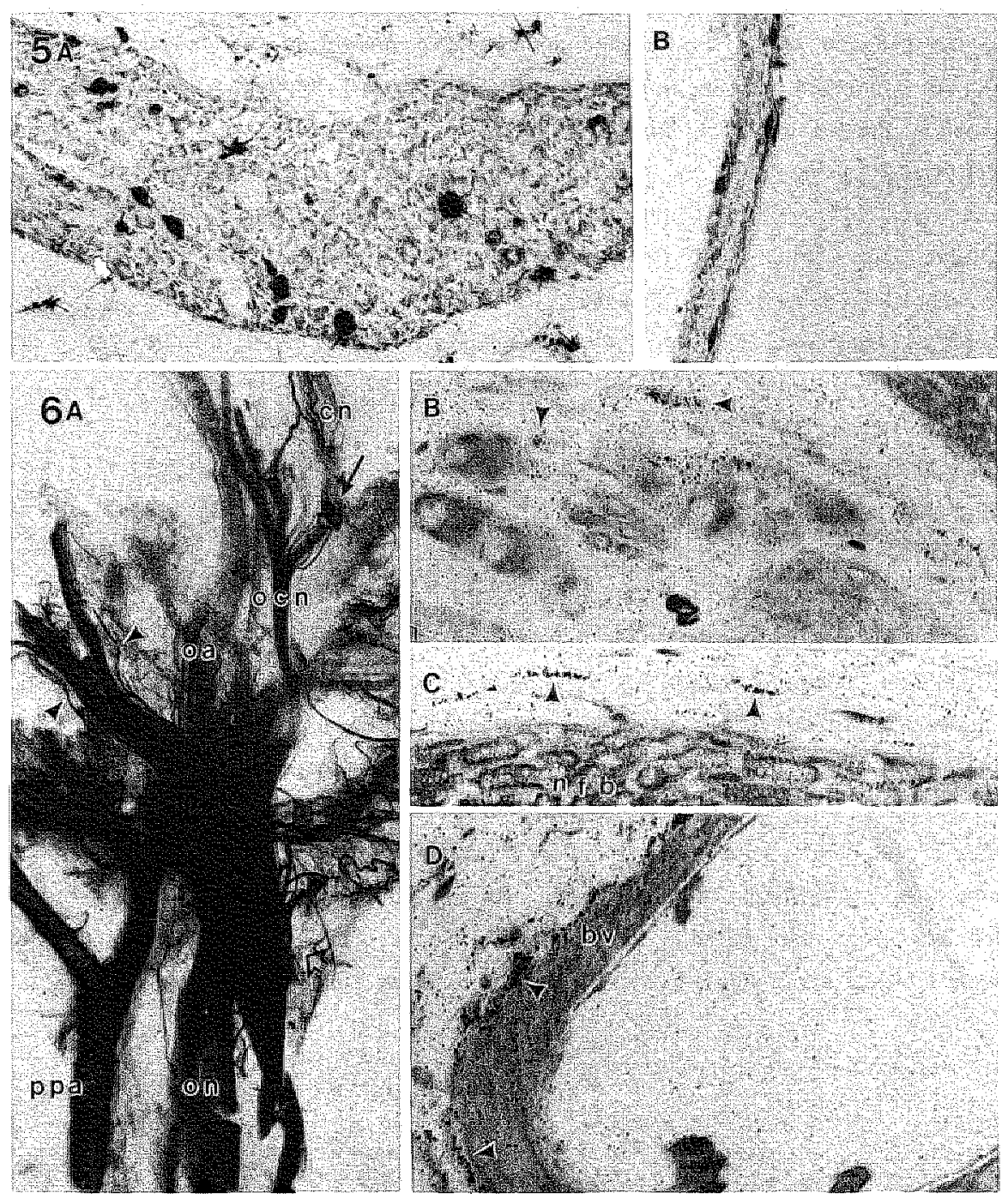


Peripheral ganglia: Labelled somata appeared in the superior cervical and trigeminal ganglion. In the trigeminall ganglion, labelled somata were found exclusively in the ipsilateral ganglion whereas both the ipsi- and contralateral superior cerwical ganglion contained labelled somata. As to the trigeminal ganglion labelled somata were restricted to the ophthalmo-maxillary compartment of the ganglion. Within the superior cervical ganglion somata containing the WOA-HRP reaction product appeared mostly in the rostral pole of the ganglion but a few labelled somata were present in the caudal pole (Fig. 4). As compared to the ipsilateral superior cervical ganglion the contralateral ganglion showed only few labelled somata.

\section{Retrograde tracing:}

Injections of WGA-HRP into the lacrimal gland, the conjunctiva and the anterior eye chamber all resulted in labelling of pterygopalatine somata (Fig. 5). The largest number of labelled somata was found after injection into the lacrimal gland whereas the smallest number was found after injection into the anterior eye chamber. After injection into the lacrimal gland labelled somata. were located in the distal ganglionic cell mass only. Labelled somata appeared only in the proximal ganglionic extension between the cell mass and the trigeminal ganglion after injection into the anterior eye chamber. Labelled somata were located both in the cell mass and the extension after conjunctival injection.

\section{${ }^{3}$ H-leucine infections}

The injected pterygopalatine ganglia showed an abundance of silver grains (Fig. 7A). Few labelled large nerve fibre bundles were found in the retrobulbar tissue. Most labelled nerve fibres appeared in small bundles surrounding blood vessels and large nerve fibre bundles (Figs. 6C and D). Labelling was almost completely confined to the nerve fibres coursing within the structures dellineated by the retractor muscle: the ciliary nerves. A large number of these labelled nerve fibres passed through the ciliary ganglion (Fig. 6B): Both

Figure 7 Autoradiographs \& days after injection of tritiated leucine into the prerygopalatine ganglion. 7A: Dark-field photomicrograph of the pterygopalatine ganglion. Magnificatian: 55* $7 \mathrm{~B}^{\circ}$ Bright-field photomicrograph showing the conjunctiva and the abundant labelling of its pithelium (ce). Magnification: 350* $7 C$ : Bright-field photomicrograph showing labelling (arrows) in the choroid (ch). sc: sclera; rpe: retinal pigment epithelium. Magnification: $550^{*}$ 

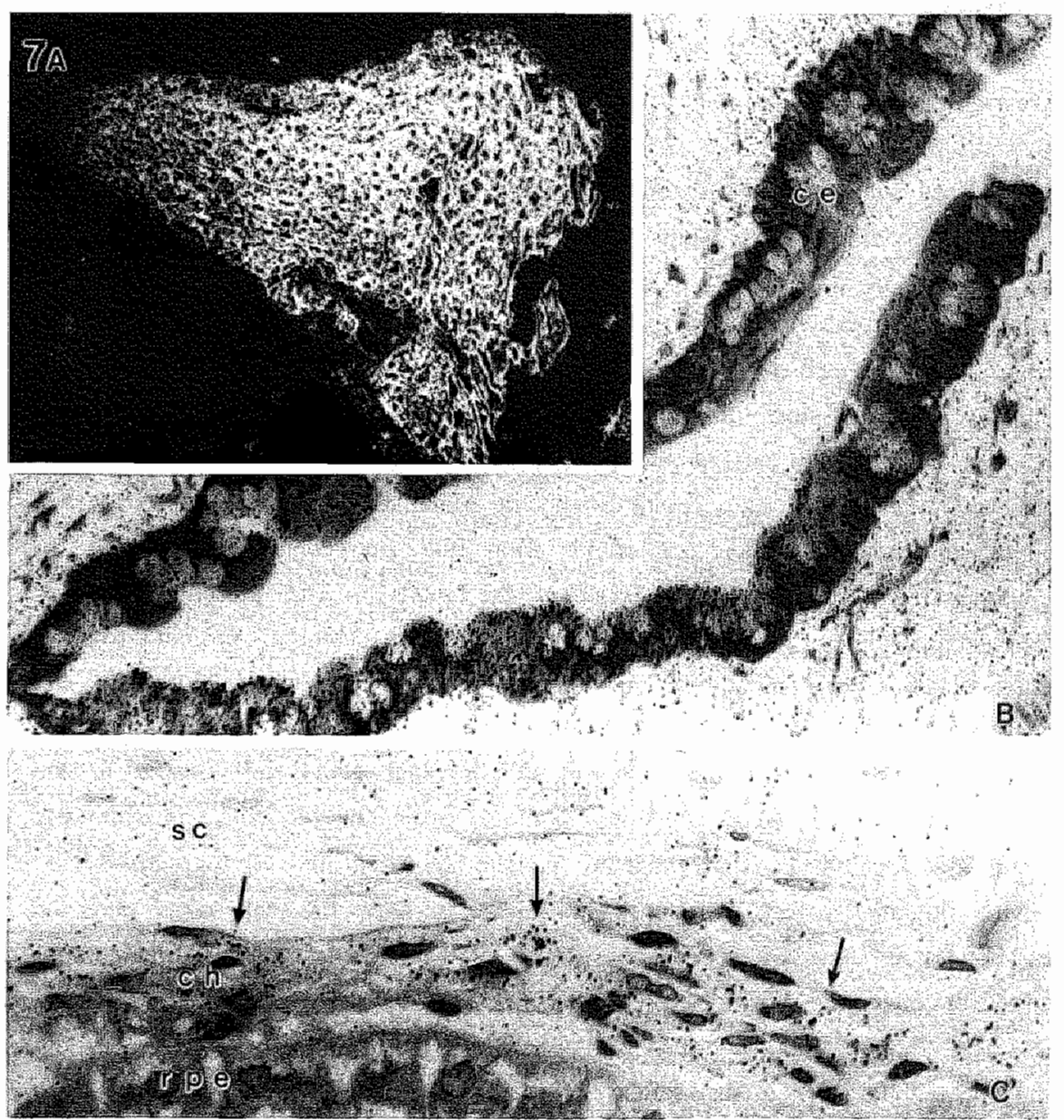
myelinated and unmyelinated nerve fibres appeared to be labelled, although most were unmyelinated.

Within the eyeball labelling was restricted to the conjunctiva, the limbic area and the choroid (Figs. $7 B$ and $C$ ). Both choroid and conjunctiva were heavily labelled. Within the conjunctival stroma labelled nerve fibres occurred but labelling was nost abundant over the conjunctival epithelium (Fig. 7B). The part of the conjunctival epithelium containing goblet cells was more heavily labelled as compared to the epithelium that does not contain goblet cells. Labelling did not appear in the trigeminal ganglion.

\section{DISCUSSION}

Acetylcholinesterase staining and light microscopical analysis revealed the elongated structure of the pterygopalatine ganglion containing a distal triangular cell mass and a proxinal exiension of perikarya up to the trigeminal ganglion. In contrast to previous descriptions 10,11 , the nerve of the pterygoid canal consists of a distinct major petrosal nerve and a nerve plexus of the inferior petrosal sinus. The latter contains many neuronal perikarya and is supplied by nerve fibres that originate in the superior cervical ganglion and reach the petrosal sinus through the plexus surrounding the internal carotid artery and the palatine part of the pterygopalatine artery.

The major results of the present study are summarized in Fig. 8. Retrograde tracing experiments showed projections from the pterygopalatine ganglion to the conjunctiva and anterior eye segment in rabbits ${ }^{14}$. The present retrograde tracing experiments revealed that pterygopalatine somata project to the lacrimal gland, the conjunctiva and the anterior eye segment. Moreover, the pterygopalatine ganglion appeared to be somatotopically organized along its rostral-caudal axis; somata projecting to the lacrimal gland are located in the distal triangular cell mass whereas somata projecting to the amterior eye segment are located in the proximal ganglionic extension. Retrograde tracing liom the conjunctiva revealed labelled somata in both the cell mass and the extension. Since some of the WGA-HRP may leak to the lacrimal gland after conjunctival injection, the localization of the somata that supply the conjunctiva is less definite than the other projections.

The preganglionic neurons which supply the pterygopalatine ganglion were lound to be lacated in an ipsilateral discrete nucleus in the pons dorsolateral 


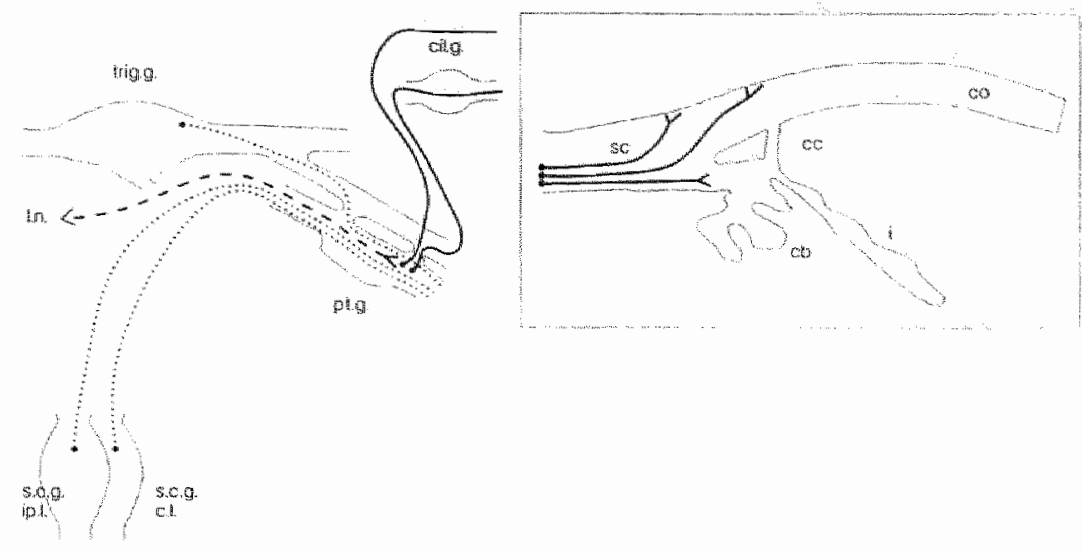

Figure 8 Summary of the main results of the present siudy. Application of WGA-HRP to the transected pterygopalatine ganglionic nerve fibres revealed retrogradely labelled somata in a discrete mucleus in the pons: the lacrimal nucleus (L.N.), in the ipsilateral (s.c.g. ip.L.) and contralateral (s.o.g. c.L.) superior cervical ganglion as well as in the ipsilateral trigeminal ganglion (trig.g.). Anterograde tracing with tritiated leucine from the pterygopalatine ganglion (pt.g.) showed labelled nerve fibres in the cillary ganglion (cil.g.) and the eye (boxed area). In the eye labelled nerve fibres appeared in the conjunctiva, the limbic area and the choroid. sc: sclera; cb: ciliary body; cc: clliary cleft: $i$ : iris; co: cornea.

to the facial motor nucleus and medial to the descending facial nerve root. Since WGA-HRP application after rostral transection failed to label these somata, one may assume that the labelling of these central somata can not have been due to WGA-HRP leakage and that these somata were retrogradely labelled from their transected axons and supply the pterygopalatine ganglion. Previous studies of these preganglionic neurons mostly dealt with both lacrimal and salivatory neurons and did not distinguish between projections to the mandibulary ganglion and projections to the pterygopalatine ganglion. The localization of these combined neurons has always been referred to as the superior salivatory nucleus. By means of the thiocholine method for cholinesterase staining the superior salivatory nucleus of rats was found to be located lateral and medial to the facial genu ${ }^{19}$, or dorsal and lateral to the facial genu ${ }^{3}$. The application of $\mathrm{CoCl}_{2}$ to the facial nerve or the gueater superficial petrosal nerve of rats revealed labelled neurons within the facial genu ${ }^{14}$. By retrograde labelling with horseradish peroxidase (HRP) in rats salivatory neurons were found in the parvicellular reticular formation extending 
salivatory neurons were found in the parvicellular reticular formation extending from the facial motor nucleus to the nucleus of the solitary tract ${ }^{7}$. Using the same method, also in rats, lacrimal and saliwatory neurons appeared to be located in the same area 4 . After the alpplication of HRP to the greater superficial perrosal nerve most labelled neurons appeared dorsolateral to the facial motor nucileus, whereas application of HRP to the chorda tympani resulted in a more dorsal localization of labelled neurons. Within the parvacelLular reticular formation dorsal to the facial motor nucleus lacrimal and salivatory neurons were found to overlap 4 . The advantages of the HRP method in comparison to the thiocholine and $\mathrm{CoCl}_{2}$ method have been described previously ; the cholinesterase stains do not identify functionally specific groups whereas passive filling of axons with $\mathrm{CoCl}_{2}$ suffers from the limited length of which it will fill axons. The localization of the preganglionic lacrimal neurons found by Contreras et al. ${ }^{4}$ after the application of HRP to the greater superficial petrosal nerve differs from the present findings using the application of WGA-HRP to the pterygopalatine ganglion. In addition to the population of labelled somata dorsolateral to the facial motor nucleus, application of HRP to the greater petrasal nerve revealed labelled neurons rostral to the tip of the solitary tract nucleus" The additional dorsal labelling of Contreras et al. ${ }^{4}$ may be due to the fact that they included the preganglionic neurons which project to the somata of the proximal ganglionic extension or may be the result of leakage. The latter, however, is the most likely since Hosoya et al. ${ }^{9}$ also failed to label the dorsal cell group, in spite of the fact that HRP was applied to the major petrosal nerve. As the HRP tracing was combined with autoradiography these results were thought to be due to fading of the HRP reaction product during autoradiographic exposure. As the distal cell mass of the pterygopalatine ganglion supplies the lacrimal gland and since this ganglion is served by a discrete nucleus which does not supply the mandibular ganglion ${ }^{4}$ the authors feel that this nucleus should be called lacrimal nucleus.

The presence of labelled somata within the superior cervical and the trigeminal ganglia corroborates anterograde tracing studies from these ganglia in which sensory and sympathetic nerve fibres were found to pass the pterygopalatine ganglion 23,24 . It was shown presently that the contralateral superior cervical ganglion gives rise to an additional projection to the pterygopalatine ganglion. This cantralateral projection is most likely due to joining of the perivascular sympathetic nerve plexus of the internal carotid 
arteries at the circle of Wills or the sinuwertebral nerve plexus at the cervicul level $^{5}$.

Since some maxillary nerve fibres in the transection area appeared to be labelled in all experiments some labelled trigeminal somata project to the maxillary nerve. Therefore, the localization of trigeminal somata that project to the pterygopalatine ganglion is not established by the present experiments.

As satellite cells in autonomic ganglia comprise a barrier for WGA-HRP and native HRP ${ }^{22}$, ${ }^{3} \mathrm{H}$-leucine was used as a tracer to investigate the projections to the eyeball. Since the pterygopalatine ganglion contains many passing sensory and sympathetic nerve fibres an additional advantage of this method is the resulting selective anterograde labelling. In the retrobulbar area parasympathetic nerve fibres of pterygopalatine origin appeared in the ciliary nerves. Many of these labelled nerve fibres coursed through the ciliary ganglion. As the ciliary ganglion in rats does not contain sensory of sympathetic nerve fibres $^{23,24}$, this ganglion is exclusively parasympathetic with nerve fibres of facial and oculomotor origin. Yet, sympathetic and sensory nerve fibres must reach the eye through the ciliary nerves. The site where these nerve fibres enter the ciliary nerves, however, is hard to indicate since nerve fibres from the nasocilliary nerve and the superior petrosal plexus distribute to the ciliary nerves at several levels. Within the eyeball labelled nerve fibres appeared in the conjunctiva, the limbic area and the choroid. These findings confirm earlier degeneration experiments and experiments in which the distribution of VIP-like immunoreactive nerve fibres was investigated. Degeneration showed the presence of nerve fibres and terminals of pterygopalatine origin in the choroid of monkeys 13,18 . VIP-like immunoreactive nerve fibres supply the choroid of cats, but also the ciliary processes and the posterior third of the clliary muscle $^{25}$. In rats, irideal VIP nerve fibres which did not disappear after ciliary or superior cervical ganglionectomy were observed ${ }^{2}$. Since the cillary mucle is rudimentary in rats the discrepancy concerns the iris and cillary processes. Cats" however, are likely to have a different innervation since ciliary ganglionectomy did not affect the VIP nerve supply, whereas VIP containing somata were shown in the ciliary ganglion of rats" 11 much as the presently described nerve fibres of pterygopalatine origin in the cillary ganglion of rats. Moreover, VIP nerves were found to originate in the choroll of guinea pigs 20 . The discrepancy may also be due to extended somata which are not reached by tracer injections into the triangular cell mass. 


\section{LITERATURE}

1. Baljet, $\mathbf{B}$. and Drukker, $J_{\text {, }}$ An acetylcholinesterase method for in toto staining of peripheral nerves. Stain Techn. 50 (1975) 31-36

2.Bjorklund, H., Fahrenkrug, I., Seiger, A., Vanderhaeghen, J.J. and Olsen, L., On the origin and distribution of vasoactive intestinal polypeptide-, peptide HI- and cholecystokinin-like-immunoreactive nerve fibres in the tat iris following sympathectomy. I. Neurosci. 5 (1985) 1633-1643

3.Bown, J.C. and Howlett, B., The facial outflow and the superior salivatory nucleus: An histochemical study in the rat. J. Comp. Neurol. 134 (1968) $175-192$

4.Contreras, R.J., Gomez, M.M. and Norgren, R., Central origins of cranial nerve parasympathetic neurons in the rat. J. Comp. Neurol. 190 (1980) $373-394$

5.Groen, G.I., Baljet, B. and Drukker, J., The innerwation of the spinal dura mater: anatomy and clinical implications. Acta Neuroch. 92 (1988) 39-46

6. Hara $H_{1}$, Hamill, $G$. and Jacobowitz, D., Origin of cholinergic nerves to the rat major cerebral arteries: coexistence with vasoactive intestinal polypeptide. Brain Res, Bull. 14 (1985) 179-188

7.Hiura, $T$., Salivatory neurons innervate the submandibular and sublingual glands in the rat: Horseradish peroxidase study. Brain Research 137 (1977) $145-149$

8.Holt, S.J., Hobbiger, E.E. and Pawan, G.L.S., Preservation of integrity of rat tissues for cytochemical staining purposes, J. Biophys. Biochem. Cytol. 7 (1959) $383-386$

9.Hosoya, Y., Matsushita, M. and Sugiura, Y., Hypothalamic descending afferents to cells of origin of the greater petrosal nerve in the rat, as revealed by a combination of retrograde $H R P$ and anterograde autoradiographic techniques. Brain Research 290 (1984) 141-1.45

10.Kuder, T., Comparative morphology and topology of the cranial parasympathetic ganglia connected with the trigeminal nerve in mouse, rat and hamster. Part II. Pterygopalatine ganglion. Folia Morphol. (Warsz.) 42 (1983) $27 \|-281$

11.Kuwayama, Y., Grimes, P.A., Ponte, B. and Stone, R.A., Autonomic neurons supplying the rat eye and the intraorbital distribution of vasoactive intestinal polypeptide (VIP)-like immunoreactivity. Exp. Eye Res, 44 (1987) $907-922$

12.Lin, T., Grimes, A. and Stone, R.A., Nerve pathways between the pterygopalatine ganglion and eye in cats. Anat. Rec. 222 (1988) 95-102

13.Macintosh, S.R. The innervation of the conjunctiva in monkeys: An electron microscopic and nerve degeneration study. Alb. v. Graefes Arch. klin. exp. Ophthalmol. 192 (1974) $105-116$

14. Martin, M.R. and Mason, C.A., The seventh cranial nerve of the rat. Visualisation of afferent and efferent pathways by cobalt precipitation. Brain Research $12 \Downarrow$ (1977) $21-41$

15.Mesulan, M.M., Tracing neural connections with horseradish peroxidase. In: IBRO Handbook Series: Methods in Neurosciences (Ed. Smith A.D.) John Wiley, New York 1982 Pp. 3-247

16. Ruskell, G.L., The orbital distribution of the sphenopalatine ganglion in the rabbit. In: The structure of the eye, Vol.II: Eighth International Congress of Anatomists, Wiesbaden. Ed. Rohen, J.W., Schattauer, Stuttgart, 1965 Pp. $355-368$

17.Ruskell, G.L., The orbital branches of the pterygopalatine ganglionand their relationship with internal carotid nerve branches in primates. J. Anat. 106 (1970) $323-329$ 
18. Ruskell, G.L., Faciall parasympathetic innervation of the choroidal blood vessels in monkeys. Exp. Eye Res. 12 (1971) 166-172

19.Shute, C.C.D. and Lewis, P.R., The salivatory centre in the rat. J. Anat. 94 (1960) $59-73$

20.Terenghi, G., Polak, J.M., Probert, L., McGregor, G.P., Ferri, G.L., Blank, M.A., Butler, J.M. Unger, W.G., Zhang, S., Cole, D.F. and Bloom, S.R., Mapping, quantitative distribution and origin of substance $\mathrm{P}_{-}$and VIPcontaining nerves in the uvea of guinea pig eye. Histochem. 75 (1982) $399-41.7$

21.Tusscher ten, M.P.M. Klooster, J. and Vrensen, G.F.J.M., "The innervation of the rabbit's anterior eye segment: a retrograde tracing study. Exp. Eye Res. 46 (1988) 717-730

22.Tusscher ten, M.P.M., Klooster, J. and Vrensen, G.F.J.M., Satellite cells as blood-ganglion cell barrier in autonomic ganglia. Brain Research, in press

23. Tusscher ten, M.P.M., Klooster, J." Want van der, J.J.L., Lamers, W.P.M.A. and Vrensen, G.F.J.M. The allocation of nerve fibres to the anterior eye segment and peripheral ganglia of rats. Part I: The sensory innervation. Brain Research, in press

24.Tusscher, M.P.M., Klooster, J., Want van der, J.L.L., Lamers, W.P.M.A. and Vrensen, G.F.J.M., The allocation of nerve fibres to the anterior eye segment and peripheral ganglia of rats. Part II; The sympathetic innervation. Brain Research, in press

25.Uddman, R., Alumets, J. Ehinger, B., Hakanson, R., Lorén, I. and Sundler, F, Vasoactive intestinal peptide nerves in ocular and orbital structures of the cat. Invest. Ophthalmol. Vis. Sci. 19 (1980) 878-885 



\section{CHAPTER VII}

SUMMARY AND CONCLUSIONS 



\section{SUMMARY AND CONCLUSIONS}

Elements of the central and peripheral nervous system innervating the eyeball and in particular the anterior eye segment, are involved in the regulation of the intraocular pressure. The morphological and physiological literature concerning these nervous elements is summarized in Chapter 1. Desplte the large amount of data on the anterior eye segment innervation the concept of the anatomical organization is often insufficient as to understanding the outcome of physiological experiments. This frequent mismatch between anatomical and physiological data may be due to invalidity or incompleteness. As outlined in Chapter 1 many experiments suffer from the inability to identify the anatomical origin of individual nerve fibres. The intermingling of peripheral nerve fibres within the peripheral ganglia and their possible interconnectivity has got relatively little attention. The peripheral ganglia comprise a relay station between the central nervous system and the innervated organ. Wether these relay stations ane only passing on impulses, or are capable of integrative activity or are, to a certain degree, independant of the central nervous system analogue to the enteric ganglia has not been elucidated yet.

By means of the selective anterograde tracing technique of autoradiography, and by anterograde and retrograde tracing with HRP and WGA-HRP, the allocation of peripheral nerve fibres to the eyeball and peripheral eye related ganglia was investigated in the present thesis. The results of the experiments are summarized and discussed under three separate headings: i) Blood-ganglion cell barrier, ii) Anterior eye segment innervation, and iii) Inter- ganglionic circuitry.

\section{BLOOD-GANGLION CELL BARRIER (Chapter II)}

In the course of the anterograde tracing experiments from the trigeminal and superior cervical ganglion a confusing difference in the uptake and transport of HRP and WGA-HRP was noticed between these two ganglia. Subsequent ultrastructural analysis of autonomic and sensory ganglia after intraganglionic and intravascular injections of WGA-HRP and HRP, revealed that satellite cells in autonomic ganglia comprise an effective barrier for the injected proteins and likely for large mollecules in general. The presence of numerous tightjunctions between the cell membranes of the satellite cells and their 
processes, which fully enwrap the autonomic ganglion cell somata, might be responsible for this barrier. This blood-ganglion cell barrier appeared not to exist in sensory ganglia. Hence, large substances present in the blood stream have access to the endoneurial space in both autonomic and sensory ganglia, and these substancest also reach the cell membranes of sensory ganglion cell somata by which they are taken up. In atutonomic ganglia, however, the cell somata are screened from these substances by the enwrapping intercellulary lirked satellite cell processes. Consequently, peripheral sensory neurons may be more vulnerable to circulating toxic agents as compared to the autonomic peripheral neurons. The significance of the fact that sensory ganglion cell somata are not protected like the autonomic ganglion cell somata will be discussed later.

\section{ANTERIOR EYE SEGMENT INNERVATION}

Retrograde tracing experiments in both rabbits and rats revealed no major differences between these species (Chapter III). The anterior eye segment was found to be supplied by nerve fibres originating in the sensory trigeminal ganglion, the sympathetic superior cervical ganglion and the parasympathetic ciliary and pterygopalatine ganglia. Intraciorneal injections of WGA-HRP studied after increasing survival times showed that the innervation of the cornea is exclusively of trigeminal, i.e. sensory, origin. Electron microscopy showed four different cell types in the trigeminal ganglion. The indiwidual cell types had no specific projection area. Anterograde tracing with tritiated leucine and WGA-HRP revealed that sensory trigeminal nerve fibres (Chapter IV) coming from the cornea, the conjunctiva, the anterior stroma of the ciliary body and the iris course through the cliary cleft and the suprachoroid to the anteromedial part of the trigeminal ganglion (Fig. 1). Whether the cillary cleft has a sensory innervation of its own could not be definitely proved.

Sympathetic nerve fibres from the rostral pole of the superior cervical ganglion (Chapter V) project, after coursing the suprachoroid and the base of the ciliary body, to the stroma of the ciliary processes, the iris, the limbic area and the conjunctiva. Few sympathetic nerve fibres appeared in the cillary cleft. In accordance with the retrograde tracing experiments in rabbits no sympathetic innervation of the cornea was found by anterograde tracing in rats.

The parasympathetic innervation mediated by the pterygopalatine ganglion 
(Chapter VD) appeared to be restricted to the choroid the limbic area and the conjunctiva.

\section{INTERGANGLIONIC CIRCUITRY}

It has been established that in primates and sub-primates the pterygopalatine ganglion contains nerve fibres of mixed origin " whereas the cillary ganglion of only dogs and primates has a mixed character. The cilliary ganglion of rats and rabbits is thought to receive parasympathetic nerve fibres of oculomotor origin only. In addition, the superior cervical and trigeminal ganglion are supposed to contain only sympathetic and sensory nerve fibres respectively (Chapter 1).

The circuitry between the four eye related ganglia of rats was studied by anterograde and retrograde tracing with ${ }^{3}$ H-Lewcine and WGA-HRP from the trigeminal ganglion (Chapter IV), the superior cervical ganglion (Chapter V) and the pterygopalatine ganglion (Chapter VI). The results concerning the circuitry between the peripheral ganglia are summarized in Figure $\mathbb{L}$.

Sensory trigeminal nerve fibres were found in the parasympathetic pterygopalatine ganglion and the sensory nodose ganglion. Sympathetic nerve fibres from the superior cervical ganglion project to the trigeminal ganglion and the ipsi- and contralateral pterygopalatine ganglion. Parasympathetic nerve fibres from the pterygopalatine ganglion project to the parasympathetic cilliary ganglion. So, in comparison to the supposed circuitry, outlined in Chapter $I_{\text {, }}$ only the superior cervical ganglion was not found to be supplied by nerve fibres of different or additional sources. Whether the intermingling of distinct peripheral nerve fibres in the peripheral ganglia is due to the fact that these nerve fibres simply pass these ganglia on their way to the target structures, or is due to the fact that these merve fibres synaptically interact with the ganglionic neurons could not be evidenced. However, the light-microscopical observations concerning the presence of trigeminal nerve fibres in the nodose ganglion, and the presence of sympathetic nerve fibres originating in the superior cervical ganglion, in the trigeminal ganglion, are in strong support of a synaptic interaction between these nerve fibres and the ganglion cells. As to the trigeminal ganglion, numerous ganglion cell somata were retrogradely labelled in the superior cervical ganglion after WGA-HRP injection into the trigeminal ganglion. In addition, anterograde tracing with tritiated leucine from the superior cervical ganglion showed individual labelled nerve fibres adjacent 
to cell somata in addition to labelled nerve fibre bundles. As to the nodose ganglion, labelled trigeminal nerve fibres were found rostral to the ganglion but not caudal to the ganglion. To appreciate these results one has to consider whether or not there are synapses in these ganglia. Sensory ganglia in general have long been supposed not to contain synapses. Recently, however, synapses have been identified in the nodose ganglion and the dorsal root ganglia $1,2,3$. In the trigeminal ganglion, synapses have not been found yet. This means that there are so few that they are hard to find in ultrathin sections or that the trigeminal ganglion is indeed devoid of synapses. If there are no synapses, it may be that a non-synaptic release of neurotransmitters or peptides takes place. Since sensory ganglion cell somata have no barrier separating them from the endoneurial space only few symapses or sites of transmitter release would theoretically be enough to modulate sensory ganglion cell somata.

The pterygopalatine ganglion was found to be somatotopically organized (Chapter VI). A distal cell mass projects to the lacrimal gland and receives preganglionic projections from a discrete mucleus dorsolateral to the facial motor nucleus in the pons : a lacrimal nucleus. A proximal extension of somata of the pterygopalatine ganglion projects to the choroid and conjunctiva. As ganglionectomy of the pterygopalatine ganglion has a dramatic effect on the intraocular pressure, it may be that the proximal neurons regulate the venous resistance within the aqueous veins.

Figure I Summary of the main results of this thesis referring to the anterior eyo segment Inmervation (boxed area on top) and the interganglionic circuttry (betow). Sensory nerve fibres originating in the trigeminal ganglion (interrupred lines) project to the sensory nodose ganglion (nodg.) and the parasympathetic ptorygopalatine ganglion (pt.g.). Within the anterior eye segment these sensory nerve fibres were found in the cornea (co) " the iris (i) "the anterior stroma of the cillary body (cb) and the conjunctiva. Most sensory nerve fibres course through the ciliary cleft (co). Sympathetic nerve fibres (uninterrupted lines) from the superior cervical ganglion likely synaptically supply and course throwgh the trigeminal ganglion (trig.g.) and appear in the pterygopalatine ganglion. Both nerve fibres originating in the ipsilateral superior cervical ganglion (i.s.c.g.) and the contralateral superior cervical ganglion (c.s.c.g.) reach the pterygopalatine ganglion. Sympathetic nerve fibres were found in the cillary body, the iris, the conjunctiva and only occasionally in the ciliary cleft. Tracing from the plerygopalatine ganglion revealed labelled nerve fibres (dashed lines) in the cillary ganglion (cil.g.). the choroid and the conjunctiva. 

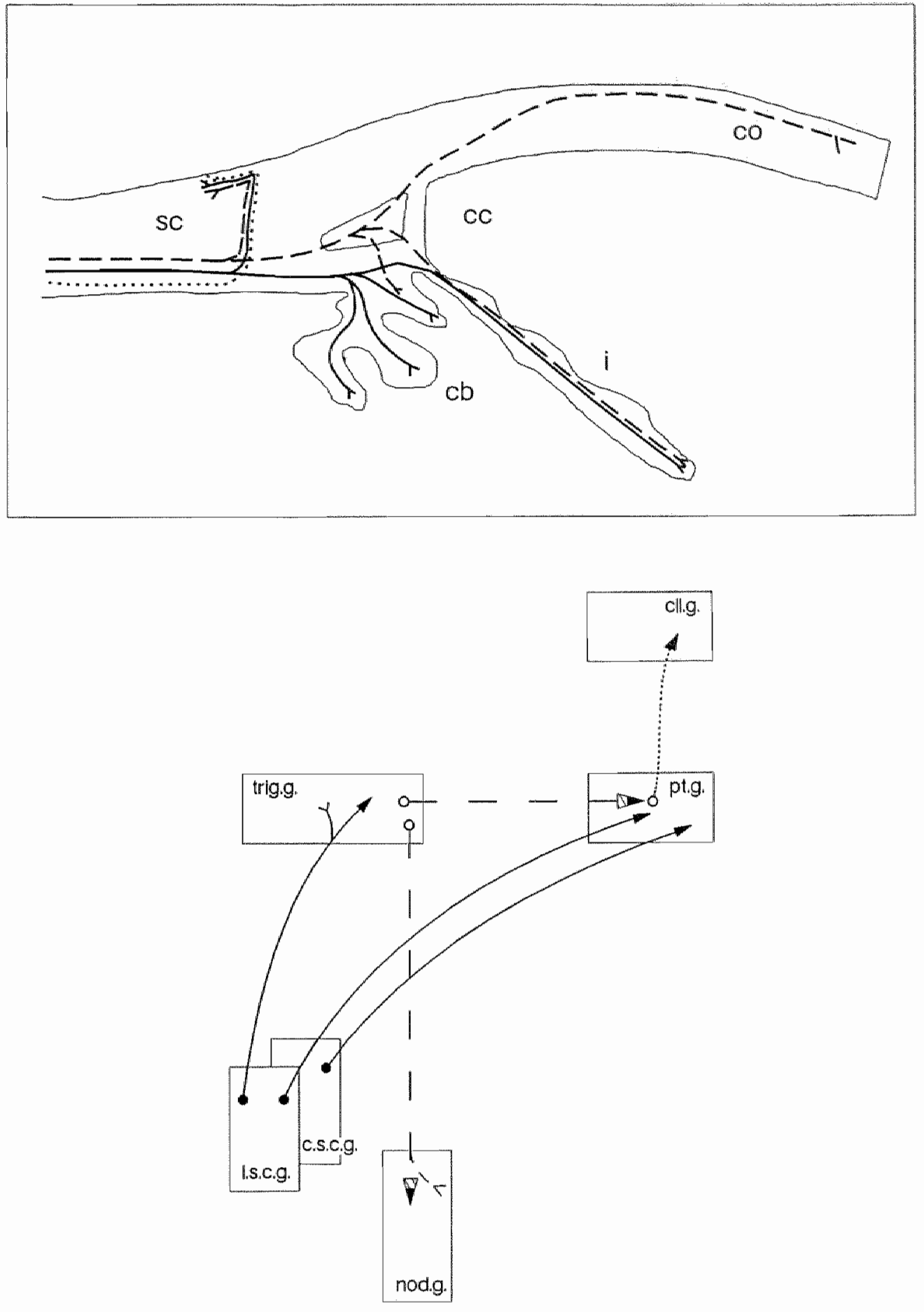


\section{REFEENCES}

1. Kayahara, T., Sakashita, S. and Takimoto, T., Evidence for spinal origin of neurons synapsing with dorsal root ganglion cells of the cat. Brain Res., $293(1984) 225-230$

2. Kayahara, $T$. Synaptic connections between spinal motoneurons and dorsall root ganglion cells in the cat. Brain Res., 376 (1986) 299-309

3.Ling, E.A. and Wong, W.C., Ulirastructure of the nodose (inferior vagaly ganglion cells in the monkeys. Abstracts of the 11 th annual meeting of the european neurostience association. Supplement to the european journal of neuroscience. P.256 


\section{SAMENVATTING}

Een deel van de zenuwvezels welke de oogbol en met name het voorste oogsegment innerweert is betrokken bij de regulatie van de oogdruk. De morfologische en fysiologische gegevens, die dit deel wan het zenuwstelsel betrefen, zijn samengevat in hoofdstuk I. Ondanks het grote aantal gegevens, blijkt het onmogelijk om de resultaten van de fysiologische experimenten te begrijpen vanuit het huidige idee van de anatomische organisatie. De frictie tussen de anatomische en de fysiologische gegevens moet to wijten zijn aan de onjuistheid of de onvolledigheid van bepaalde gegevens. Zoals aangegeven in hoofdstuk I zijn er veel anatomische experimentern die niet selectief zijn ten aanzien van de herkomst wan zenuwwezels. Daarnaast is er nauwelijks aandacht besteed aan de mogelijke vermenging van, en de mogelijke synaptische contacten tussen verschillende perifere zenuwvezels in perifere ganglia. De perifere ganglia vormen een soort schakelstation tussen het centraal zenuwstelsel en het geinnerveerde organ of weefsel. of deze schakelstations alleen informatie doorgeven, of in staat zijn, deels onafhankelijk van het centraal zenuwstelsel, tot verwerking en bewerking van informatie (vergelijkbaar met de ganglia in de darmwand) is tot op heden niet duidelijk.

In dit proefschrift werd de aanwezigheid van verschillende typen zenuwvezels in de structuren van het voorste oogsegment en in de aan het voorste oogsegment gerelateerde perifere ganglia onderzocht met behulp van tracertechnieken. Hierbij werden twee tracer-technieken gebruikt: i) autoradiografie, een selectieve anterograde techniek, en ii) mierikswortel peroxidase al of niet gekoppeld aan een lectine (HRP en WGA-HRP), een zowel anterogradie als retrograde techniek. De resultaten van dit onderzoek zijn samengevat onder drie hoofden: i) Bloed-ganglioncel barriere, ii) De innervatie van hot voorste oogsegment, en iii) Het interganglionaire circuit.

\section{BLOED-GANGLIONCEL BARRIERE (Hoofdstuk II)}

Tijdens de uitvoering van de tracer-experimenten vanuit het ganglion trigemini en het ganglion cervicale superior bleek or een verschil in de opname en thet transport van HRP en WGA-HRP tussen beide ganglia te bestaan. Gericht ultrastructureel onderzoek van sensibele en autonome perifere ganglia na intraganglionaire en intravasculaire injectie van HRP of WGA-HRP toonde aan dat satellietcellen in autonome ganglia een effectieve barriere wormen voor 
deze ingespoten eiwitten en warschijnlik voor grote molekulen in het algemeen. De celmembranen van de satellietcellen en van de uitlopers van de satelletcellen welke de ganglioncellen wolledig omgeven bleken in autonome ganglia aaneengesmeed door talrijke tight-junctions. In de sensibele ganglia bleek noch de verankering door tight junctions, noch de barriere aanwezig. Crote molekulen die aamwezig zijn in de bloedbaan hebben een vrije toegang tot het endoneurium van zowel sensibele als autonome ganglia. In sensibele ganglia komen deze grote molekulen eveneens in aanraking met de ganglioncellen en worden door die cellen opgenomen. De ganglioncellen in autonome ganglia worden afgeschermd wan het endoneurium en daarmee van de bloedbaan door de intercellulair werankerde satellietcellen. Op een mogelijke verklaring voor de afwezige barriere en de daarmee grotere kwetsbaarheid van sensibele ganglia voor circulerende toxische stoffen wordt werderop ingegaan.

\section{DE INNERVATIE VAN HET VOORSTE OOGSEGMENT}

In de retrograde tracer-experimenten werden zowel konijnen als ratten gebruikt (Hoofdstuk III). Grote verschillen in de innervatie van het voorste oogsegment bij konijnen en die innervatie bij ratten werden niet gevonden. De cellichamen wan de zenuwvezels die het voorste oogsegment innerveren, bleken te liggen in het sensibele ganglion trigemini, het sympatische ganglion cervicale superior, het parasympatische ganglion ciliare en het eveneens parasympatische ganglion pterygopalatinum. Bij de bestudering van WGA-HRPinjecties in de cornea na oplopende overlevingstijden bleek dat de cellichamen wan de zenuwvezels in de cornea alleen in het sensibele ganglion trigemini liggen. Door middel van electronen-microscopie van het ganglion trigemini konden de ganglioncellen worden onderverdeeld in vier typen. Deze typen bloker echter geen zenuwvezels uit aparte delen van het oog te antvangen. Anterograde tracer-experimenten met ${ }^{3}$ H-leucine en WGA-HRP vanuit het ganglion trigemini (Hoofdstuk IV) liet sensibele zenuwvezels in de conjunctiva, de cornea, het anteriore stroma van het corpus ciliare en de iris zien (figuur 1). Deze zenuwvezels lopen via de cillaire wig en de suprachoroidea naar het anteromediane deel van het ganglion trigemini. of de sensibele zenuwvezels de chllaire wig alleen doorlopen, of ook innerveren, kan op basis van deze lichtmicroscopische experimenten niet worden beslist. De cellichamen in het rostale deel van het sympatische ganglion cervicale superior projecteren naar de basis van het corpus ciliare, het stroma van de processi ciliares, de iris, de 
limbus en de conjunctiva (Hoofdstuk v), De sympatische zenuwvezels doorlopen de suprachoroidea en de basis van het corpus clliare terwijl slechts enkele sympatische zenuwrezels werden aangetroffen in de cillare wig. In overeenstemming met de retrograde experimenten bij konijnen. werden ook in de anterograde experimenten bij ratten geen sympatische zenuwvezels in de cornea aangetroffen. Parasympatische zenuwvezels waarvan de cellichamen in het ganglion pterygopalatinum liggen werden alleen aangetoond in de choroidea, de limbus en de conjunctiva.

\section{INTERGANGLIONAIR CIRCUIT}

Bij verschillende diersoorten waaronder primaten bleek het ganglion pterygopalatinum zenuwrezels te bevatten van verschillende herkomst. Een dergelijke gemengde samenstelling werd ook vastgesteld voor het ganglion ciliare van honden en primaten. Het ganglion ciliare van ratten en konijnen daarentegen, wordt verondersteld alleen parasympatische oculomotore zenuwvezels te ontvangen. Het ganglion cervicale superior en het ganglion trigemini worden verondersteld respectievelijk alleen sympatische en alleen sensibele zenuwvezels te bevatten (Hoofdstuk 1).

Door middel van anterograde en retrograde tracer-experimenten met ${ }^{3} \mathrm{H}-$-leucine en WGA-HRP vanuit het ganglion trigemini (Hoofdstuk IV), het ganglion cervicale superior (Hoofdstuk $V$ ) en het ganglion pterygopalatinum (Hoofdstuk VI), werd het circuit tussen de vier, aan het oog gerelateende, perifere ganglia van de rat bestudeerd. De resultaten zijn weergegeven in figuur $\mathbb{l}$.

Sensibele trigeminus-zenuwwezels werden aangetoond in het parasympatische ganglion pterygopalatinum en het sensibele ganglion nodosum. Sympatische zenuwvezels uit het ganglion cervicale superior projecteren naar het ganglion trigemini en het ipsi- en contra-laterale ganglion pterygopalatinum. Parasympatische zenuwvezels uit het ganglion pterygopalatinum projecteren naar het eveneens parasympatische ganglion ciliare. Dus in tegenstelling tot het in de literatuur weronderstelde circuit, weergegewen in hoofdstuk $l_{v}$ blijtht alleen het ganglion cervicale superior vanuit de onderzochte ganglia geen projectie te ontvangen. Of de gemengde samenstelling van deze perifere ganglia berust op het passeren van de zenuwvezels op weg naar het te innerweren orgaan, of op een synaptische interactie tussen de verschillende perifere neuronen, werd in deze experimenten niet opgelost. Desalniettemin werden aen synaptische interactie tussen sympatische zenuwvezels en sensibele trigeminus- 
neuronen en een syaptische interactie tussen trigeminus-zenuwezels en nodosum-newronen wharshignhilk gemaakt. Hierbij is het van belang dat de synaptische interactie in beide gevallen verondersteld wordt op te treden in een sensibel perifeer ganglion. Synapsen werden in deze ganglia eerst zeer recentelijk aangetoond. In het ganglion trigemini zijn zelfs nu nog geen syrapsen aangetcond, wat betekent dat er in het ganglion geen synaptische overdracht plaatsheeft of dat het antal synapsen enorm klein is. Het feit dat de sensibele ganglioncellichamen niet afgeschermd zijn van het endoneurium of van elkaar, door de afwezigheid van en effectieve satelietcel-barriere, betekent theoretisch dat slecht weinig synapsen voldoende zijn.

Bimen het ganglion pterygopalatinum bleek een somatotopie te bestaan. Het distale deel van het ganglion projecteen naar de traanklier en ontvangt projecties van een aparte kern in de pons: de nucleus lacrimalis. Het proximale deel wan het ganglion pterygopalatimum projecteert naar de choroidea en de conjunctiva. Daar ganglionectomie van het ganglion pterygopalatinum een dramatisch effect heeft op de oogdruk, zijn het mogelik deze proximale neuronen welke de oogdruk reguleren via de veneuze weerstand in de Watervenen.

Figum I (bladzijde 147) Wat het interganglionair circuit (onder) en de voorste oogsegment inmervatie (in de rechuloek) betreft, zijn in deze figuur de belangrijkste resultaten samengevat. Sensibele trigeminus-zenuwvezels (onderbroken tijent) projecteren natur hat sensibele ganglion nodosum (nod.g.) en het parasympattsche ganglion pterygopalatinum (pt.g.). In het voorste oogsegment werden sensibele zenumezels aangetroffen in de comea (co), de iris (1), het anteriore stroma van het corpus cillare (cb) en de conjunctiva. Veel sensibele zeruwwezels lopen door de cillaire wig (cc). Sympatische zenuwvezels komend wit het ganglion cervicale superior (ononderbroken lijnen) projecteren nat het ganglion irigemini (trig.g.) en het ganglion ptorygopalatinum. Sympatische zenuwvezels in het ganglion pterygopalatinum zijh zowel afkonstig wit het ipsilaterale ganglion cervicale superior (i.s.c.g.) als wit het contralaterale ganglion cervicale superior (c.s.c.g.). Wat het woorste oogsegment betreft, werden symparische zenuwvezels aangetroffen in het corpus clliare, de inis, de conjunctiva en slechts zelden in de clliaire wig. De parasympatische neuronen in het ganglion pterygopalatinum (stippellinen) projecteren nat het ganglion ciliare (cilg.), de choroidea en de conjunctiva. 


\section{DANKWOORD}

De werkzaamheden die geleid hebben tot dit proefschrift vonden plaats op het IOI te Amsterdam. Ik heb daar met veel plezier gewerkt. Aan het tot stand komen wan dit proefschrift en aan het plezier droegen velen bij. Alle betrokkenen ben ik daarvoor zeer dankbaar.

Er is nauwelijks een stap gezet in dit onderzoek zonder medeweten, meedenken en meewerken van Jan Klooster. Jan, ik will je danken voor jo toewijding en zeker ook woor de vriendschappelijke samenwerking.

Bob, Han, Chris en Ruud, de andere leden van het neuroclubje, waren steeds bereid tot serieuze en minder serieuze attenties.

Frits Versluis wil ik bedanken voor zijn begeleiding binnen het B-Lab en Peter Brassinga voor de technische klussen. De andere morfo's; bankwerkers, immuno's en mijn automaat: Anneke, Ben, Koendertje, Hanneke, Ina "Lenie, Lidy, Liesbeth, Marc, Paul, Rolf en Yvonne, ben ik erkentelijk voor hun sociale en andere bijdragen aan de dagelijkse gang van zaken. Juul en Nico hebben mij enorm geholpen met posters, dia's, tekeningen, routine-foto's en loto's voor artikelen en voor dit proefschrift. Geert ten Tusscher worstelde met jargon en corrigeerde het vermeende Engels van enkele teksten. Henny verzorgde de secretariële ondersteuning.

Mijn promotores wil ik bedanken woor de prettige samenwerking. Daarenboven, wil ik Prof. dr. W.P.M.A. Lamers bedanken voor zijn interesse in het onderwerp van dit proefschrift en de daaruit voortkomende aanzet tot dit onderzoek en Prof. dr. G.F.J.M. Vrensen woor zijn begeleiding bij het schrijven van de artikelen en dit proefschrift.

Al met al hoop ik dat dit onderzok voortgang zal winden en dat ik er op de een of andere manier bij betrokken bijif. 


\section{CURPICULUM VITAE}

Marecl ten Tusscher werd op 20 juli 1958 geboren te Tubbergen. In 1976 behaalde hij het einddiploma Atheneum-B aan het Carmel-Lyceum te Oldenzaal. In hetzelfde jaar begon hij met de studie biologie aan de Landbouw Hogeschool te Wageningen. In 1977 ving hij aan de Erasmus Universiteit te Rotterdam de studie geneeskunde aan. Aldaar legde hij het kandidaatsexamen af in 1980. Het doctorablexamen behaalde hij in 1982 gevolgd door het artsexamen in 1984. Vanaf 1 april 1984 was hij werkzaam als assistentgeneeskundige op de afdeling gynaecologite en verloskunde van het Elisabeth Ziekenhuis en het Maria Ziekenhuis te Tilburg. Vanaf \ januari 1986 was hij verbonden aan het Interuniversitair Oogheelkundig Instituut te Amsterdam alwatr de werkzaamheden ten behoeve van zijn promotie werden verricht. Vanaf 1 maart 1989 is hij werkzaam als assistent-geneeskundige op de afdeling oogheelkunde van het Academisch Ziekenhuis Maastricht. 
Is het niet mogelijk om alle misdaden, alle verschrikkingen, de ongehoorde wreedheden van de huidige en voorbije werelden als marteloffers te beschowwerl, op de drempel van de grootste ontdekking die de mensen ooit zullen doen: het leven.

L.F. Céline in zijn proefschrift over Semmelweis

Een wereld vol gedachten

Ging in zijn schedel om;

Wie dit niet wisten, lachten

En sleten hem voor dom.

B. Van Meurs 1835-1915 